\title{
REVIEW
}

Open Access

\section{Health outcomes associated with reallocations of time between sleep, sedentary behaviour, and physical activity: a systematic scoping review of isotemporal substitution studies}

Jozo Grgic ${ }^{1}$, Dorothea Dumuid ${ }^{3}$, Enrique Garcia Bengoechea ${ }^{1,2}$, Nipun Shrestha' ${ }^{1}$, Adrian Bauman ${ }^{4}$, Timothy Olds ${ }^{3}$ and Zeljko Pedisic ${ }^{1^{*}}$

\begin{abstract}
Background: During a 24-h day, each given period is spent in either sedentary behaviour, sleeping, light physical activity (LPA), or moderate-to-vigorous physical activity (MVPA). In epidemiological research most studies have traditionally analysed the associations of these behaviours in isolation from each other; that is, without taking into account the displacement of time spent in the remaining behaviours. In recent years, there has been a growing interest in exploring how all the behaviours across the energy expenditure spectrum influence health outcomes. A statistical model used to investigate these associations is termed an isotemporal substitution model (ISM). Considering the increasing number of ISM-based studies conducted in all age groups, the present paper aimed to: (i) review and summarise findings from studies that employed ISM in sleep, sedentary behaviour, and physical activity research; (ii) appraise the methodological quality of the studies; and (iii) suggest future research directions in this area.
\end{abstract}

Methods: A systematic search of ten databases was performed. The Newcastle-Ottawa scale was used to assess the methodological quality of the included studies.

(Continued on next page)

\footnotetext{
* Correspondence: zeljko.pedisic@live.vu.edu.au; zeljko.pedisic@vu.edu.au ${ }^{1}$ Institute for Health and Sport (IHES), Victoria University, Melbourne, Australia Full list of author information is available at the end of the article
}

(c) The Author(s). 2018 Open Access This article is distributed under the terms of the Creative Commons Attribution 4.0 International License (http://creativecommons.org/licenses/by/4.0/), which permits unrestricted use, distribution, and reproduction in any medium, provided you give appropriate credit to the original author(s) and the source, provide a link to the Creative Commons license, and indicate if changes were made. The Creative Commons Public Domain Dedication waiver (http://creativecommons.org/publicdomain/zero/1.0/) applies to the data made available in this article, unless otherwise stated. 
(Continued from previous page)

Results: Fifty-six studies met the inclusion criteria, all being of moderate or high methodological quality. Associations were reported for exchanged time varying from one minute to $120 \mathrm{~min} /$ day across the studies, with 30 min/day being the most common amount of time reallocated. In total, three different ISM methodologies were used. The most commonly studied health outcomes in relation to isotemporal substitutions were mortality, general health, mental health, adiposity, fitness, and cardiometabolic biomarkers. It seems that reallocations of sedentary time to LPA or MVPA are associated with significant reduction in mortality risk. Current evidence appears to consistently suggest that reductions in mortality risk are greater when time spent sedentary is replaced with higher intensities of physical activity. For adiposity, it seems that reallocating sedentary time to physical activity may be associated with reduced body mass index, body fat percentage, and waist circumference in all age groups, with the magnitude of associations being greater for higher intensities of physical activity. While there is a relatively large body of evidence reporting beneficial associations between the reallocation of time from sedentary behaviour to LPA or MVPA and cardiometabolic biomarkers among adults, there is a lack of studies among children, adolescents, and older adults. Although some studies investigated general health, mental health, and fitness outcomes, further investigation of these topics is warranted. In general, it seems that the strongest association with health outcomes is observed when time is reallocated from sedentary behaviour to MVPA. Most studies did not account for sleep time, which is a major limitation of the current evidence.

Conclusions: The current evidence indicates that time reallocation between sleep, sedentary behaviour, LPA, and MVPA may be associated with a number of health outcomes. Future studies should employ longitudinal designs, take into account all movement behaviours, and examine a wider range of health, psychological, social, economic, and environmental outcomes.

\section{Background}

During a 24-h day, each given period is spent in either sedentary behaviour, sleeping, light-intensity physical activity (LPA), or moderate-to-vigorous physical activity (MVPA) [1, 2]. It has been well documented that all of these time-use components across a 24 h spectrum may be significantly associated with health. For instance, an increased risk of all-cause mortality, cardiovascular disease, metabolic syndrome, type 2 diabetes mellitus (T2D), and certain types of cancer is associated with low levels of MVPA, large amounts of time spent in sedentary behaviour and inappropriate sleep duration [1-10]. As the duration of a day is fixed and finite, a change in one of these movement-related behaviours will result in a net equal and opposite change in other behaviours. Despite this fact, most previous epidemiological studies have analysed the associations of each behaviour in isolation; that is, without taking into account the displacement of the remaining co-dependent behaviours.

In recent years, there has been growing interest in exploring how all the behaviours across the energy expenditure spectrum influence health outcomes [1, 2, 11-15]. In the seminal work by Mekary et al. [12], the isotemporal substitution model (ISM) was proposed as a method for evaluating the displacement of one movement-related behaviour time-use component with another, while allowing adjustment for the confounding effect of the remaining time-use components [12]. In addition to the ISM proposed by Mekary et al. [12], Chastin et al. [13] and Dumuid et al. [14] recently introduced two different compositional isotemporal substitution models that account for the compositional properties of time-use data $[1,2,15]$. The findings of studies employing ISM may improve our understanding of the interrelationships between different movement-related behaviours and their relationships to health and may also help in shaping public health guidelines and promotion strategies [11]. Whilst, for example, most public health guidelines on physical activity recommend people to engage in a certain amount of MVPA, they lack an instruction on which movement/non-movement behaviour should preferably be displaced by MVPA $[16,17]$. Studies using ISM may enable creating specific, evidence-based recommendations on favourable reallocations of time between sleep, sedentary behaviour, and physical activity, which has the potential to improve the translation of research findings on these behaviours into practice, and, consequently, increase the uptake of public health messages.

A recent meta-analysis of five studies using ISM concluded that reallocating sedentary time to MVPA was significantly associated with a reduction in percentage of body fat [18]. However, the review focused only on studies conducted among children, with markers of adiposity being the only outcome of interest. An increasing number of ISM-based studies conducted in all age groups have recently been published, investigating outcomes such as adiposity, metabolic biomarkers, mental health, chronic musculoskeletal pain, fitness, mortality, and health-related quality of life [19-39].

A comprehensive review on the topic of time reallocation and its associations on health outcomes seems warranted, to summarise the current state of knowledge in 
this growing field and provide directions for its future development. Therefore, the aim of this paper was threefold: (i) to review and summarise findings from studies that employed ISM in sleep, sedentary behaviour, and physical activity research; (ii) appraise the methodological quality of the studies; and (iii) suggest future research directions.

\section{Methods \\ Protocol}

The methods employed in this review were registered in advance in the PROSPERO register of systematic reviews (ref: CRD42017071606). The Preferred Reporting Items for Systematic Reviews and Meta-Analyses guidelines were followed in this systematic scoping review [40].

\section{Search strategy}

A systematic search of the following databases was performed in July 2017: Academic Search Premier, CINAHL, Health Source: Nursing/Academic Edition, MasterFILE Premier, PsycINFO, PubMed/MEDLINE, Scopus, SPORTDiscus, and Web of Science (including Arts \& Humanities Citation Index, Conference Proceedings Citation Index- Science, Conference Proceedings Citation Index- Social Science \& Humanities, Science Citation Index Expanded, and Social Sciences Citation Index). The following keywords were used for the search: "physical activity", "physical inactivity", sedentar", sleep*, sitting, standing, isotemporal, compositional. The terms used for the search were combined with Boolean operators (Additional file 1). No limitations regarding publication date were applied. The search results were downloaded and scrutinized in the EndNote software X8 (Clarivate Analytics, New York, USA). A secondary search was performed by: (i) screening the reference lists of each read full-text; and (ii) by performing forward citation tracking of the included studies through Google Scholar and Scopus.

\section{Inclusion criteria}

To be included in the current review, studies were required to meet the following criteria: (i) the study was published in an English-language refereed journal with full-text availability; (ii) the study was an original research (reviews were not considered) with data collected among human participants; (iii) the study used ISM to explore the association between reallocating relevant movement-related behaviours (e.g., sleep, sedentary behaviour, LPA and/or MVPA) and health outcomes. The World Health Organisation [41] defines health as the absence of disease and frailty, as well as complete physical, mental, and social well-being. For the purpose of this paper, any analysed outcome aligned with this definition was considered a health outcome. Observational studies conducted in any age group were considered.

\section{Study coding and data extraction}

The information extracted from the included studies comprised descriptive data including: the geographic location of the study; study design; sample size; measures of sleep, sedentary behaviour, LPA, and MVPA; the ISM used; amount of reallocated time; adjustments for confounding; and the main findings related to the health outcome(s). The data were extracted and tabulated to an Excel spreadsheet predefined for the purpose of this review.

\section{Methodological quality appraisal}

In order to assess the methodological quality of the studies that met the inclusion criteria we used the NewcastleOttawa quality assessment scale for observational studies [42]. The scale details can be found elsewhere [42]. The maximum score on the scale was eight. Studies that scored more than six points were considered of high quality, studies scoring 4-6 points were considered as moderate quality and studies with scores less than four points were considered as being of low methodological quality [43].

The search and methodological quality appraisal was performed independently by two authors of the review (JG and EGB). In addition, two authors (JG and NS) independently performed the data extraction. Any discrepancies between the reviewers were resolved with discussion and consensus or in consultation with a third investigator (ZP).

\section{Results \\ Study selection}

In total, 5859 items were screened in the study selection process. The initial database search identified 1741 results. For 88 studies the full-text was retrieved and assessed for eligibility. Of those, 48 studies met the inclusion criteria. Forward citation tracking of the included studies yielded another 1789 search results, of which eight studies were included. By screening through the reference lists of all the included studies (2329 results) we identified no additional studies relevant for this review. Therefore, the total number of studies included in this review is $56[12,13,19-39,44-76]$. The search and study selection process is depicted in Fig. 1.

\section{Study characteristics}

Of the 56 included studies, 36 had a cross-sectional design while 18 were prospective cohort studies. Two studies reported both cross-sectional and prospective relationships. Most of the studies were performed in the USA $(n=21)$, eleven studies were performed in the UK, five in Australia, four in Sweden, three in the Netherlands, two in Canada and Spain, and one in Portugal, Norway, Japan, Greenland, Finland, China, and Denmark. One study used data from Brazil, Europe, and the USA. Accelerometers were used in 41 studies, self-reports were used in 12 studies, while heart 


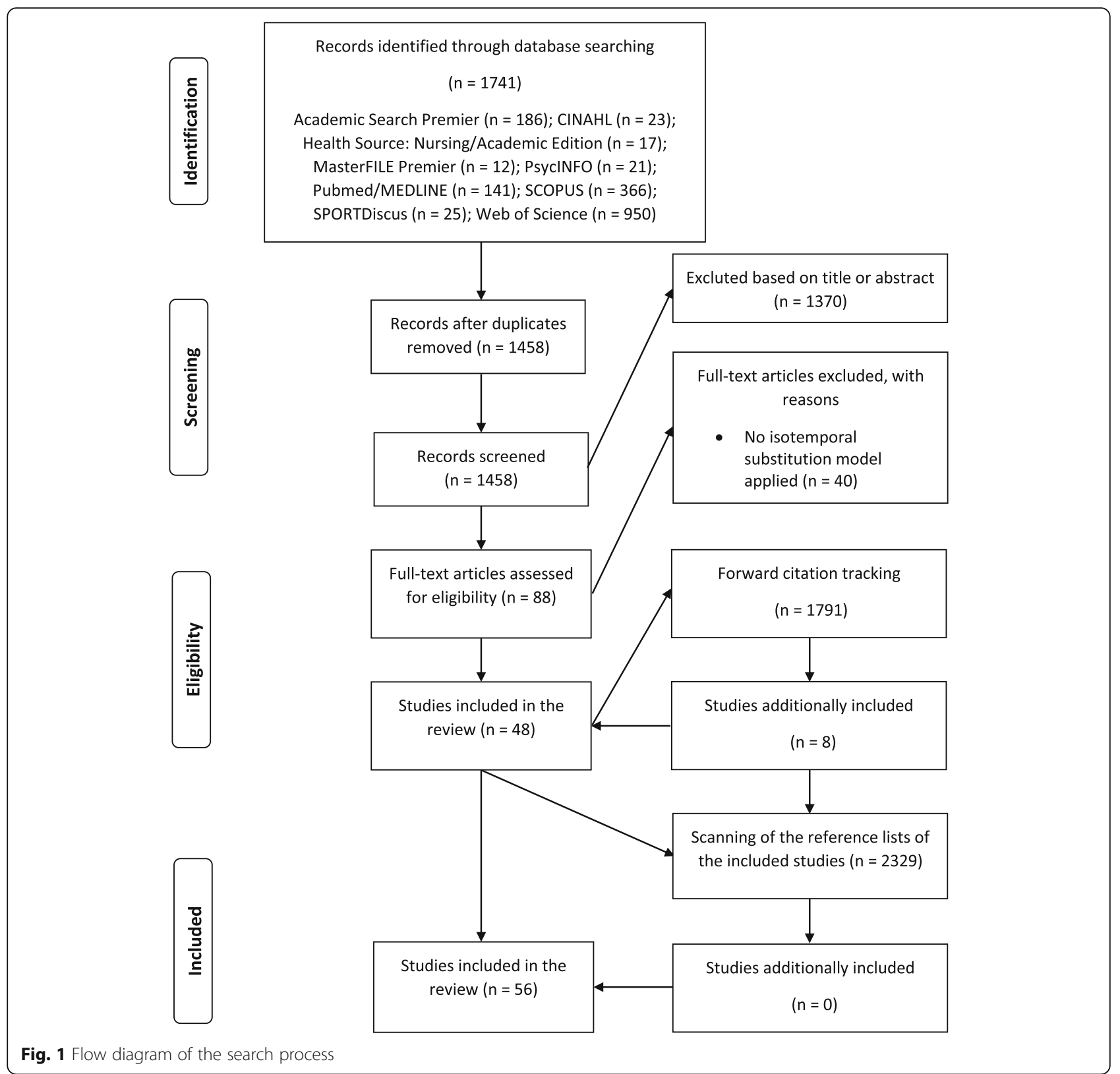

rate and other movement monitors were used in three studies. Most studies did not include all the relevant daily or 24-h movement-related behaviours. For example, sleep duration was included in only 22 studies. Associations were reported for exchanged time varying from one minute to $120 \mathrm{~min} /$ day across the studies, with $30 \mathrm{~min} /$ day being the most common reallocation. The model proposed by Mekary et al. [12] was used in 53 studies. Two studies used the model proposed by Chastin et al. [13], and one study used the model proposed by Dumuid et al. [14].

\section{Participants and outcomes}

The sample sizes of the included studies ranged from 87 to 423,659 participants. The median number of participants per study was 1497. Studies were performed in children and youth [20, 21, 23, 25, 27, 28, 45, $49,59,60,63,64,70]$, adults $[12,13,22,24,30-33,35$, $36,38,39,46,48,50-52,54-56,58,62,65-69,71,72$, $75,76]$, older adults $[26,29,45,48,61]$ and clinical populations $[19,34,53,57,73,74]$. The outcomes were categorised into six major categories: mortality $(n=9$ studies; Table 1), perceived health ( $n=6$ studies; Table 2), mental health ( $n=3$ studies; Table 3$)$, adiposity ( $n=29$ studies; Table 4$)$, fitness $(n=8$ studies; Table 5), cardiometabolic biomarkers ( $n=18$ studies; Table 6) and chronic diseases and conditions $(n=6$ studies; Table 7). Some of the studies assessed multiple outcomes, therefore, the total number of exceeds 56 . 


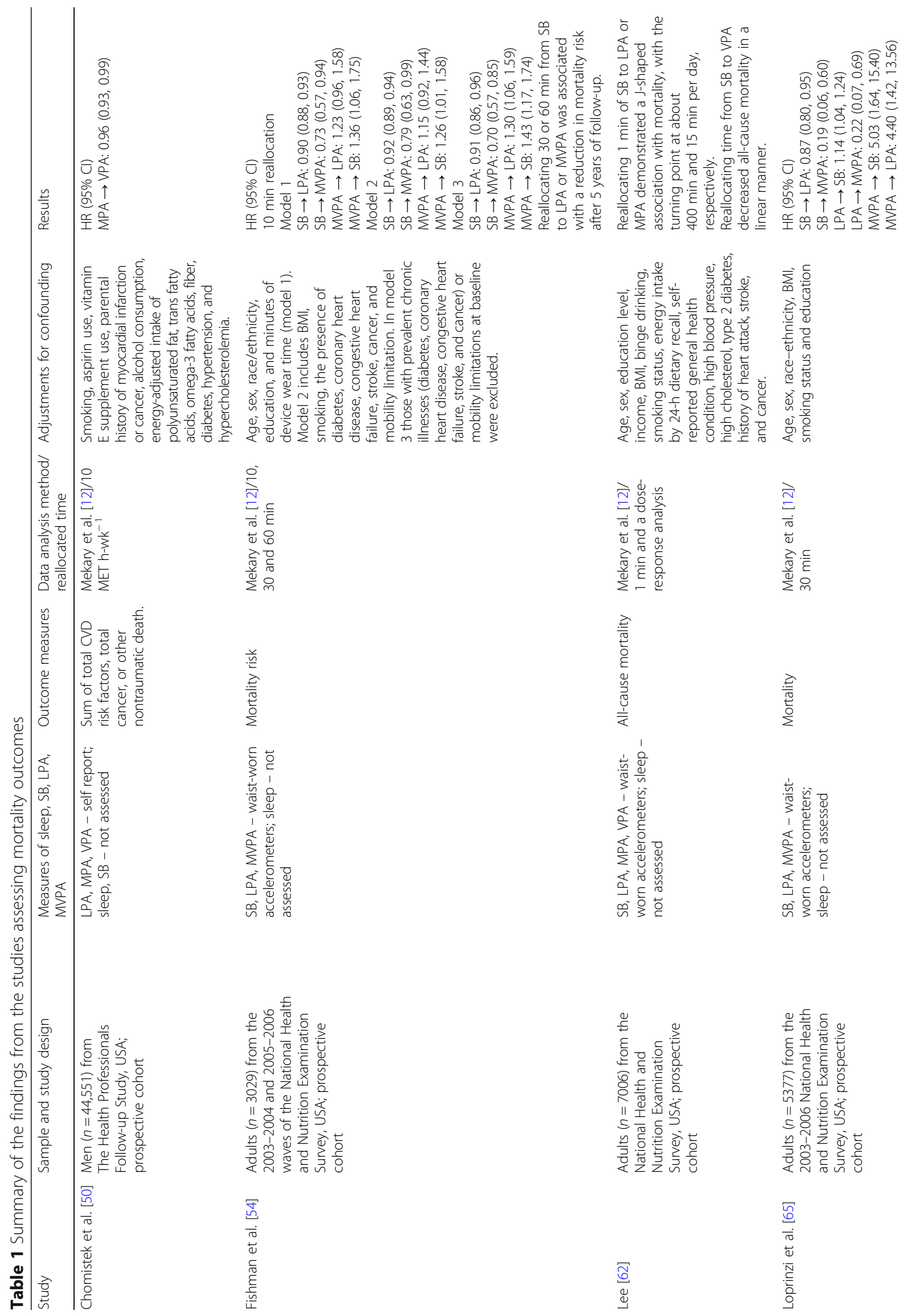




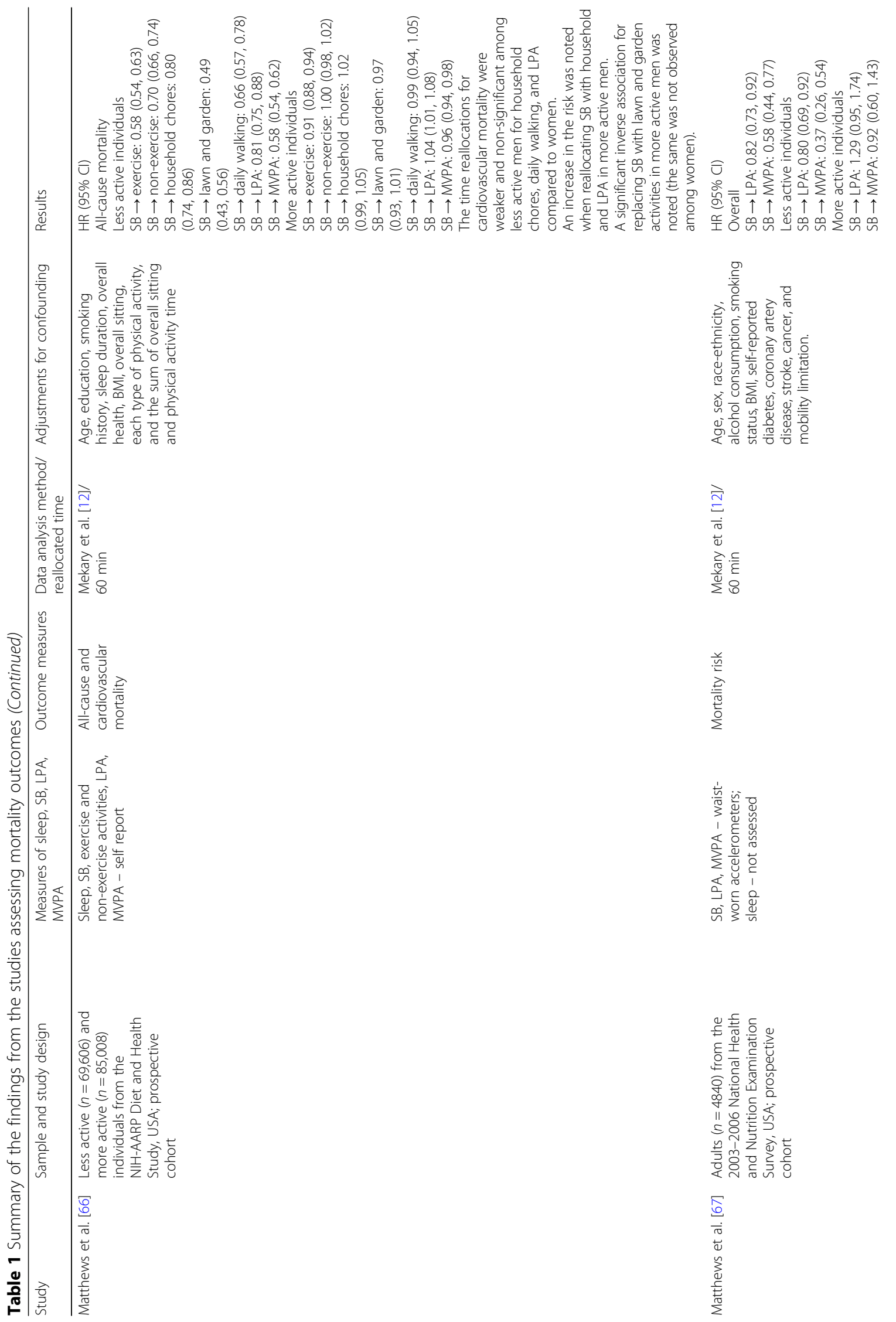




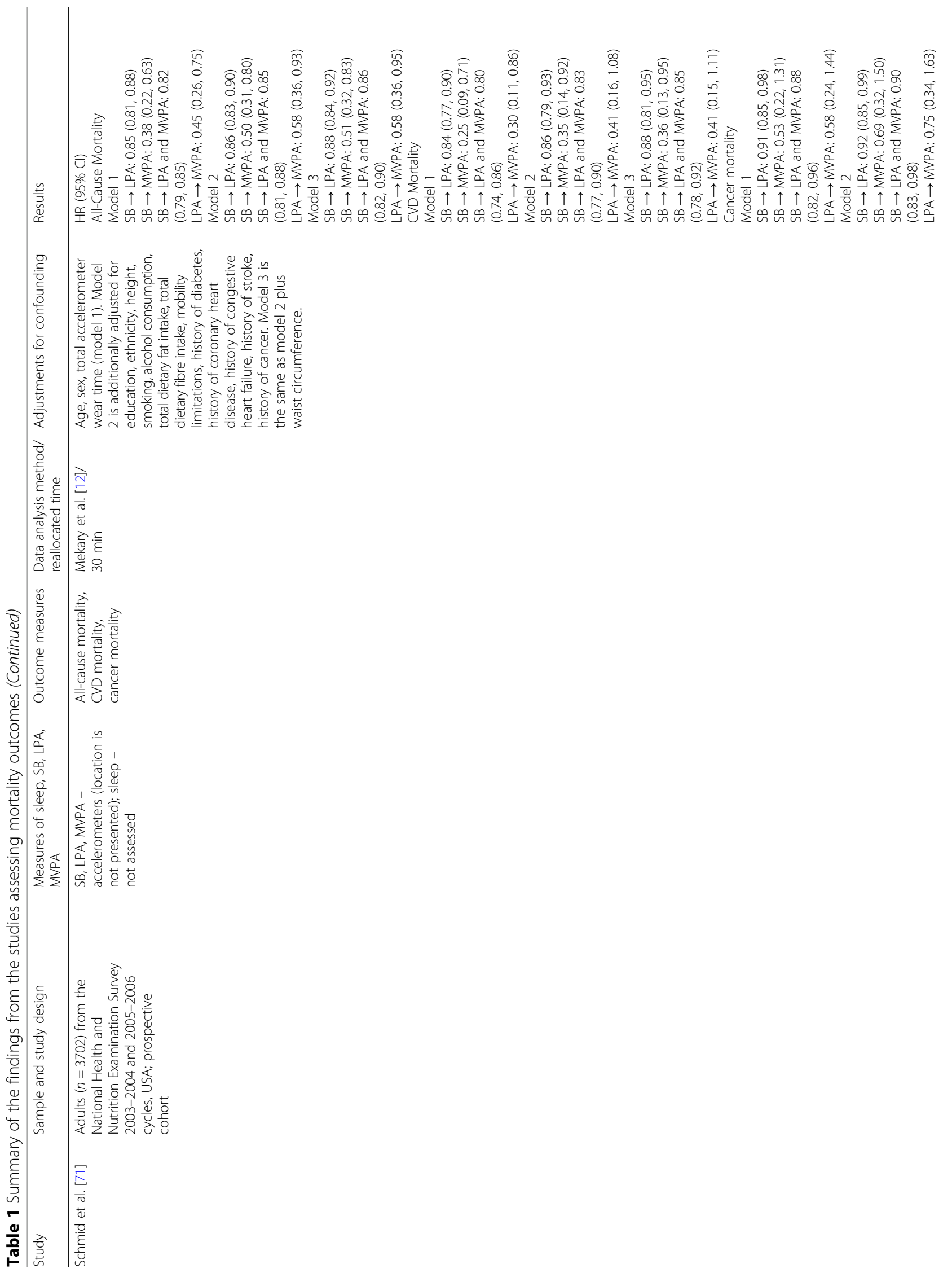




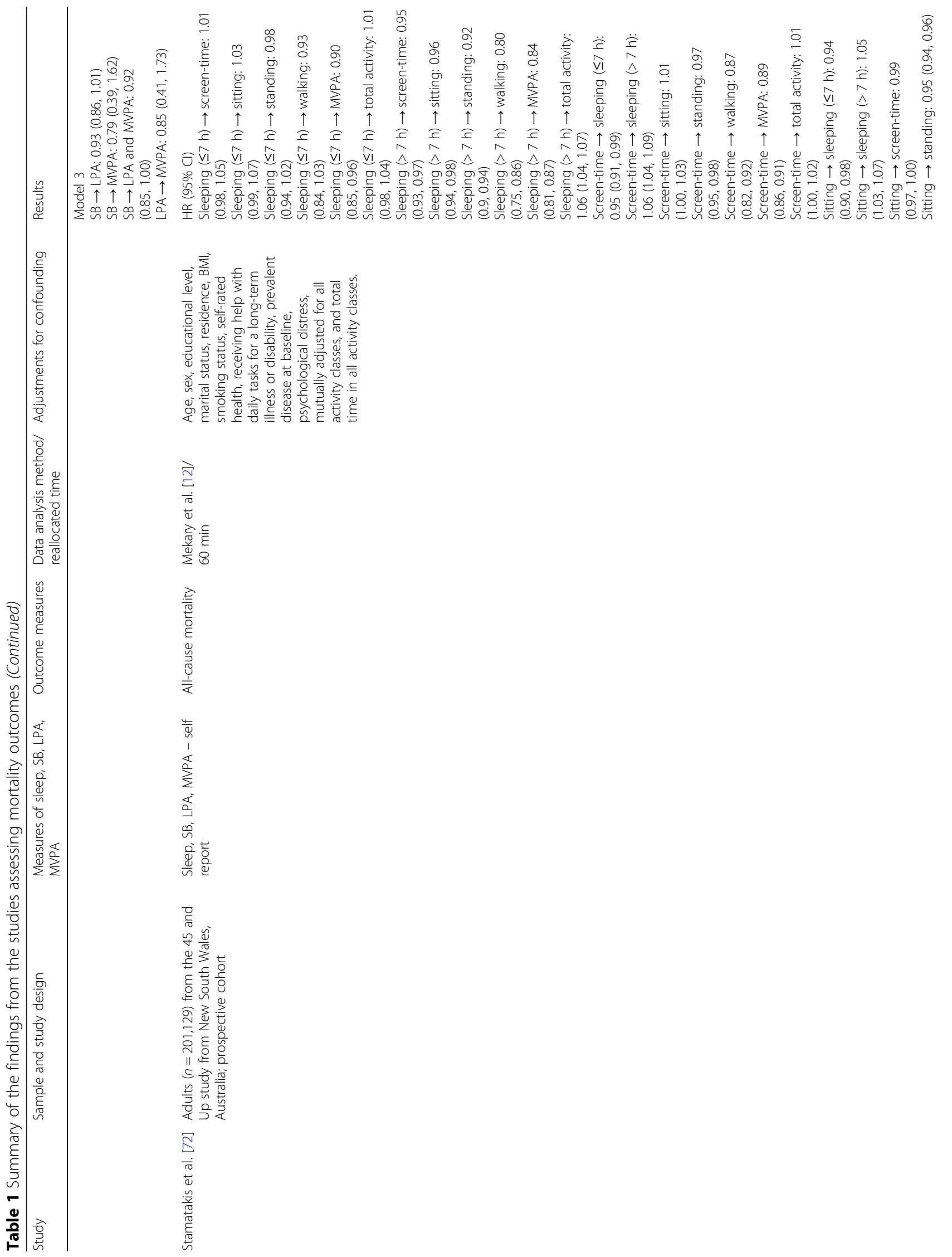




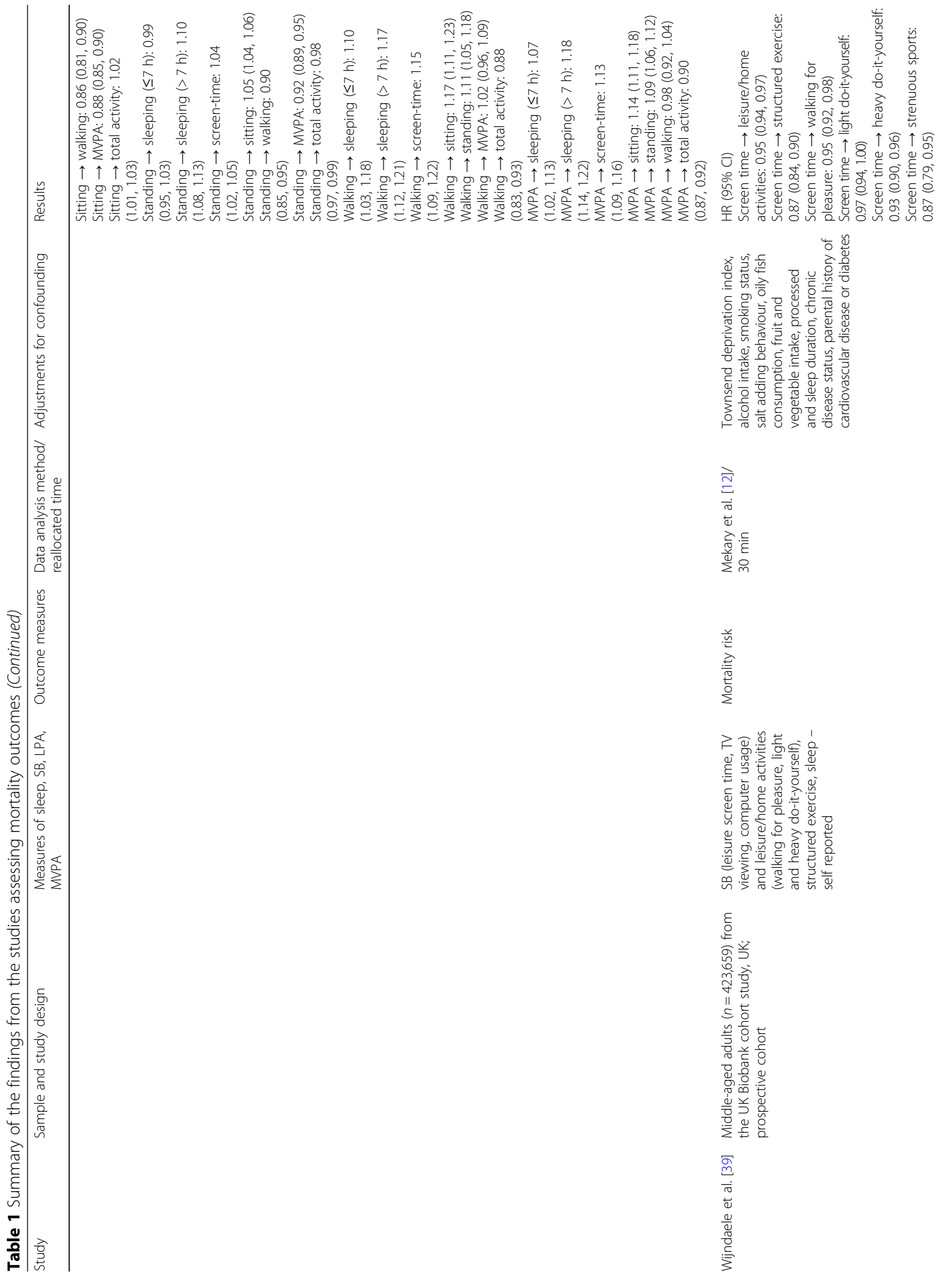




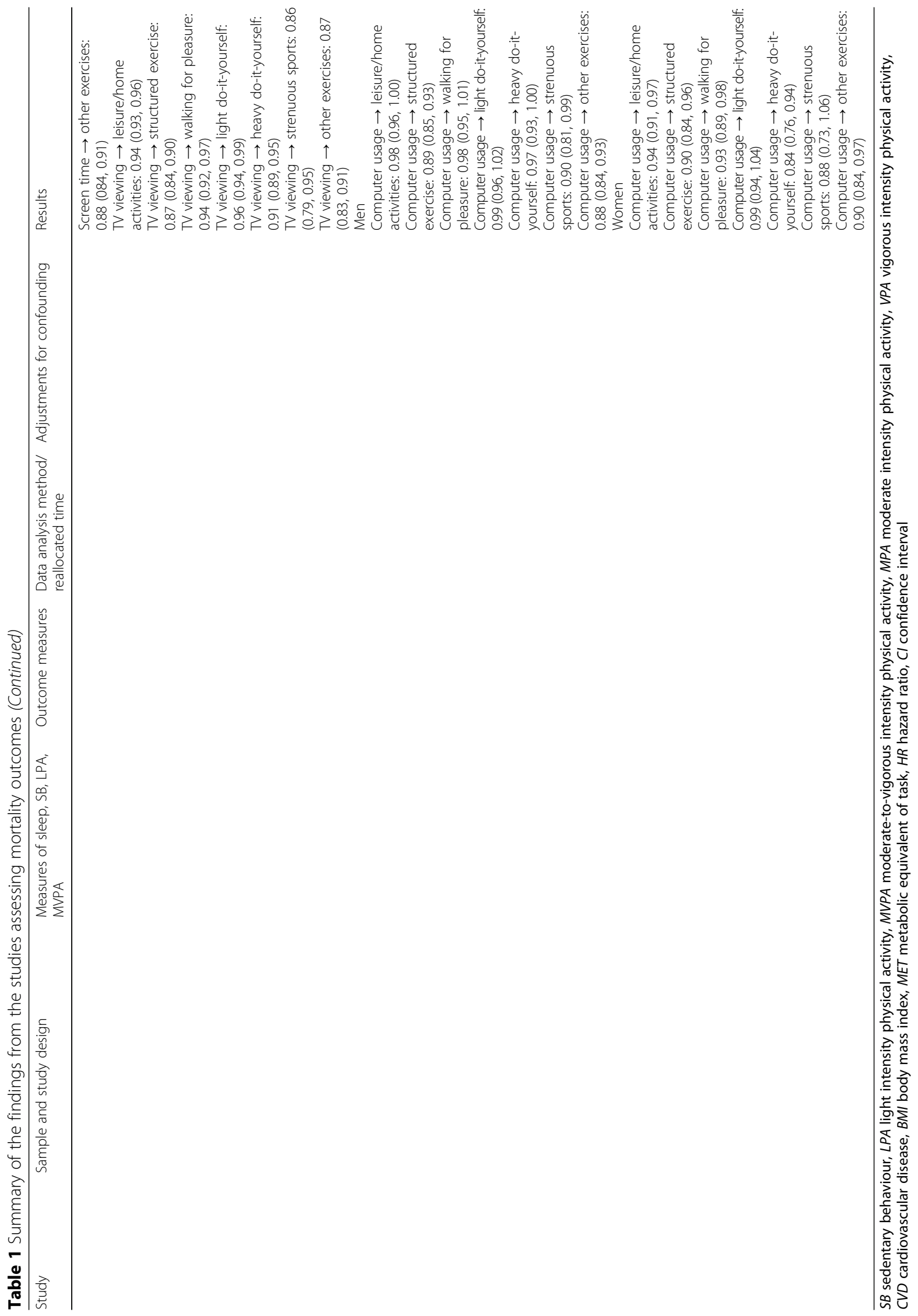




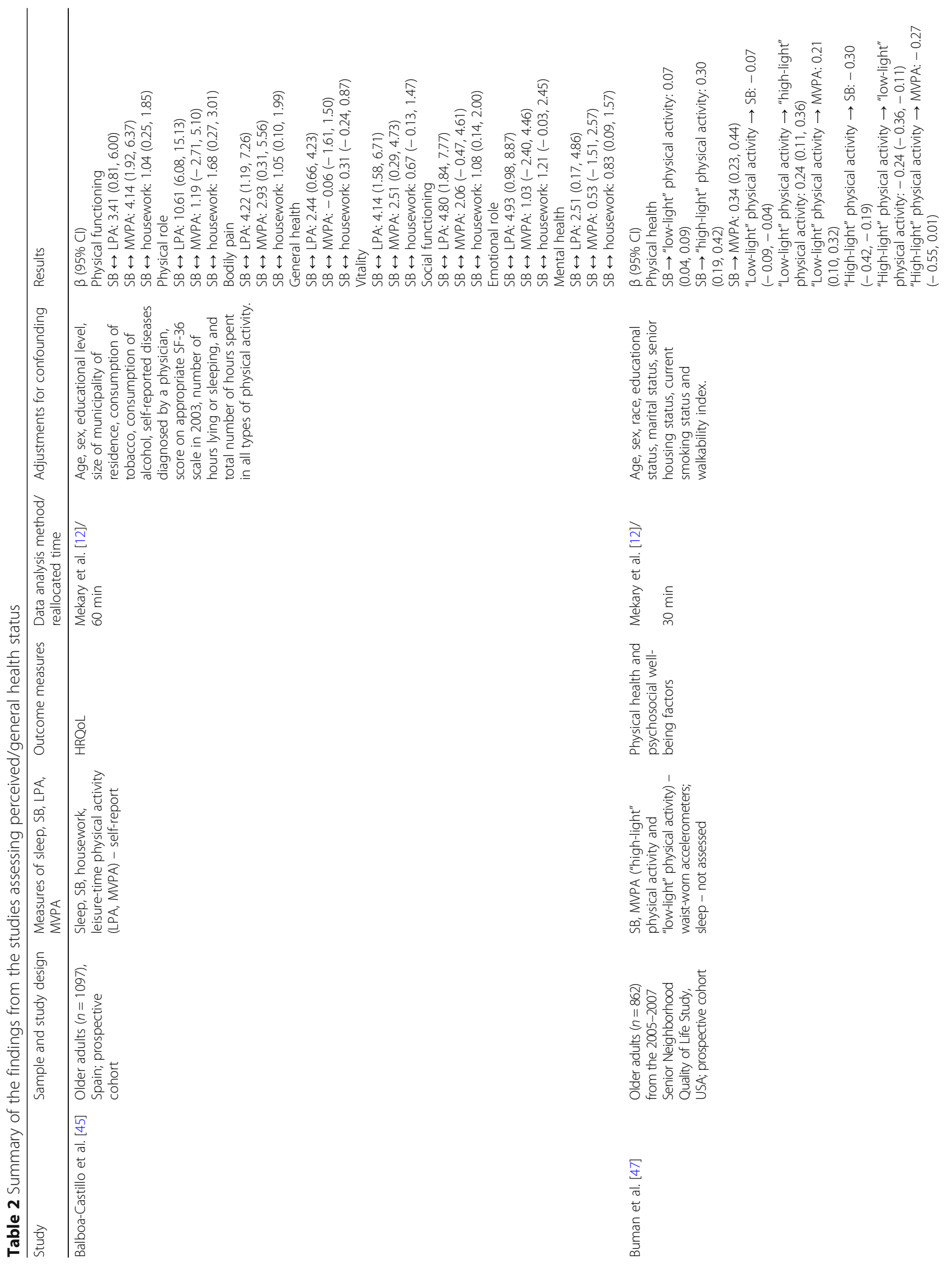




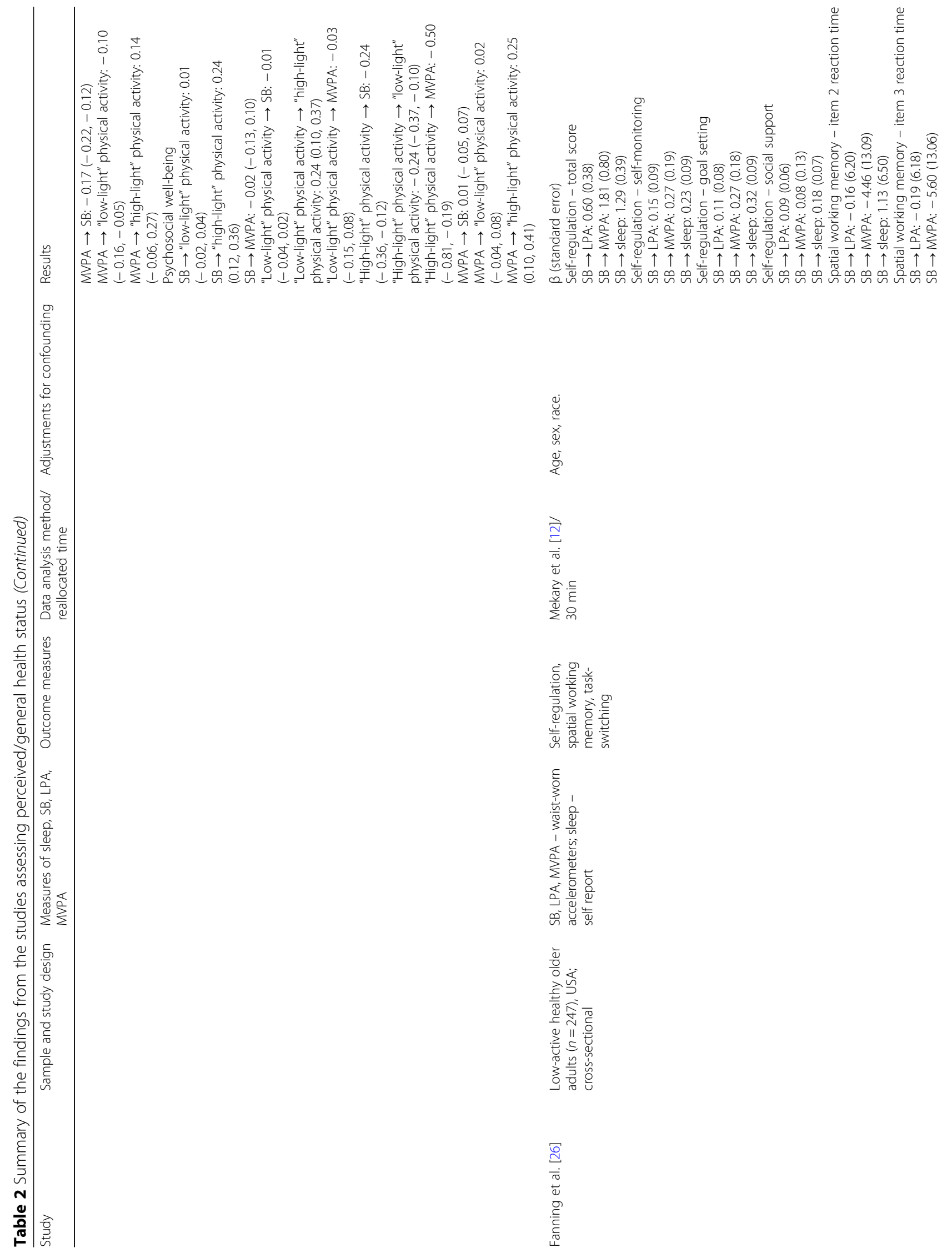




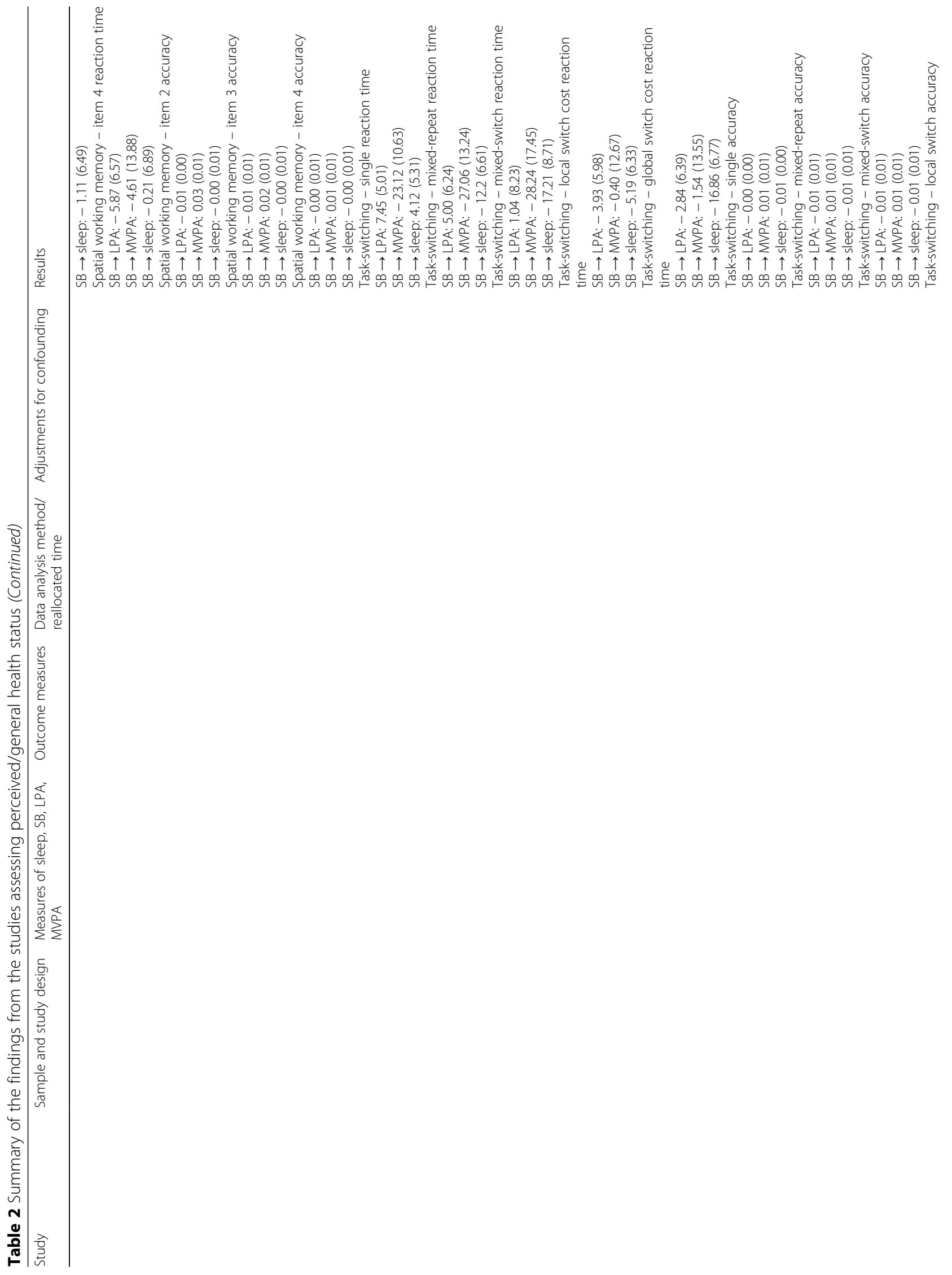




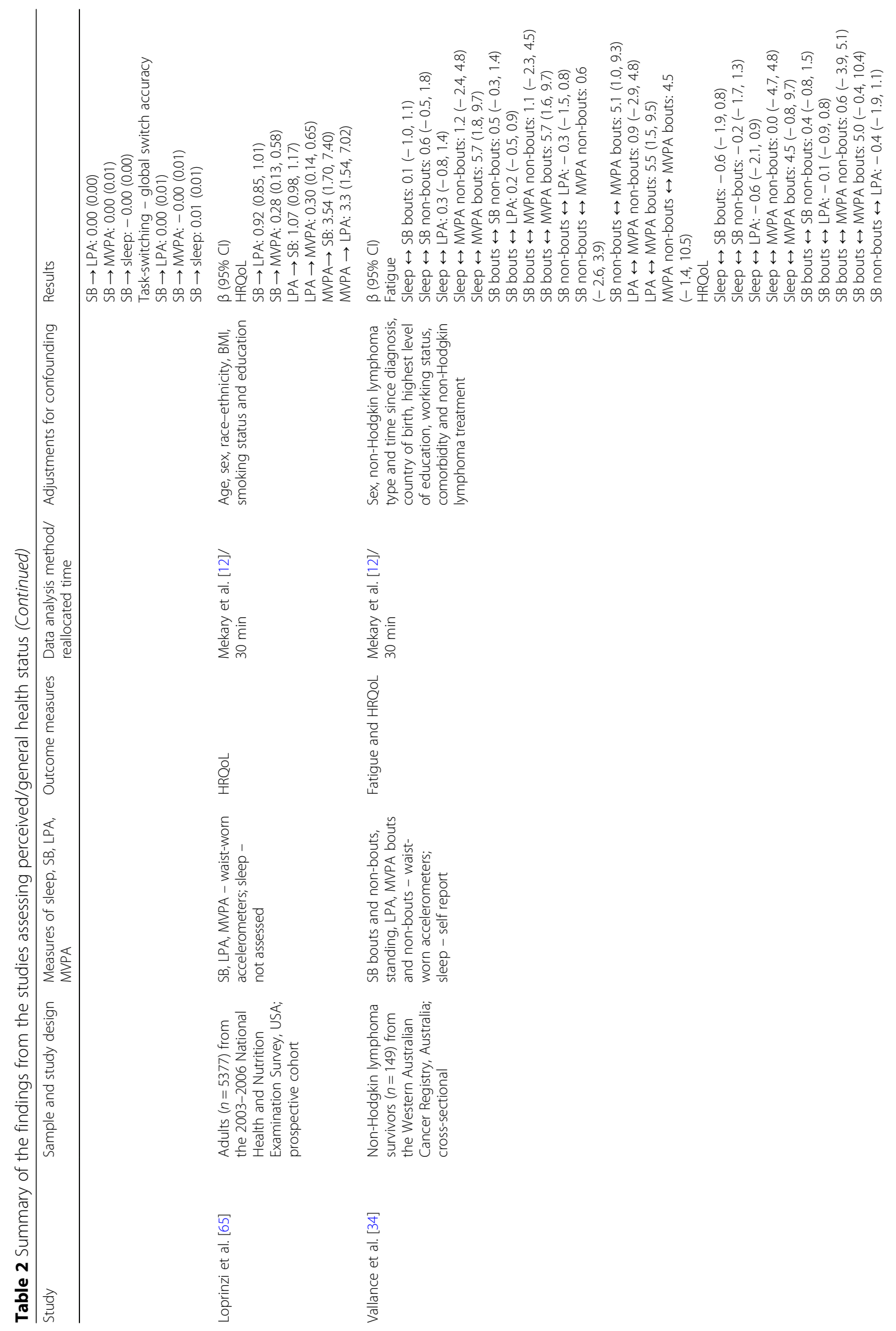


Grgic et al. International Journal of Behavioral Nutrition and Physical Activity (2018) 15:69

Page 15 of 68

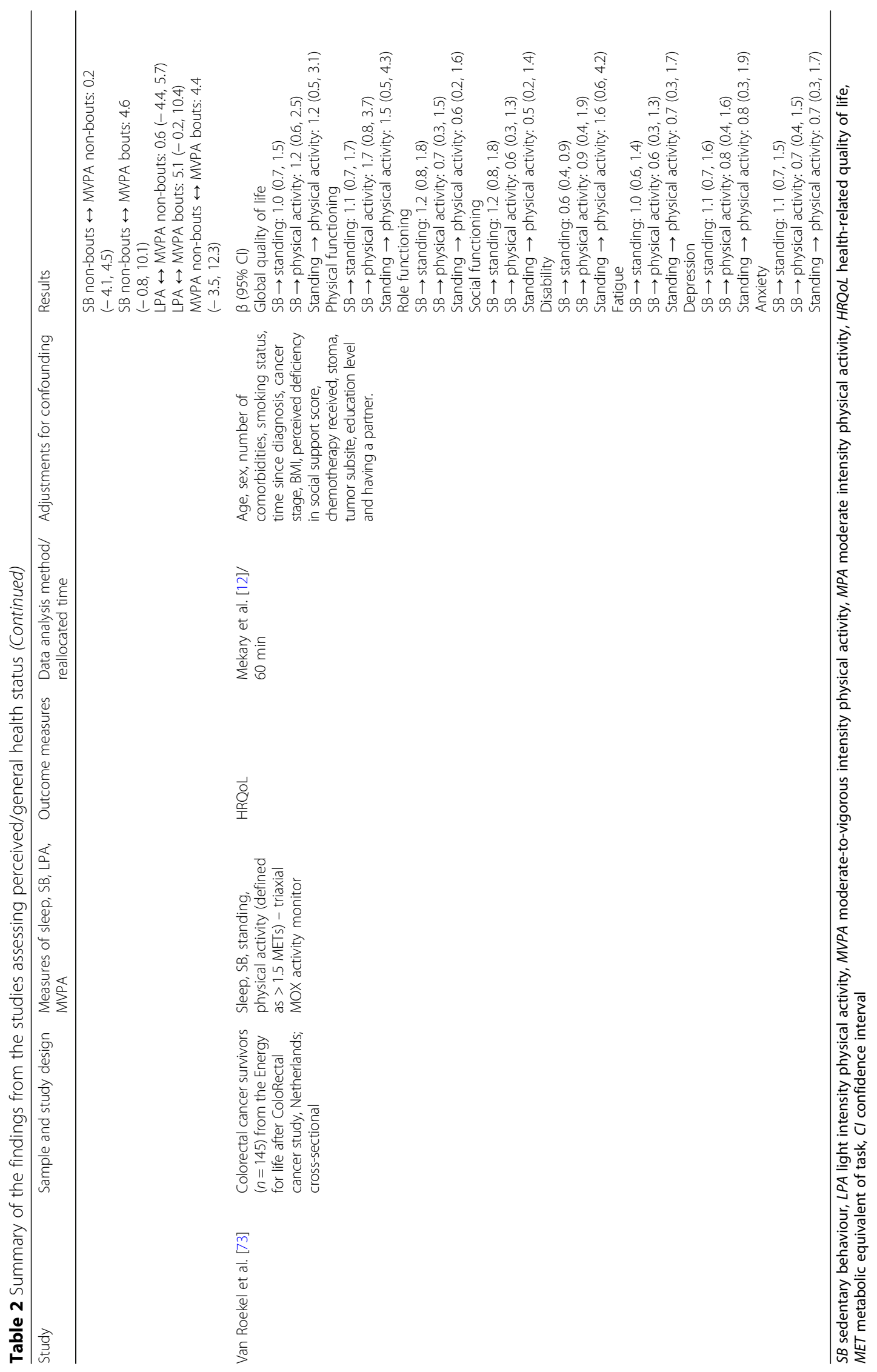




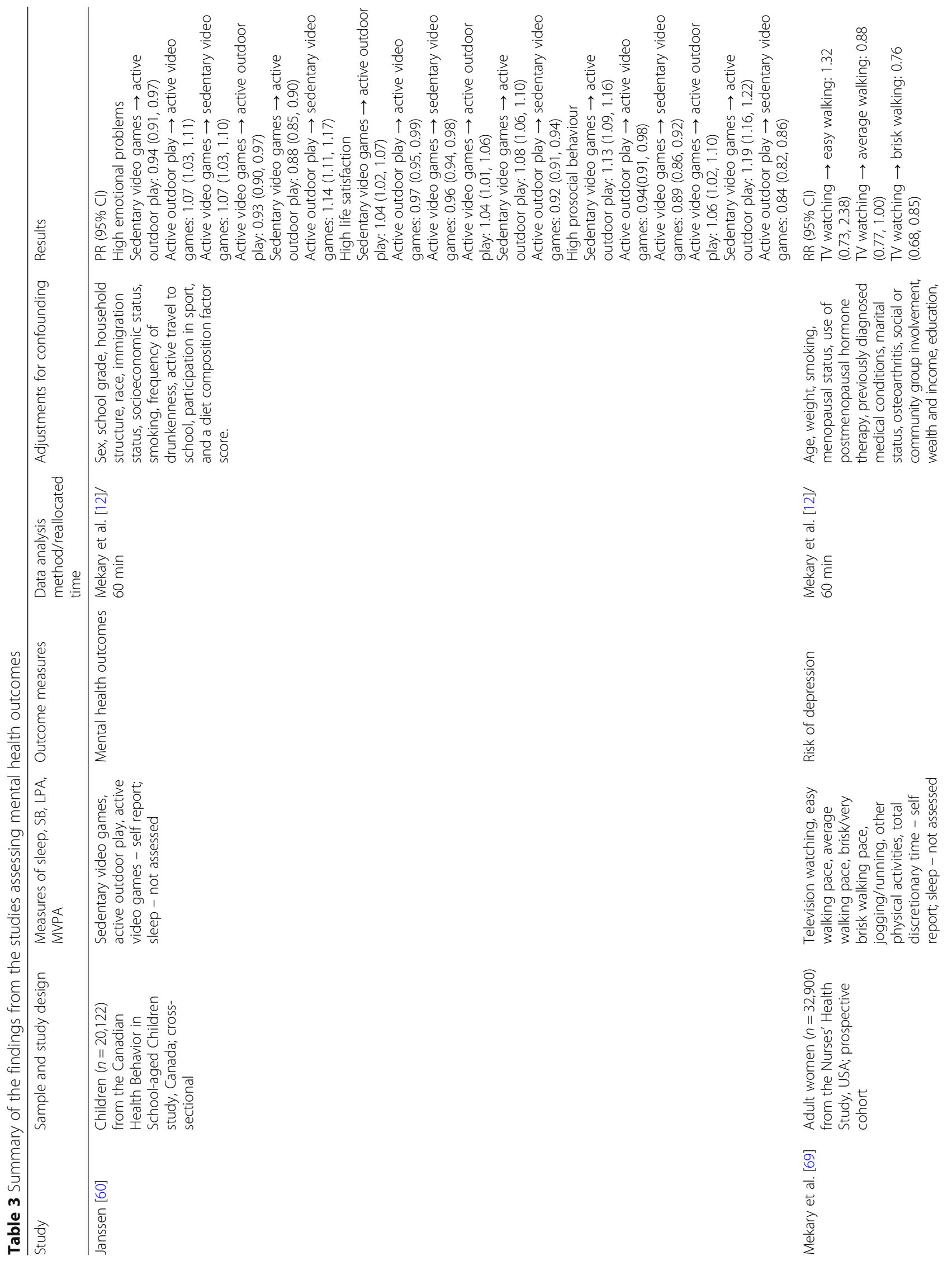




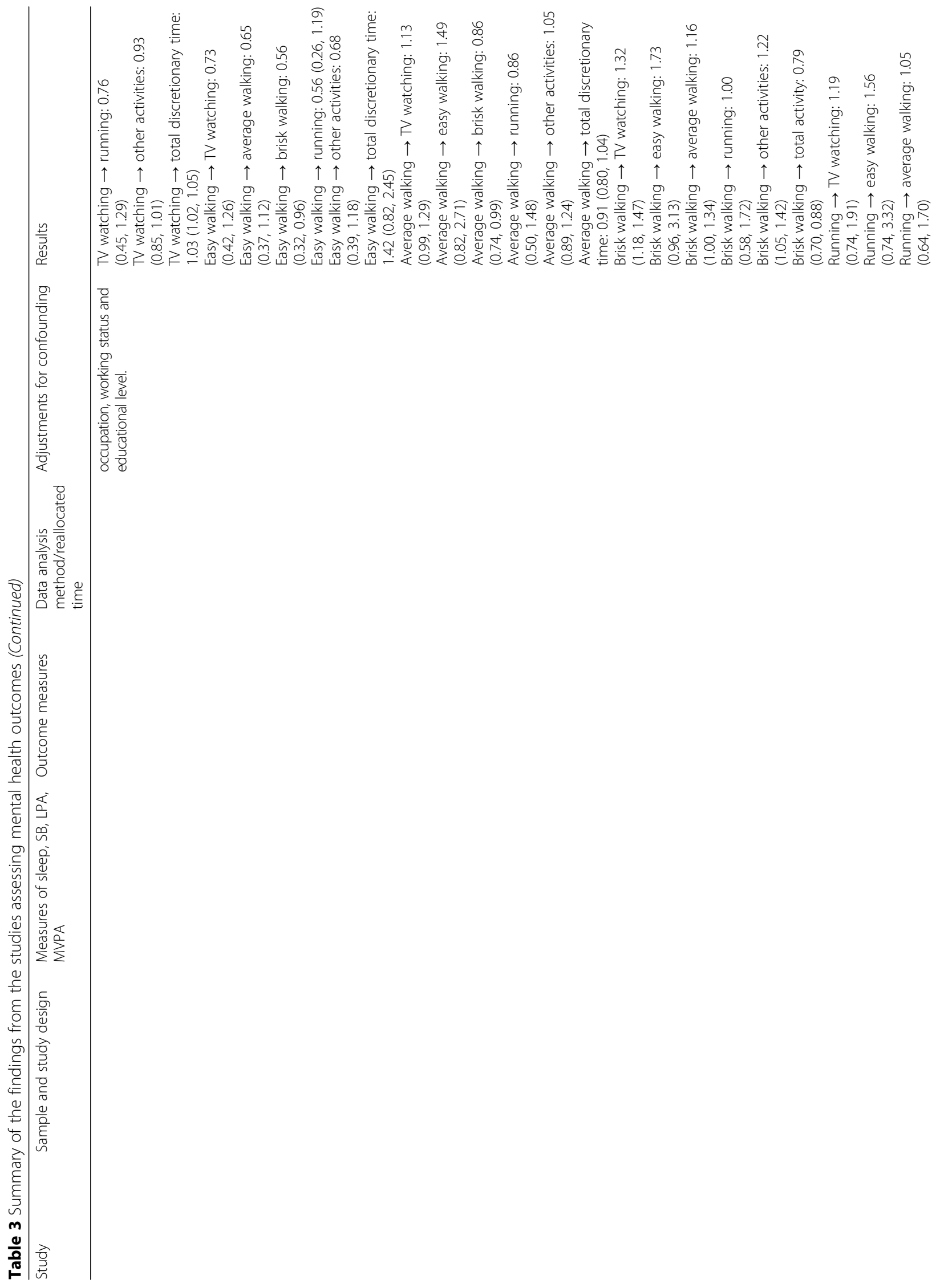




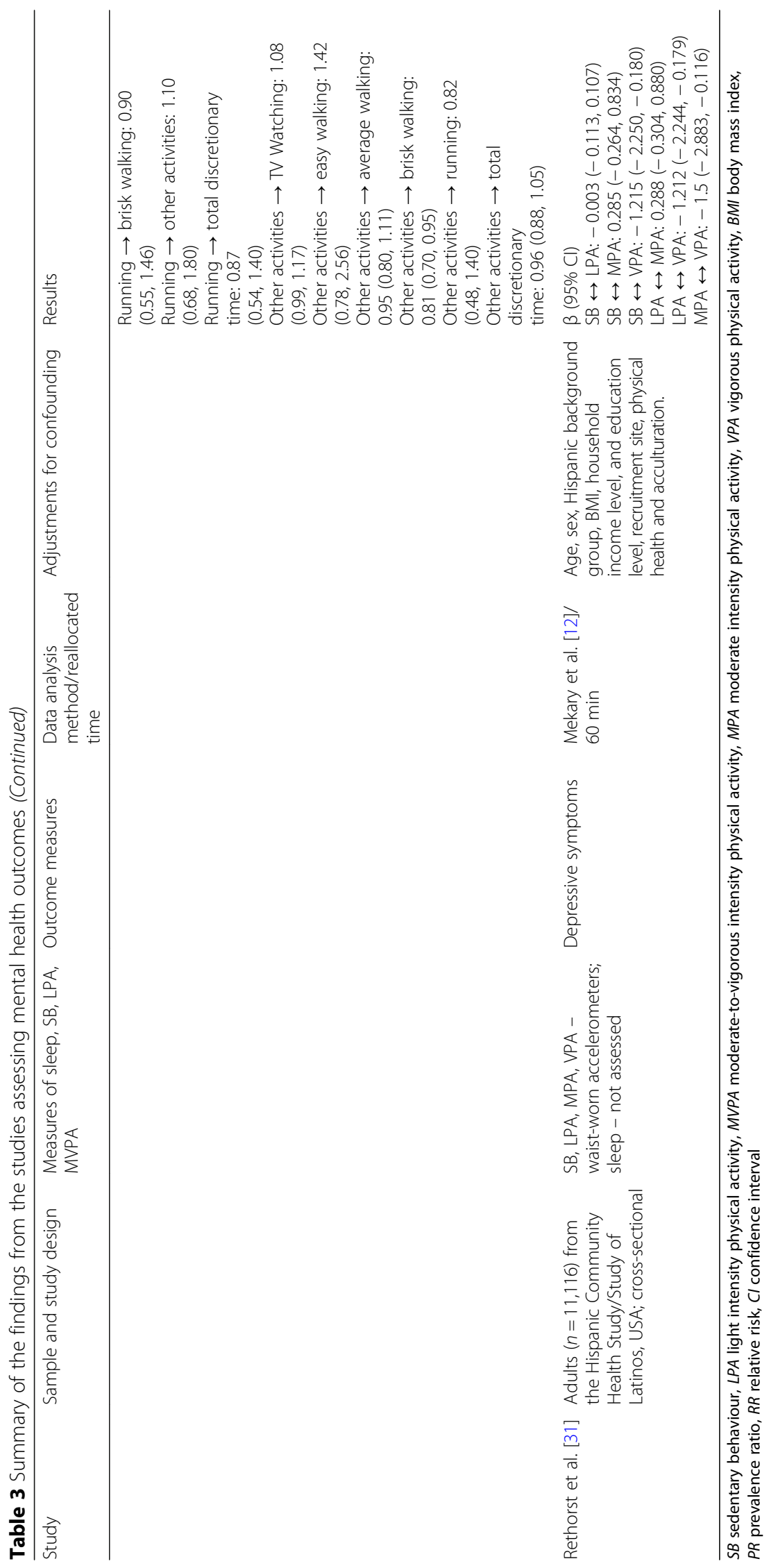




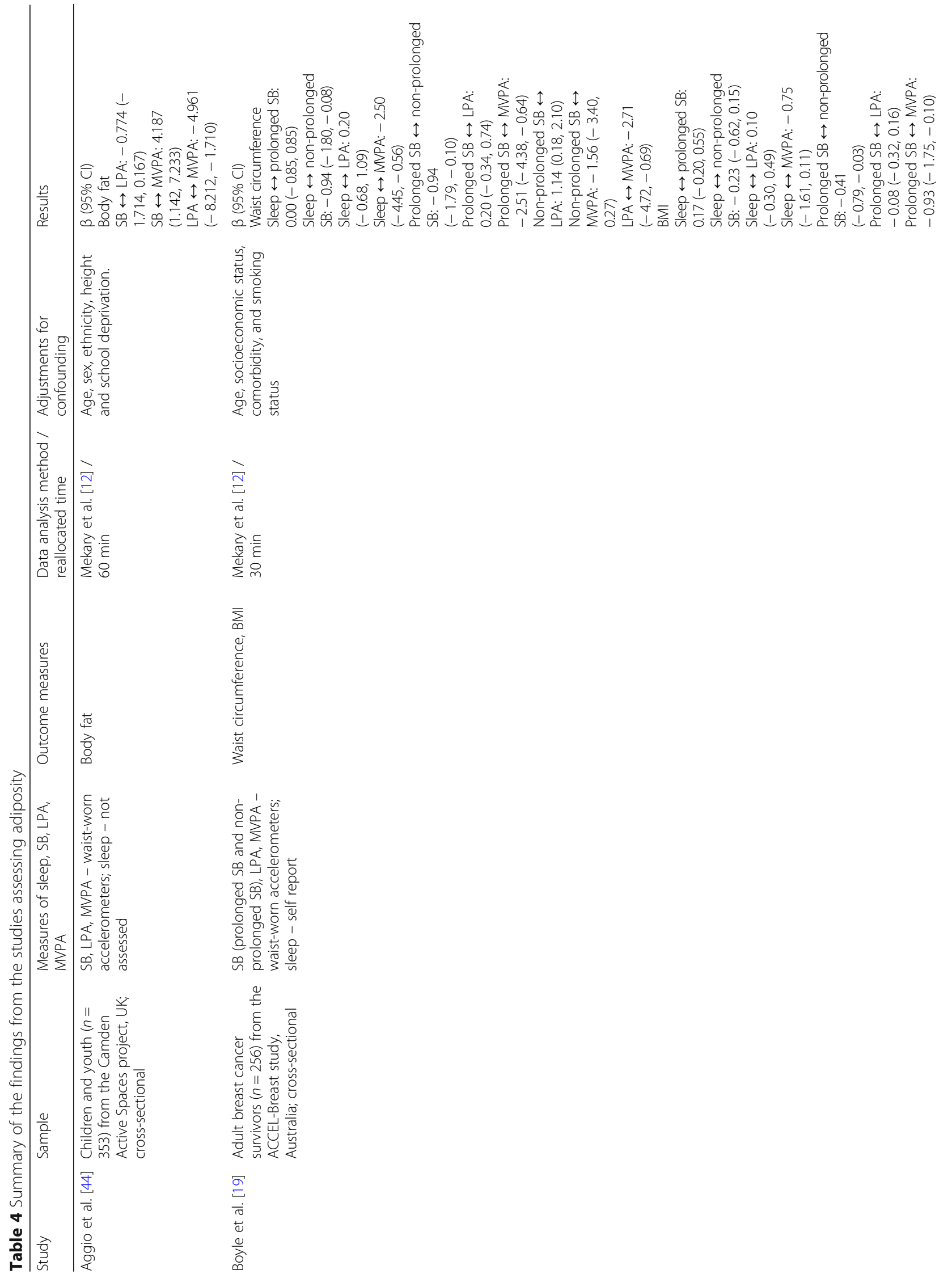




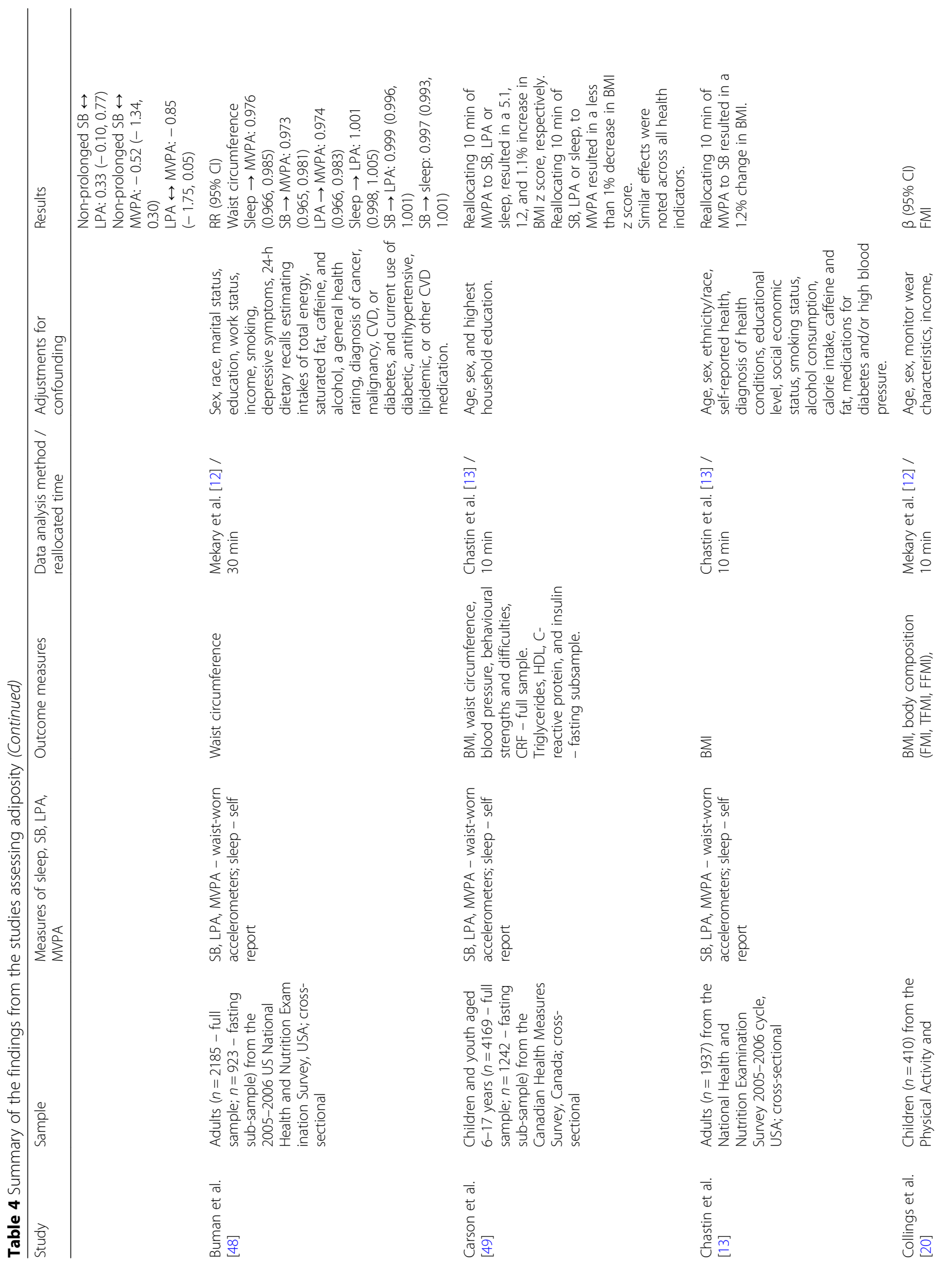




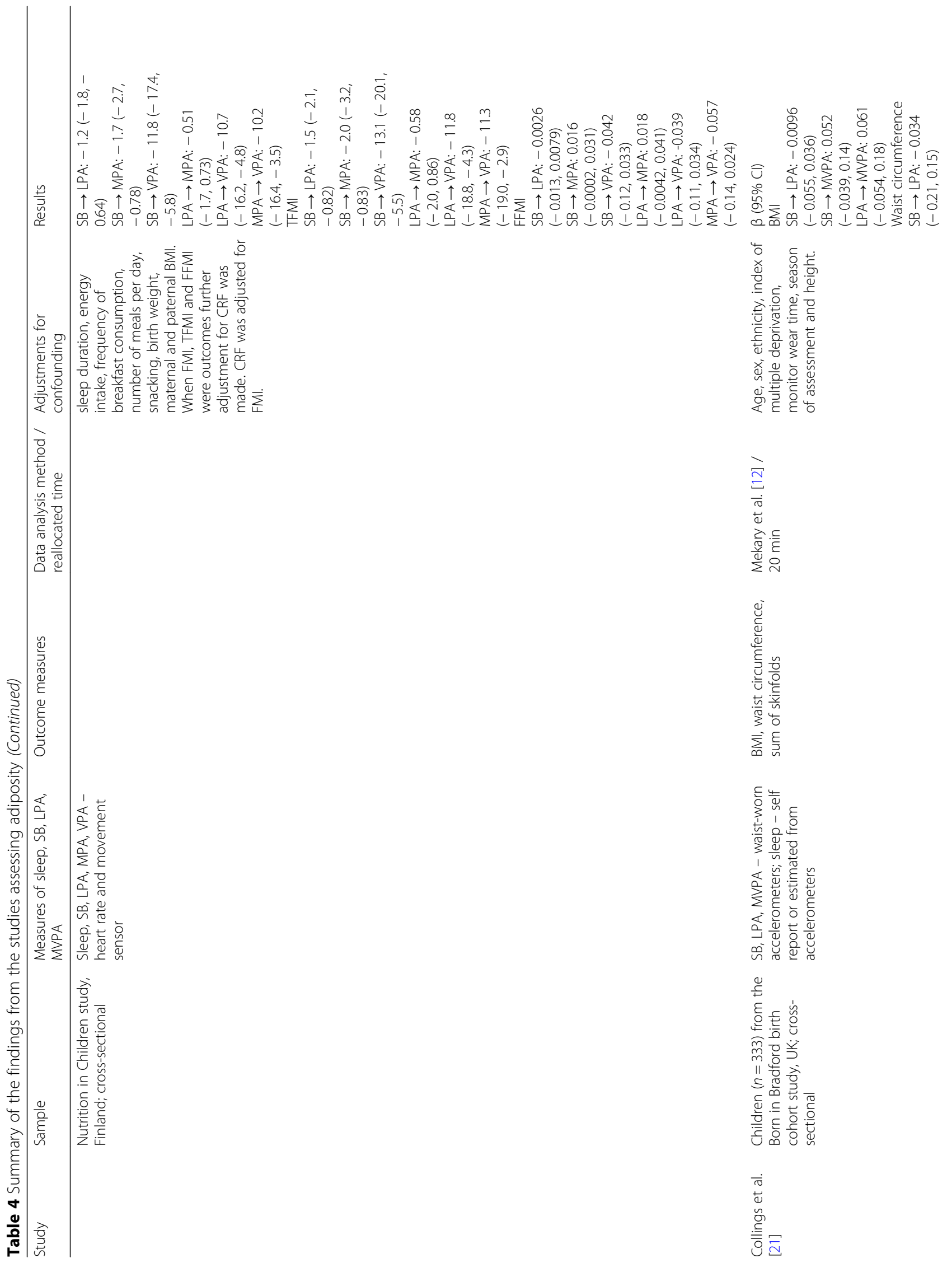




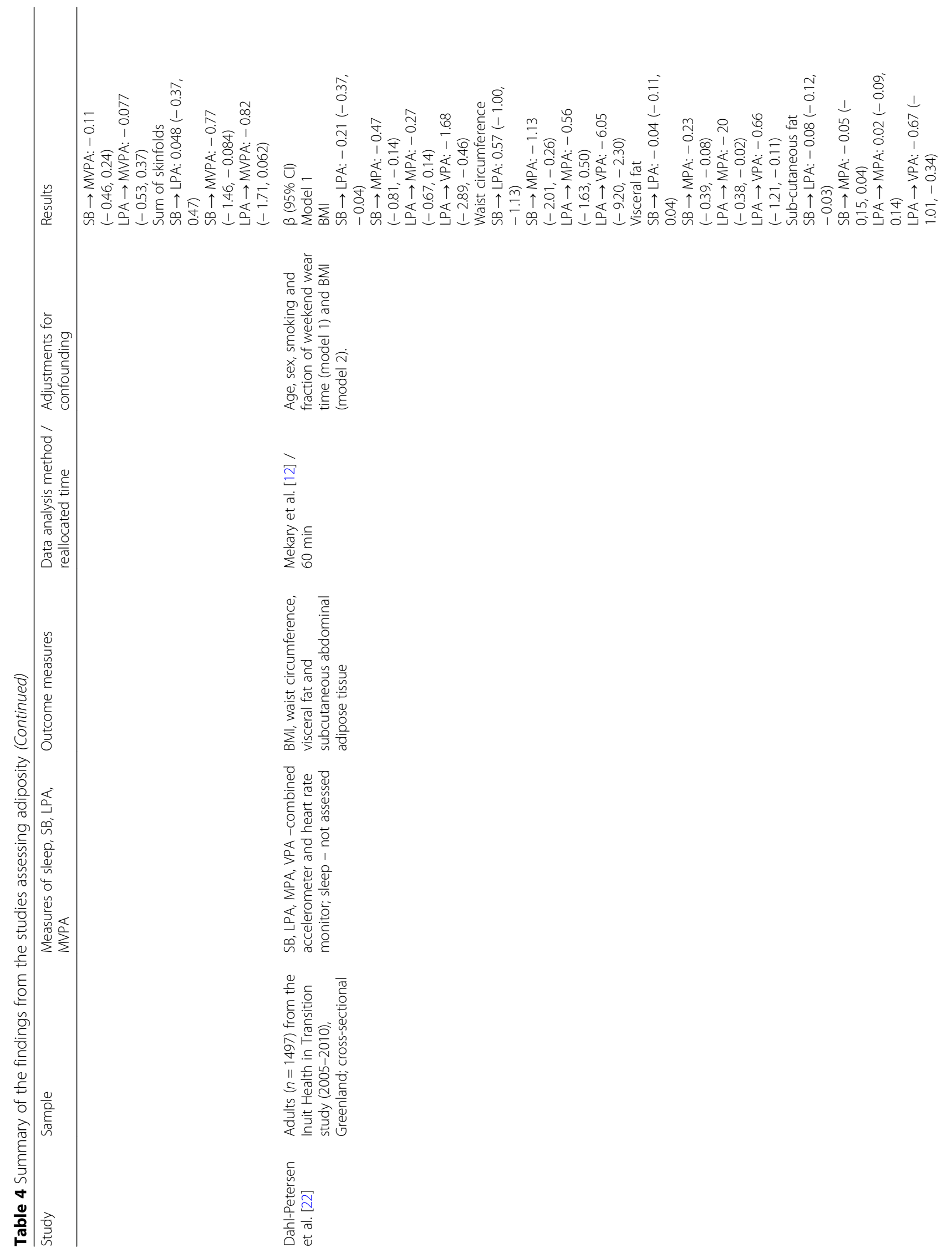




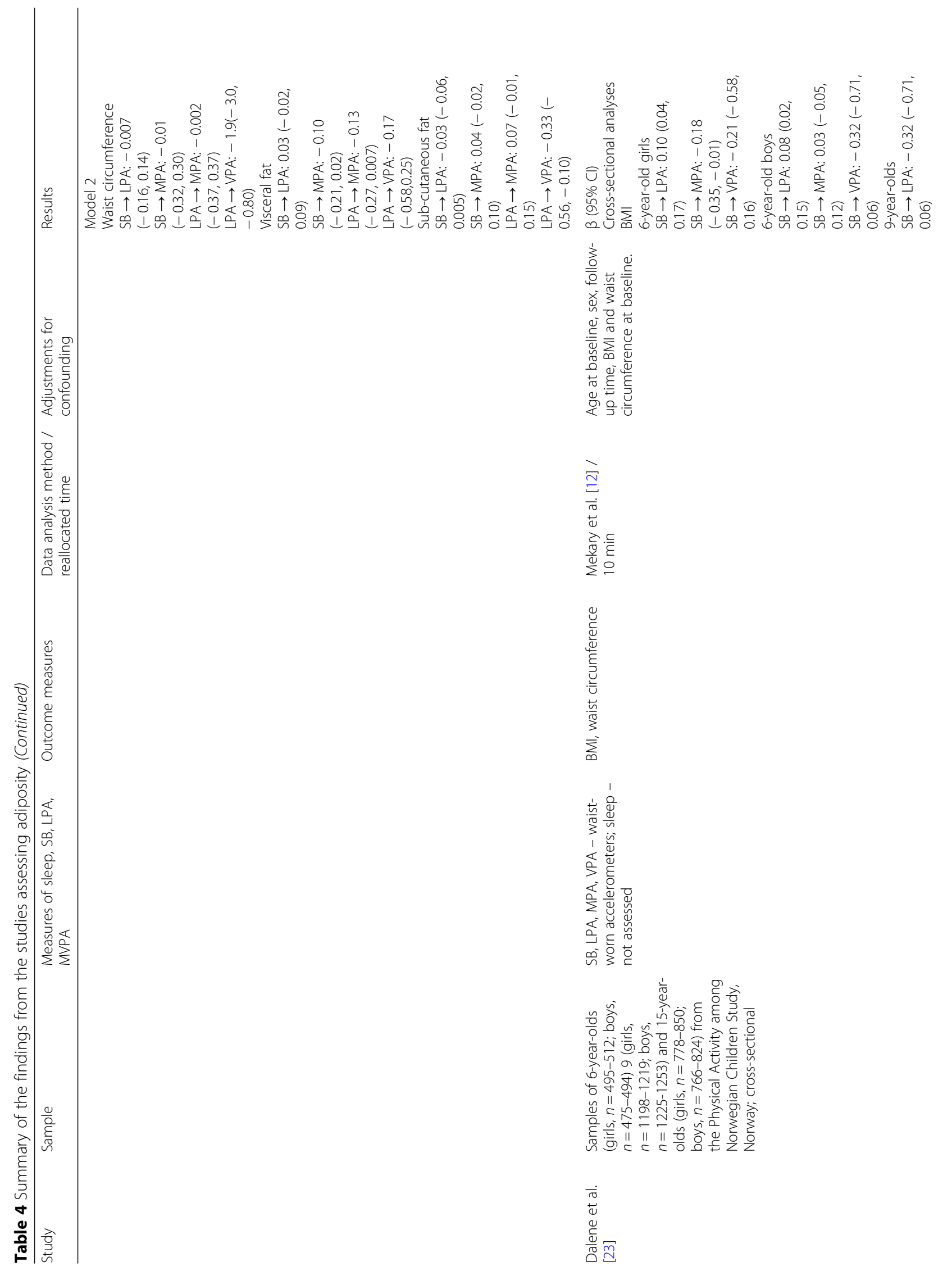




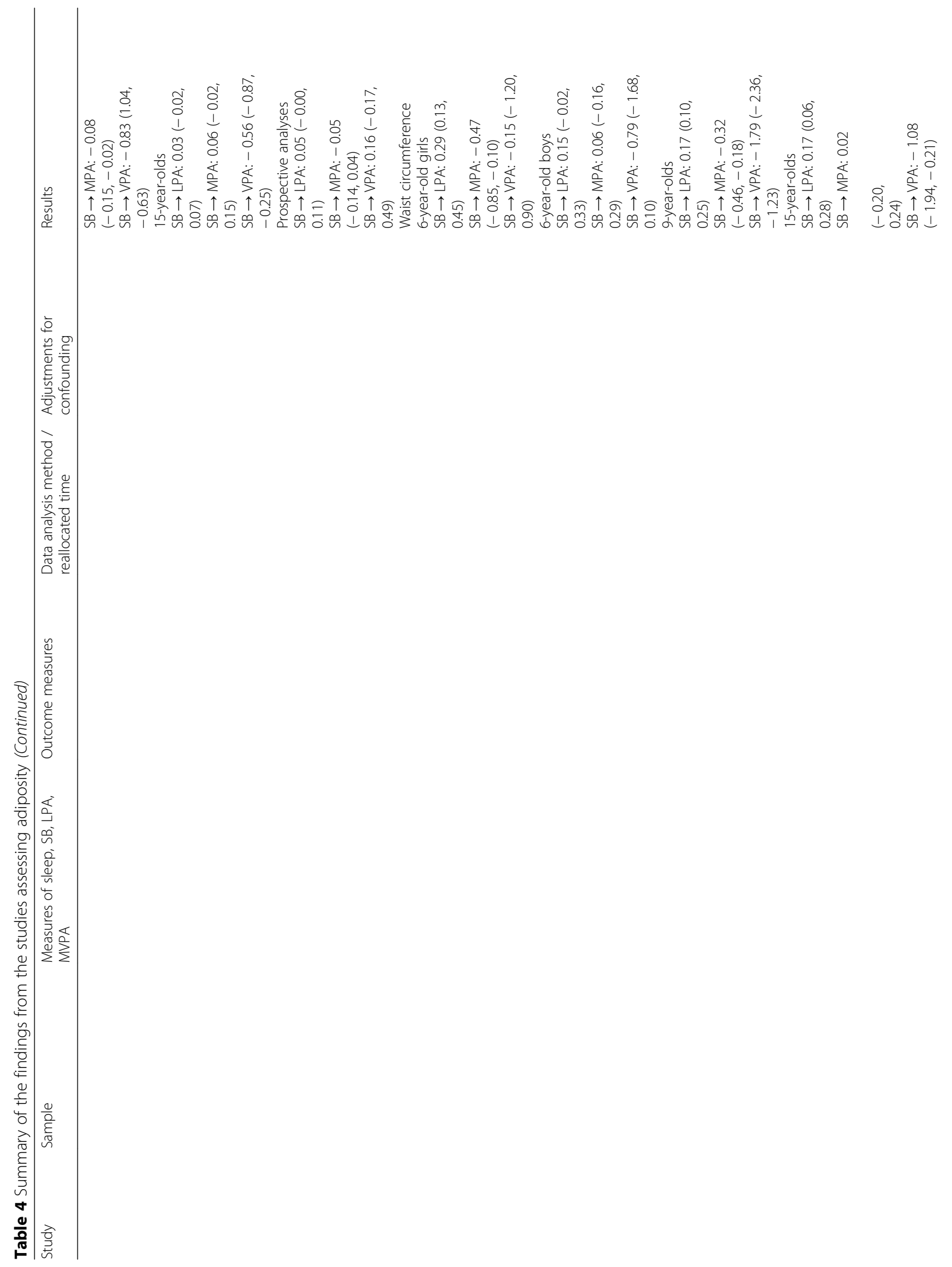


Grgic et al. International Journal of Behavioral Nutrition and Physical Activity (2018) 15:69

Page 25 of 68

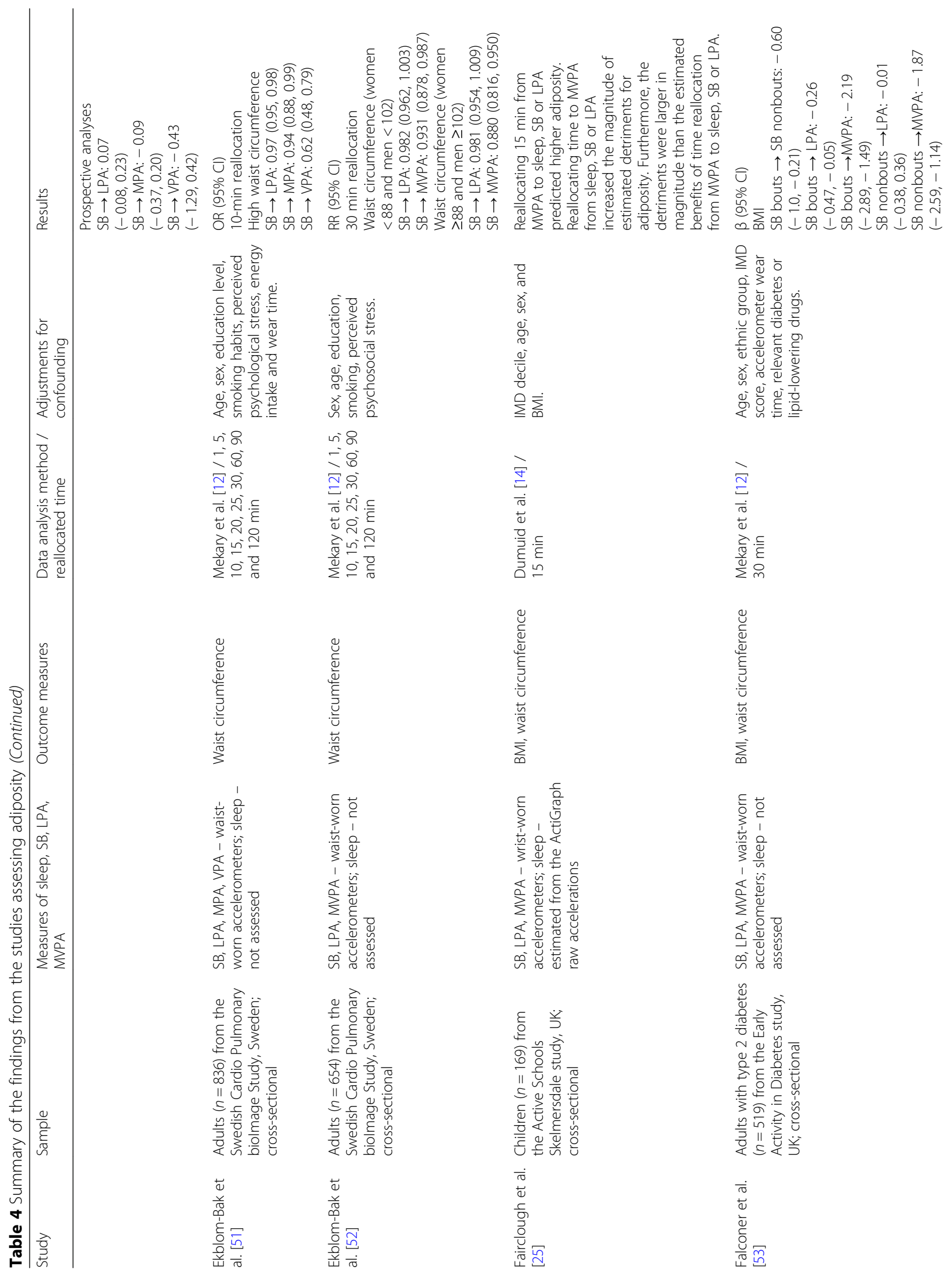




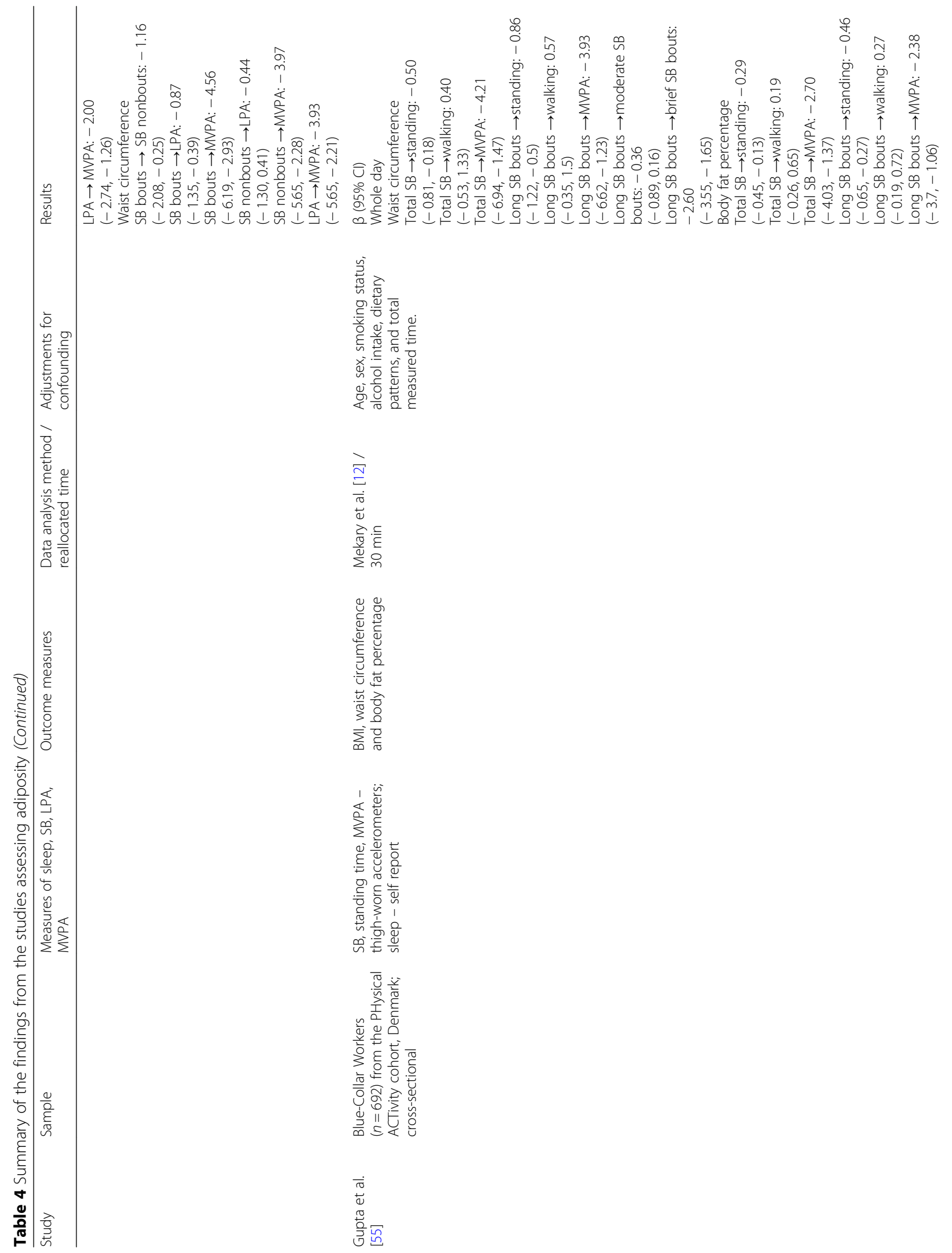




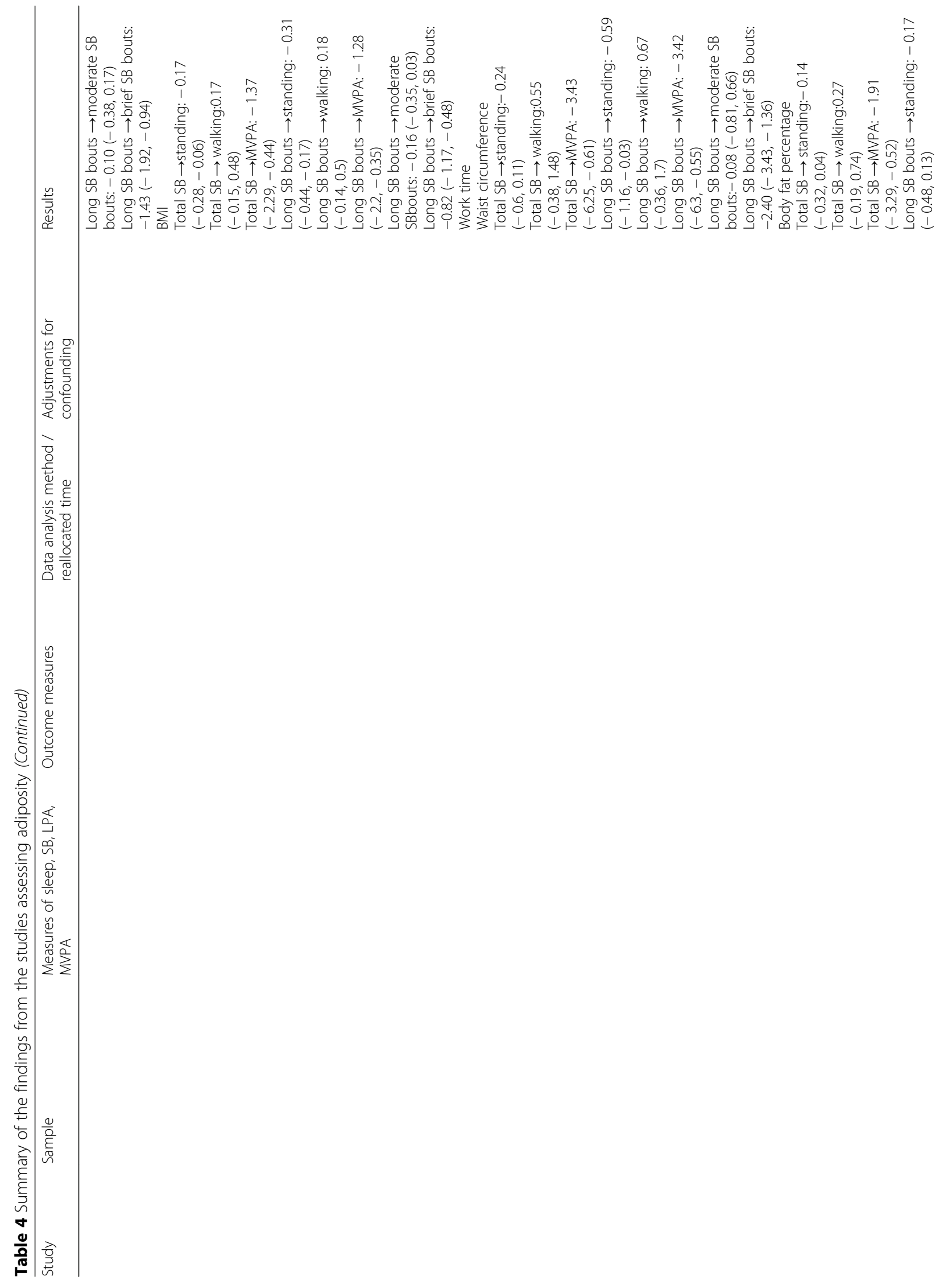




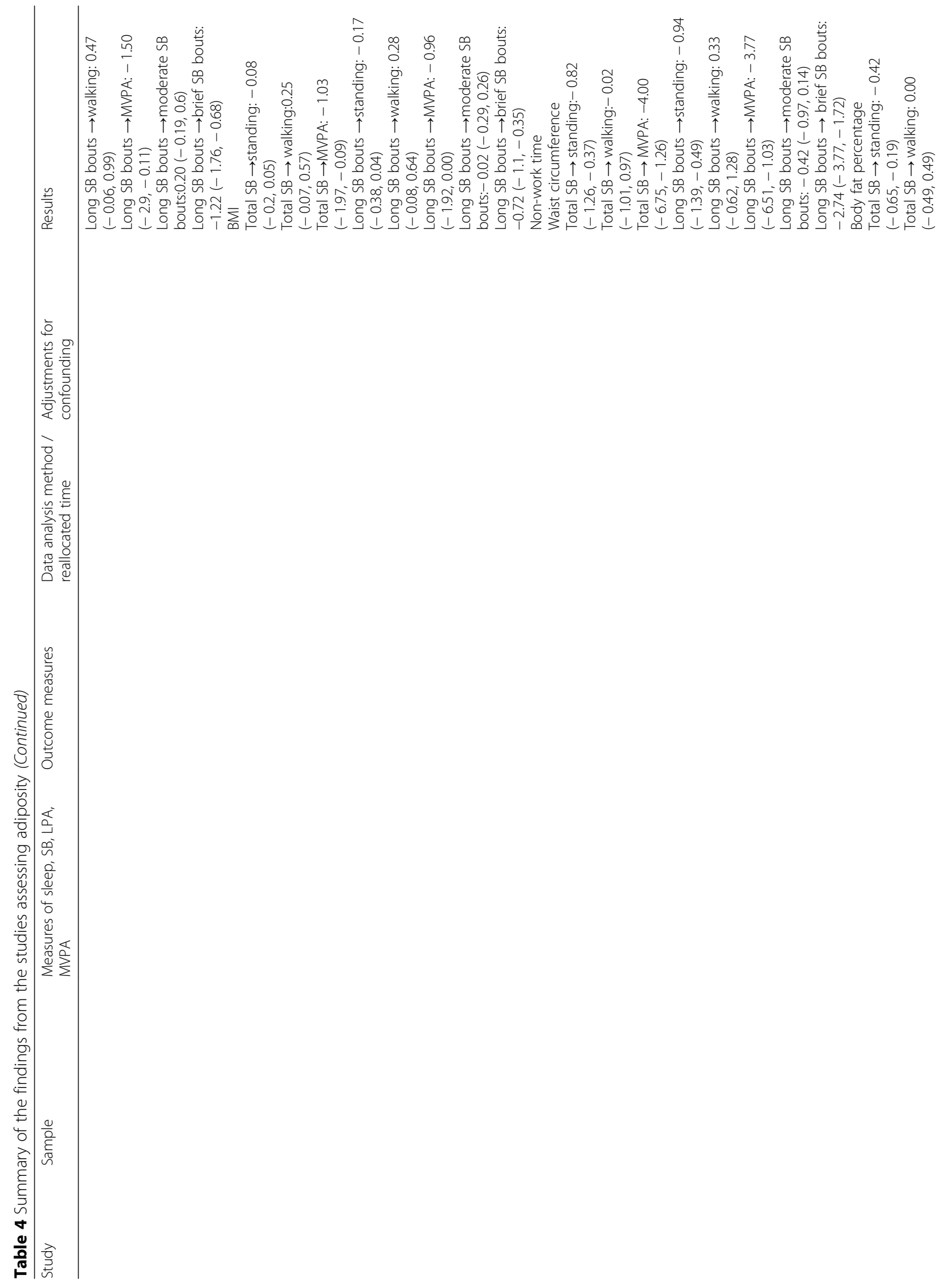




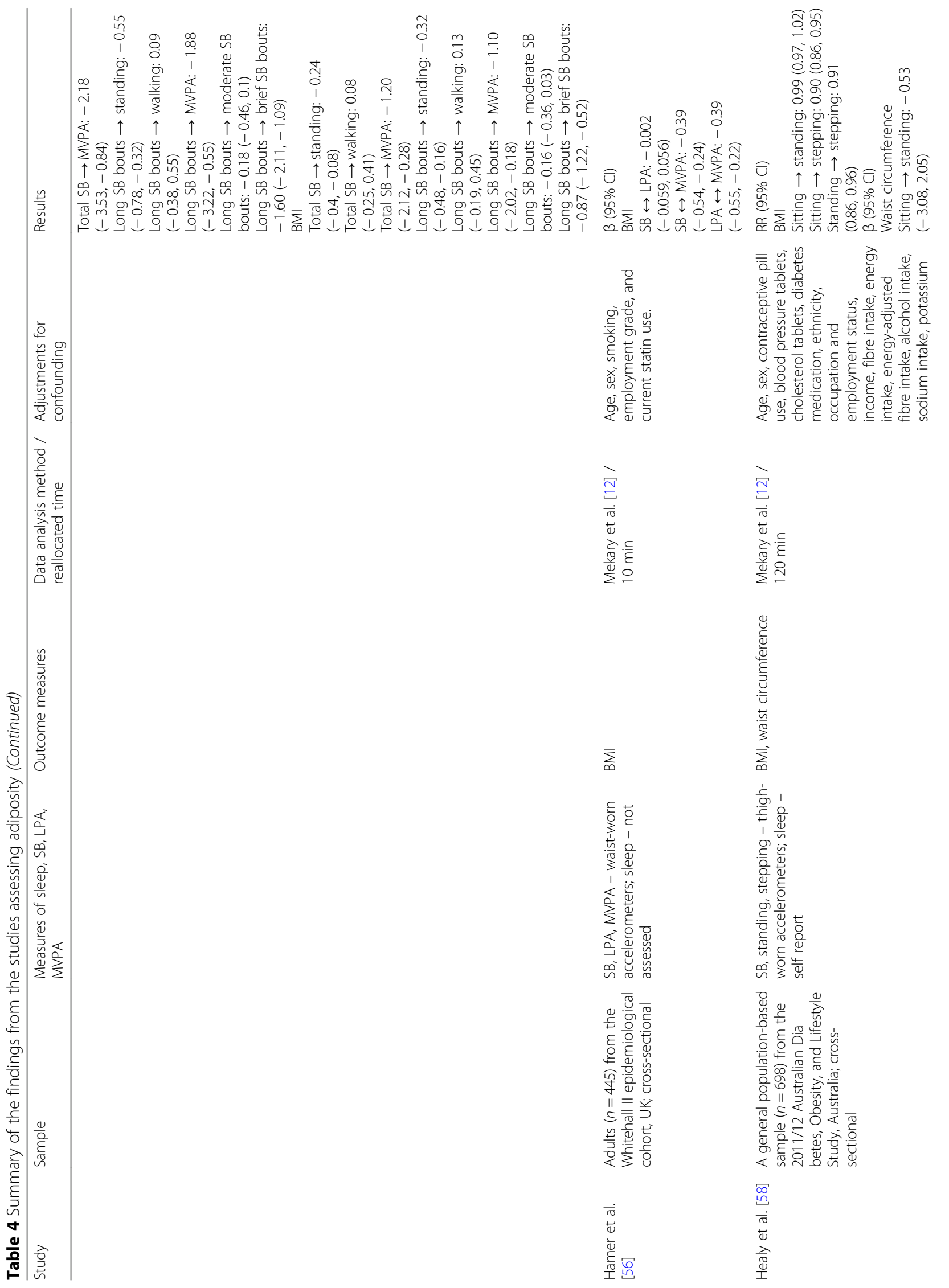




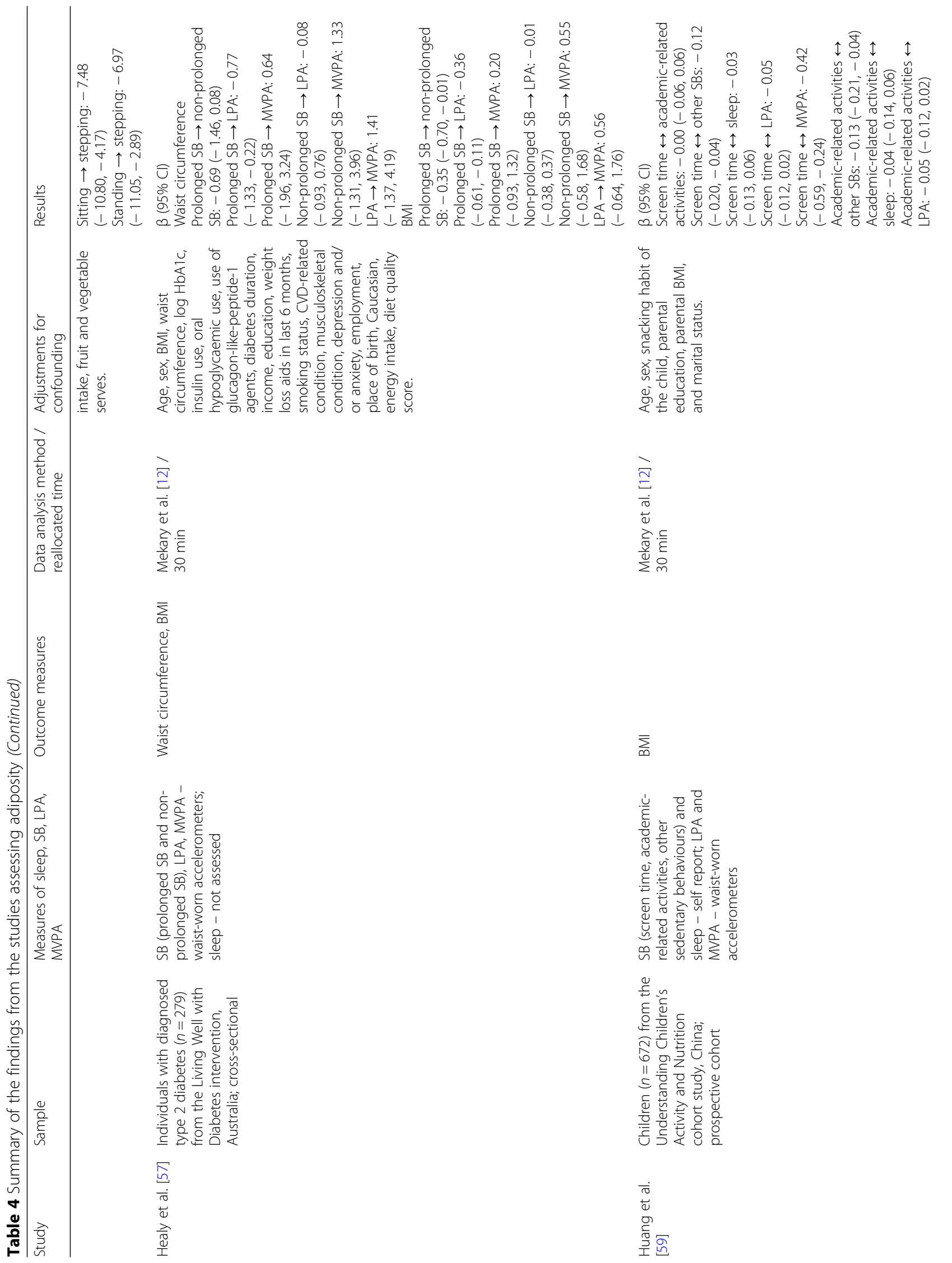




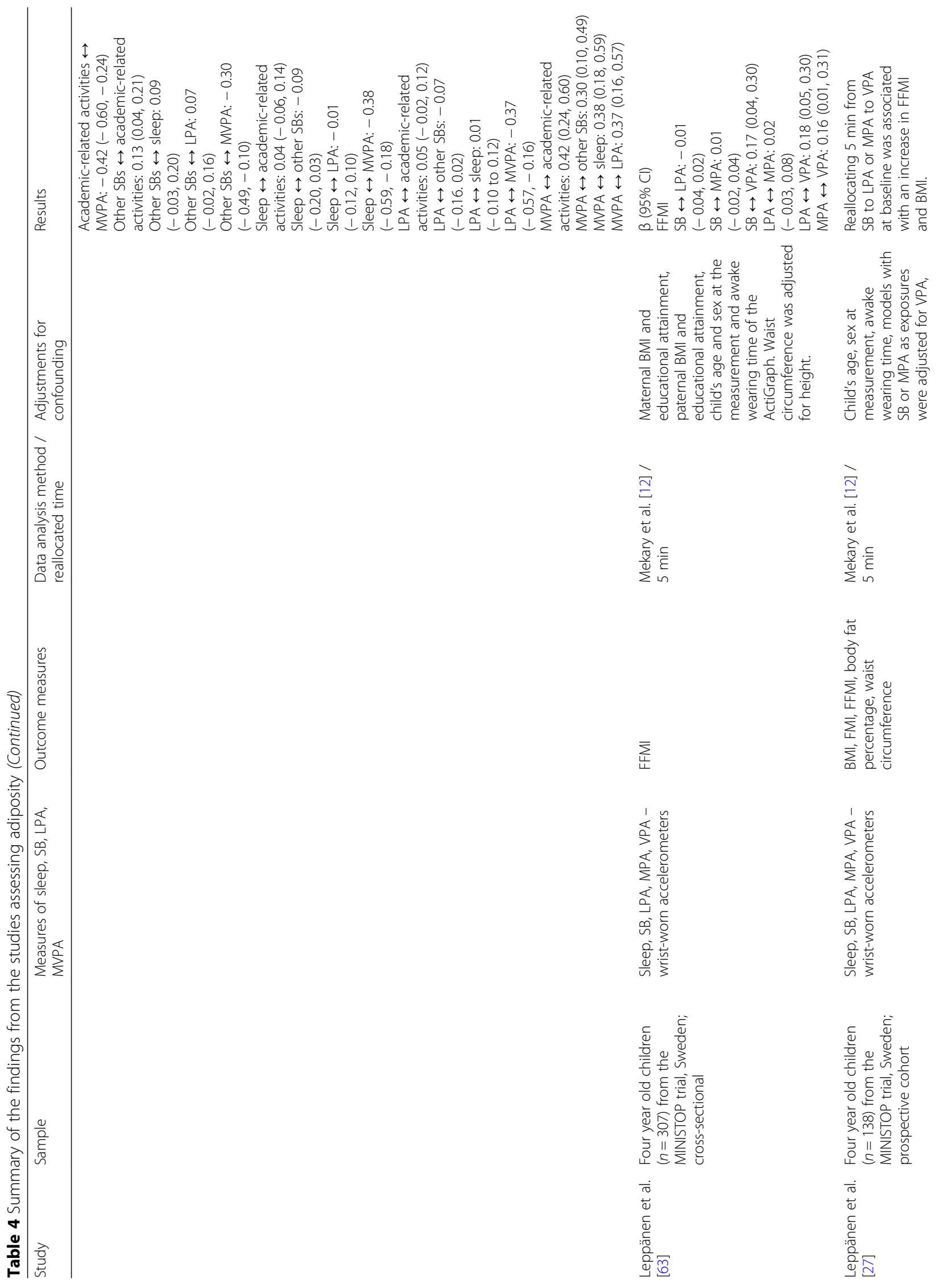




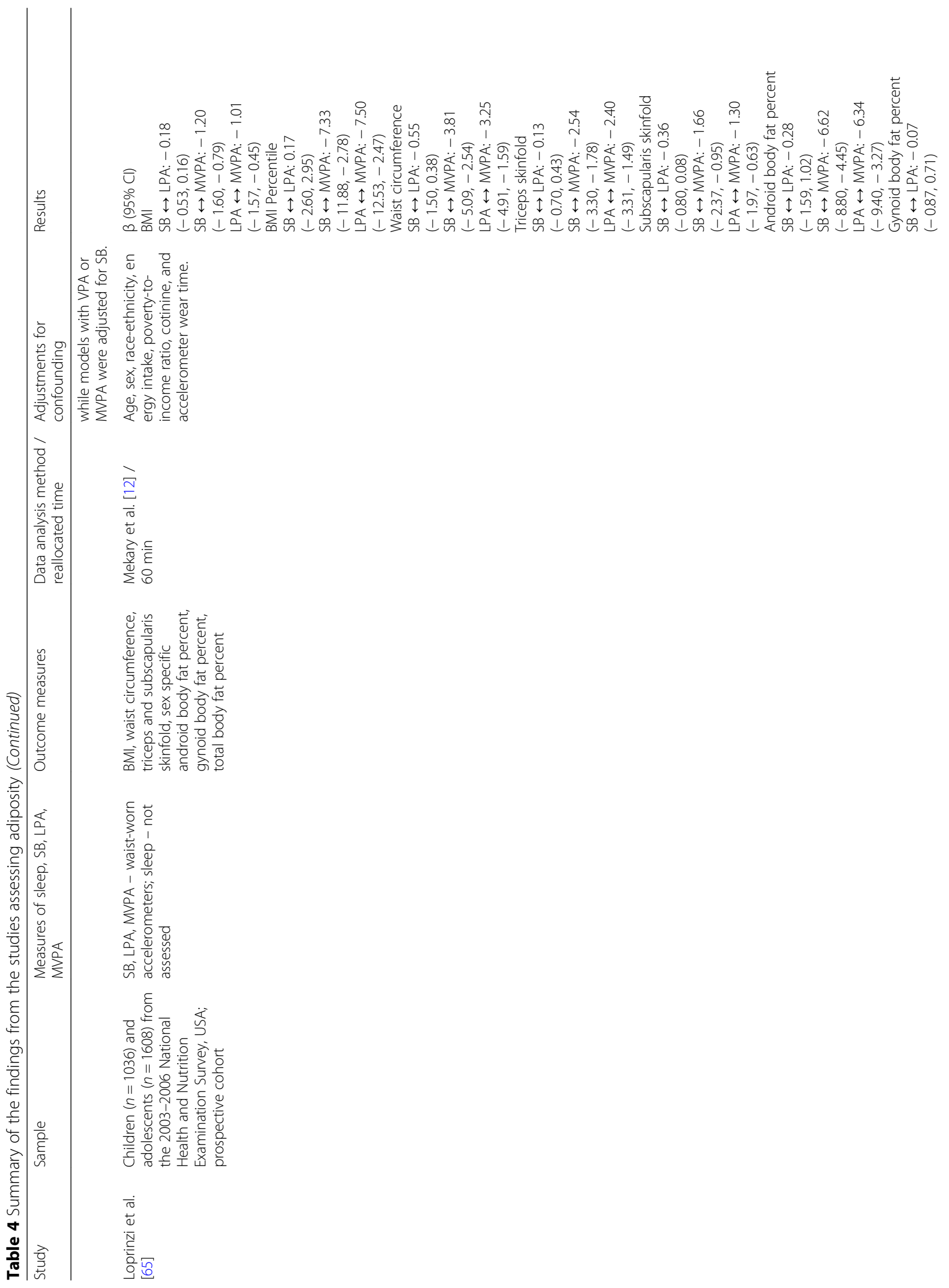




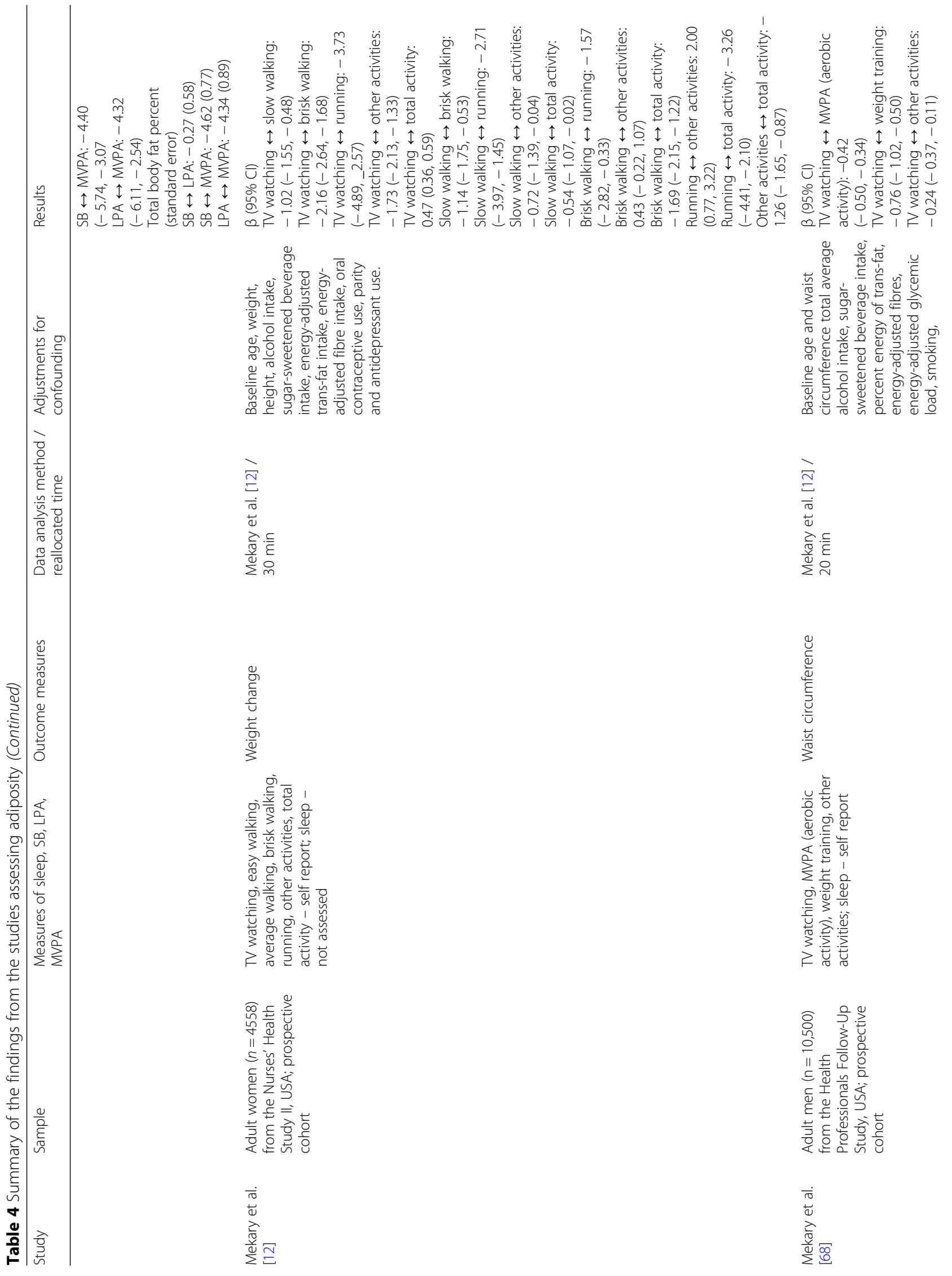




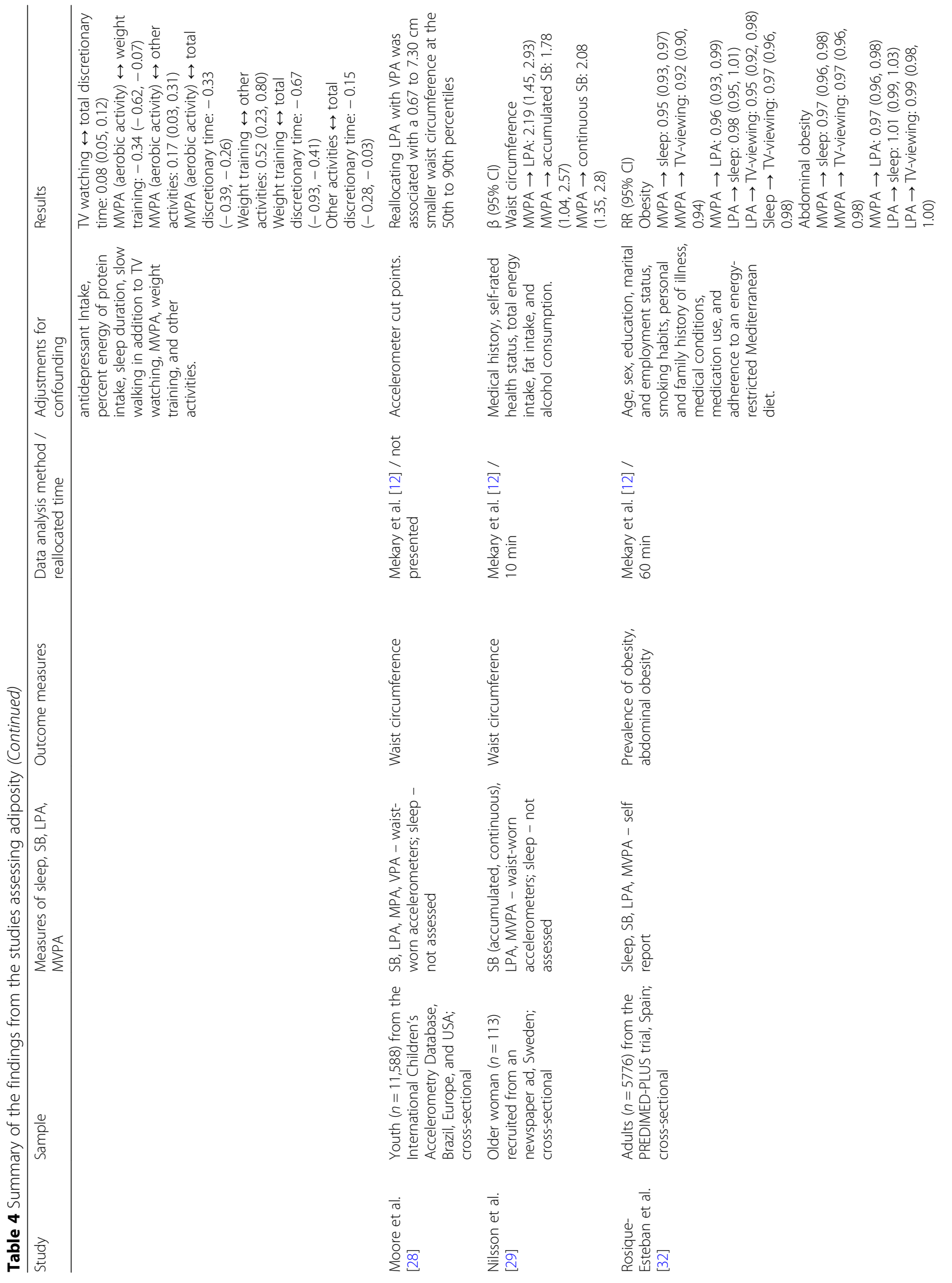




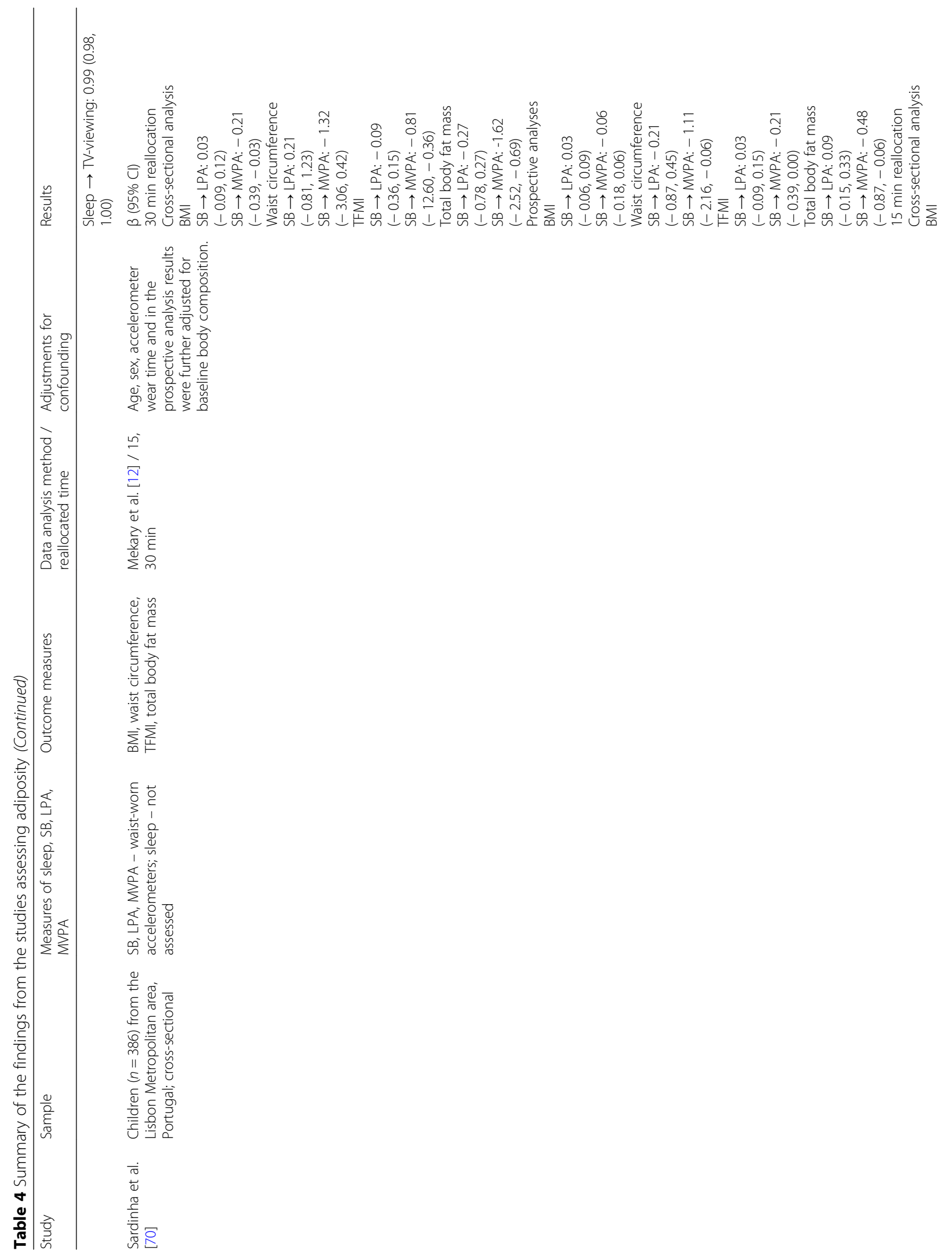




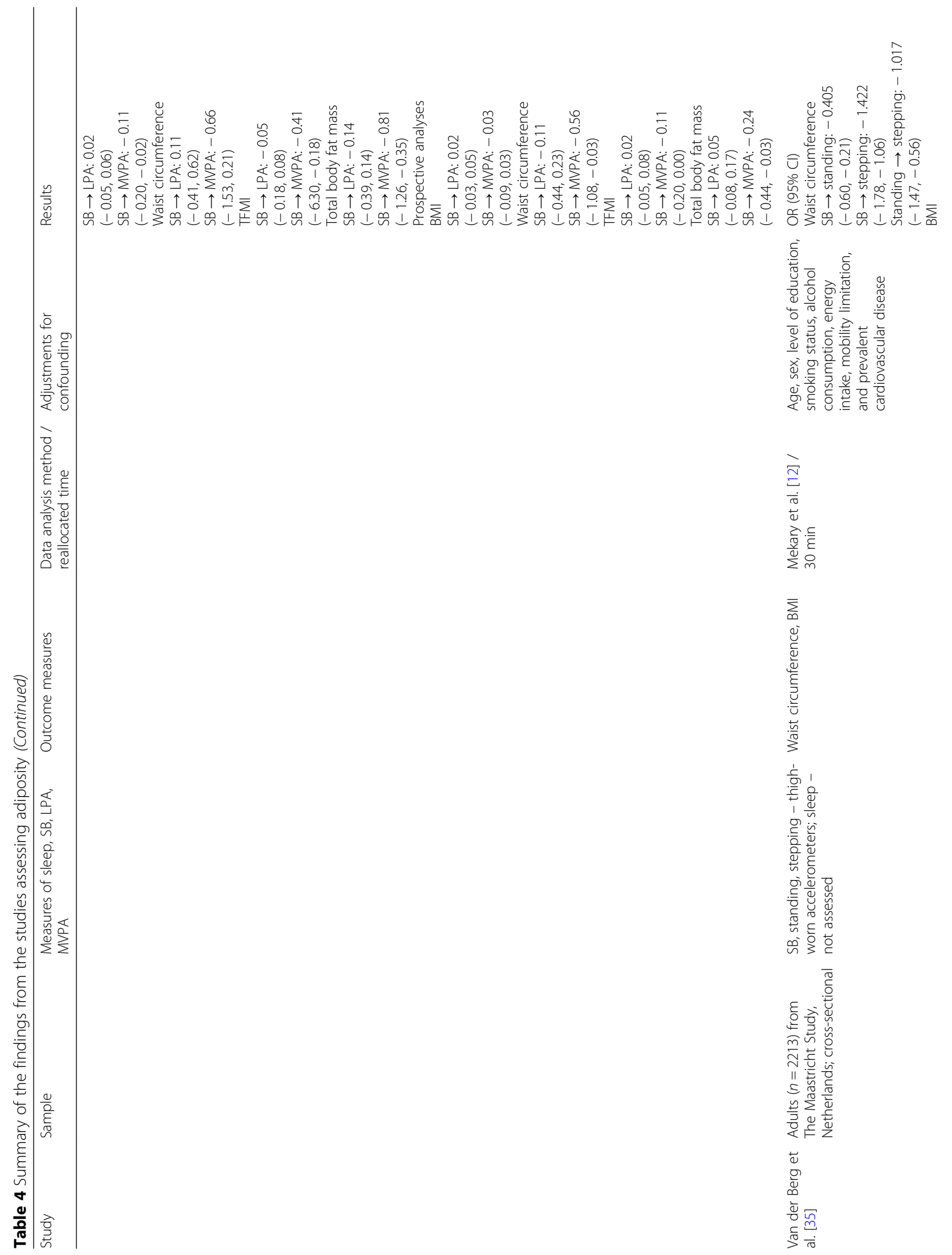




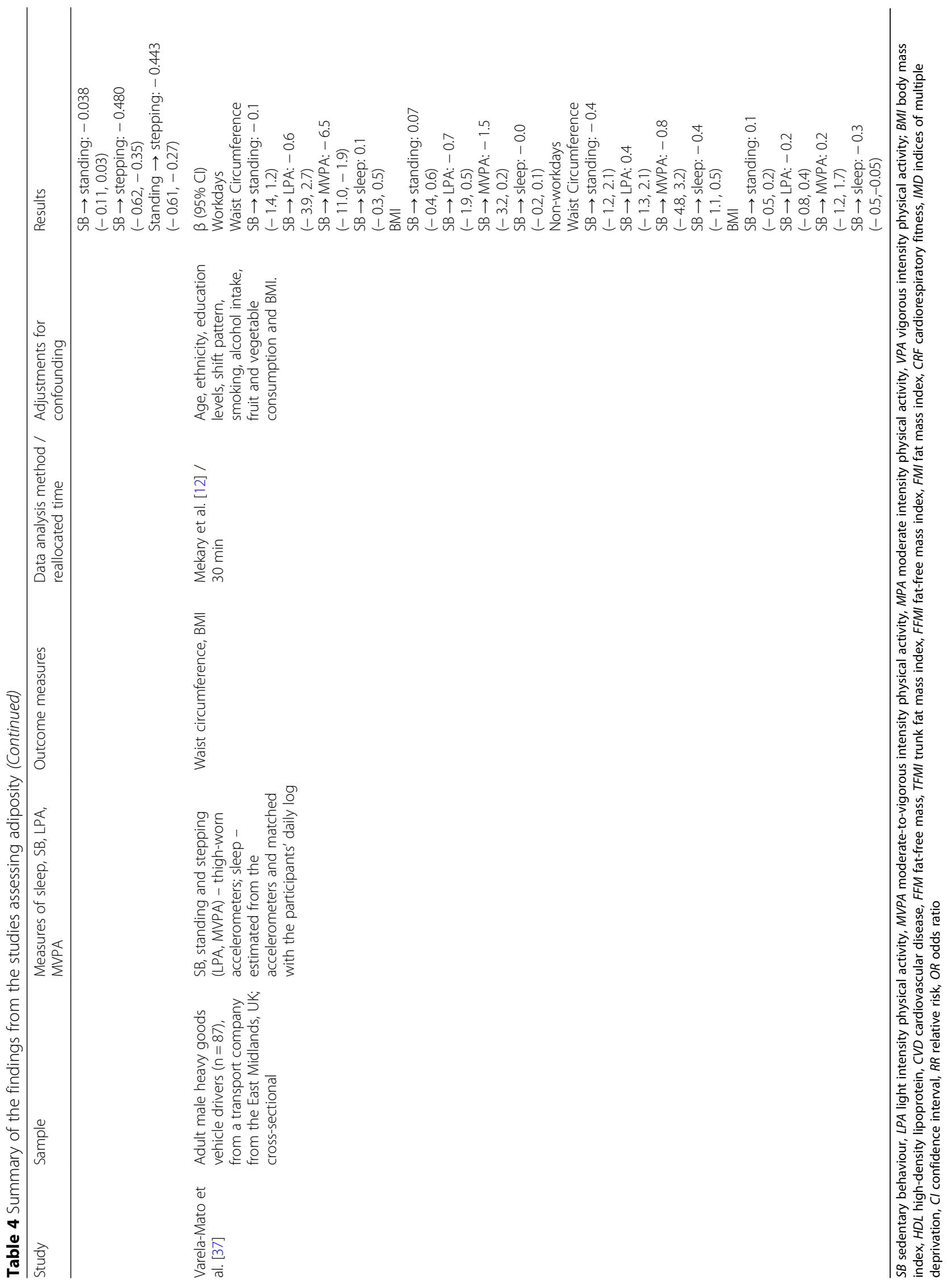




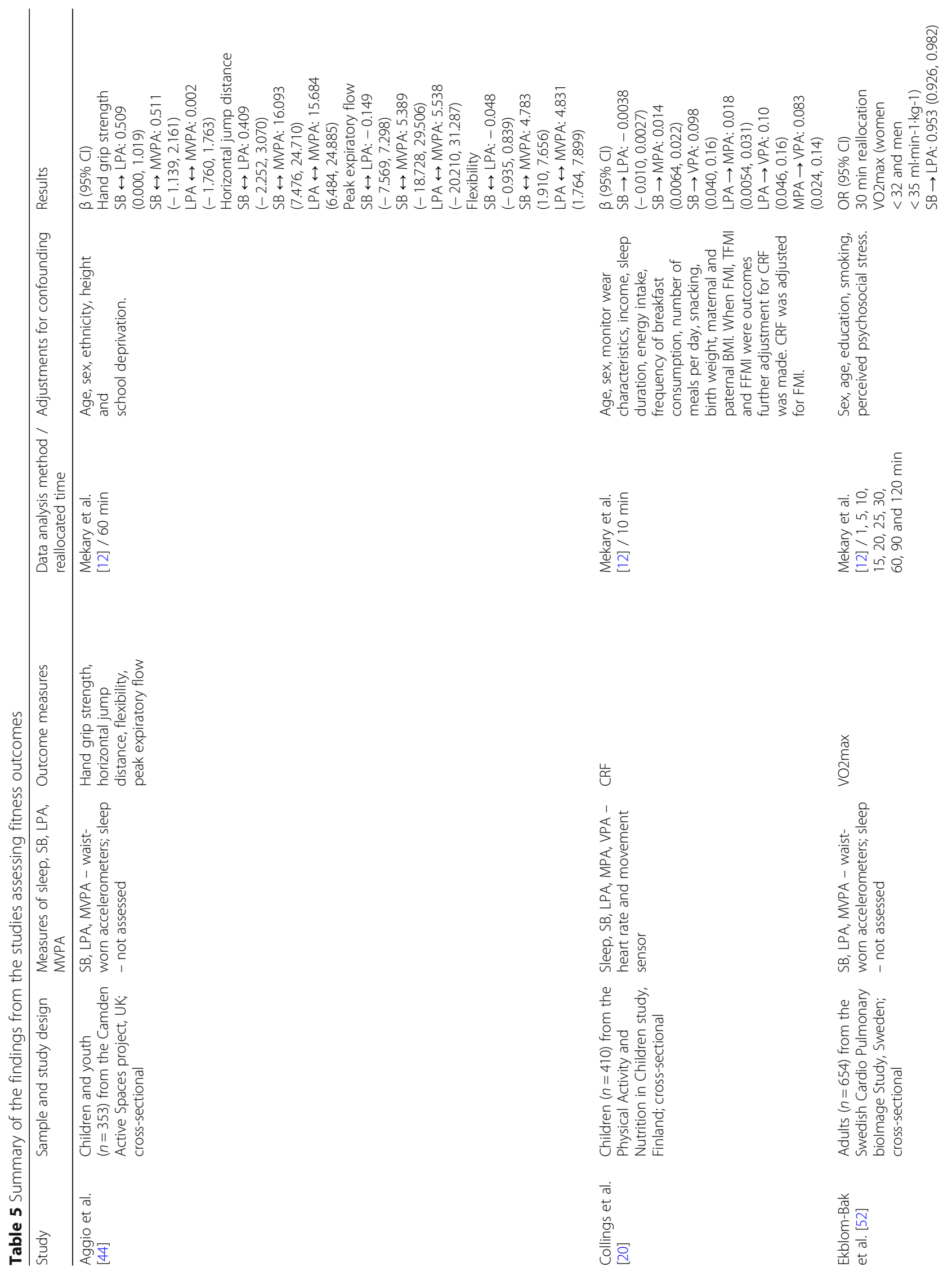


Grgic et al. International Journal of Behavioral Nutrition and Physical Activity (2018) 15:69

Page 39 of 68

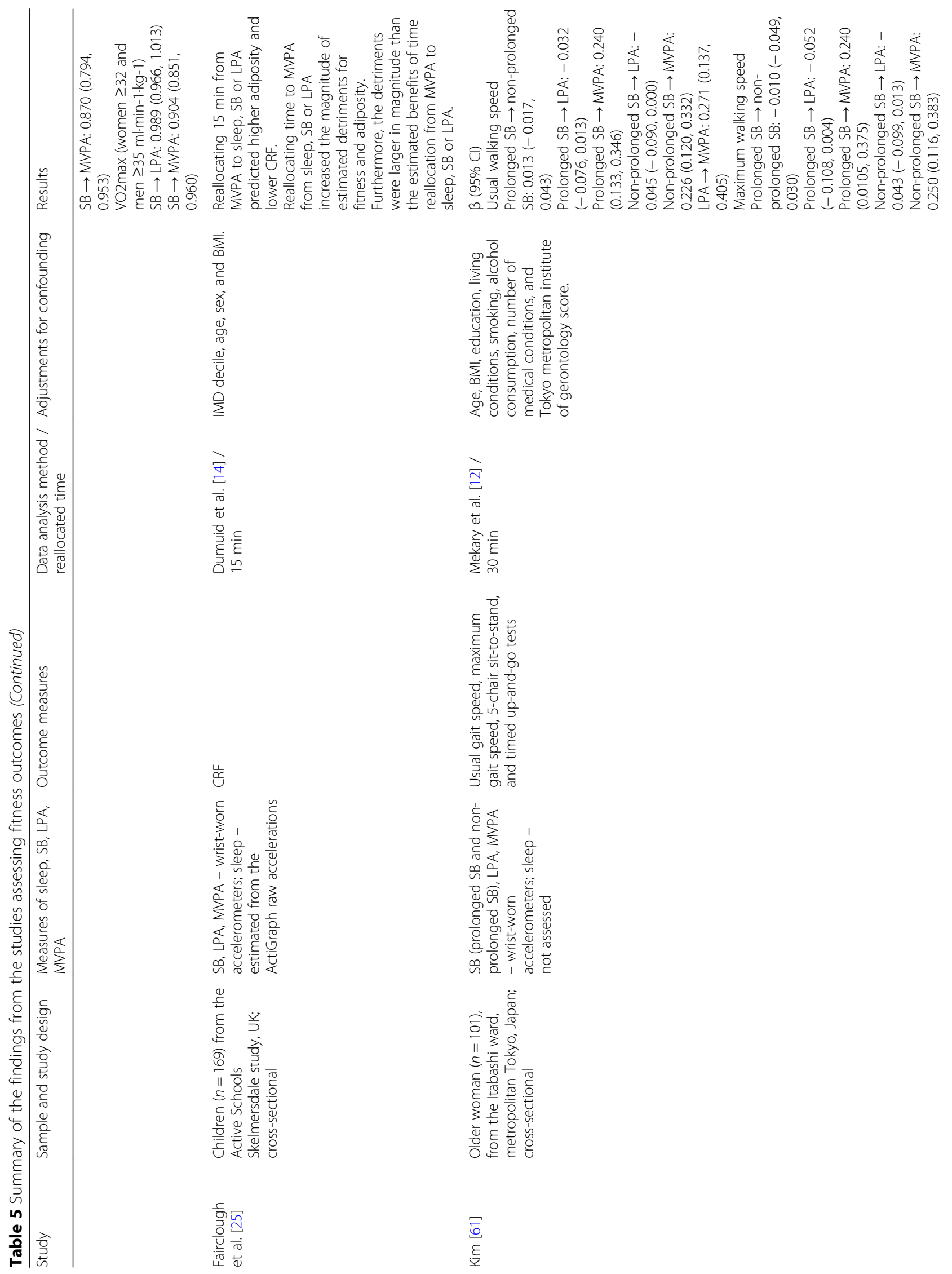




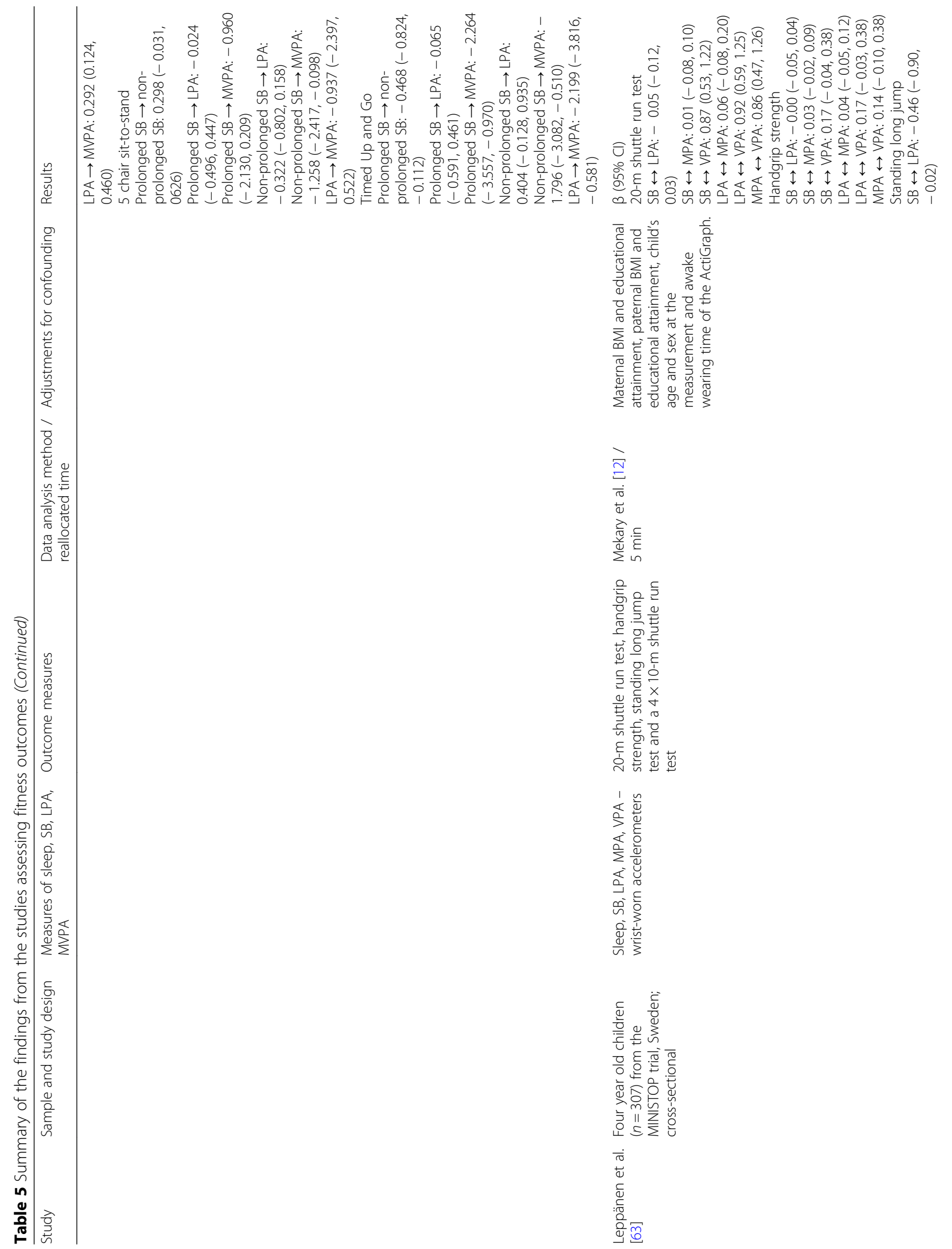




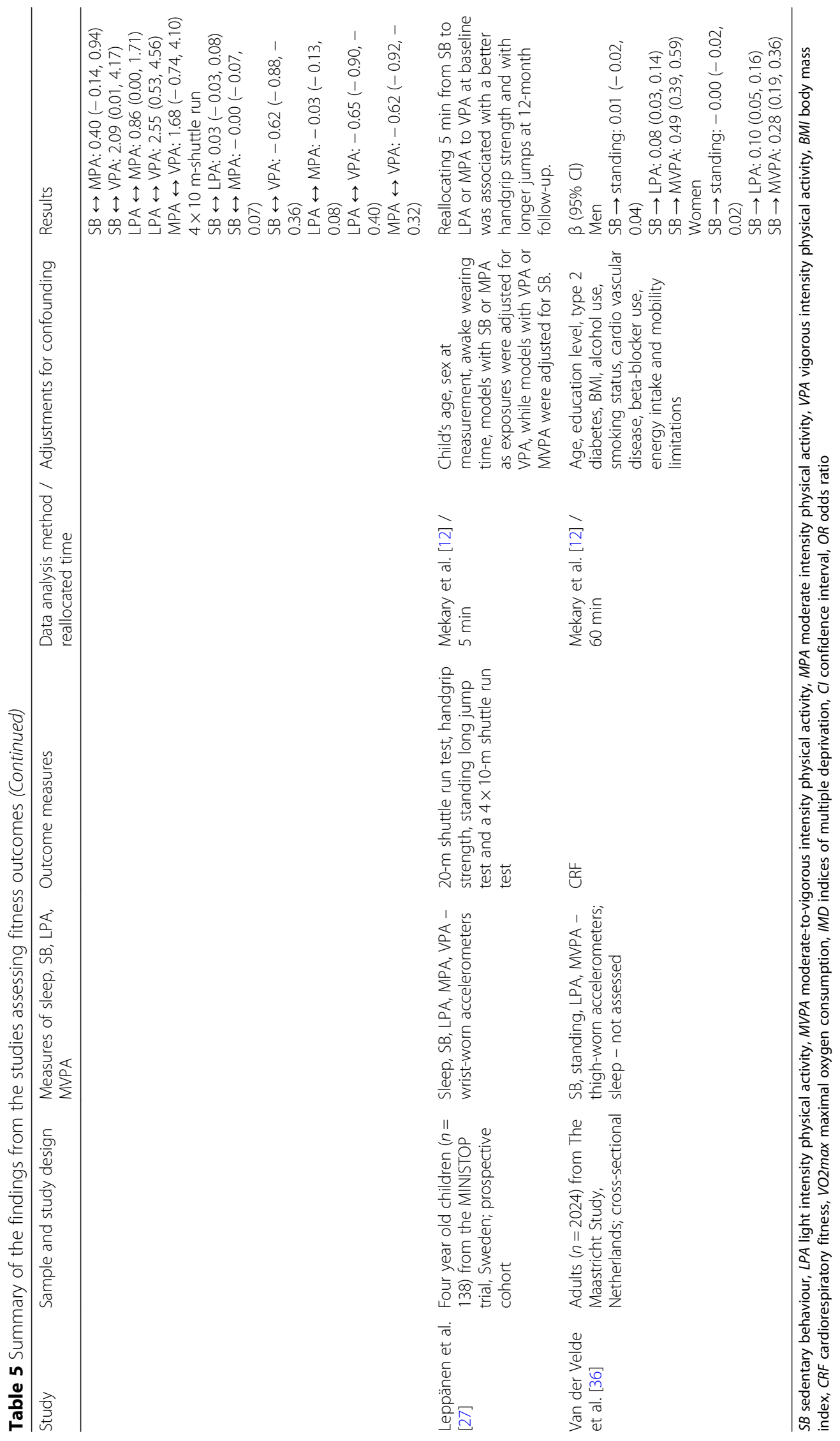




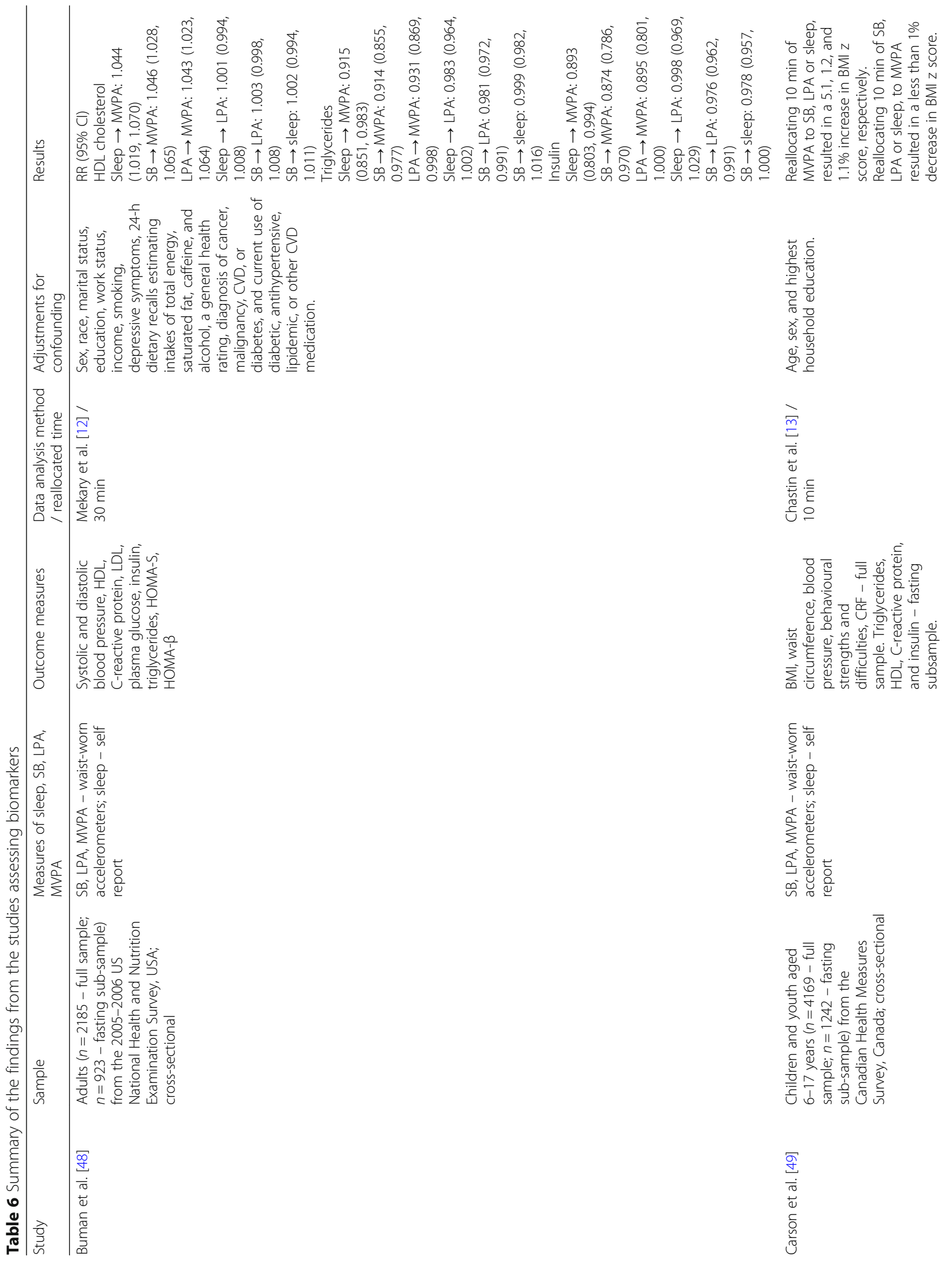




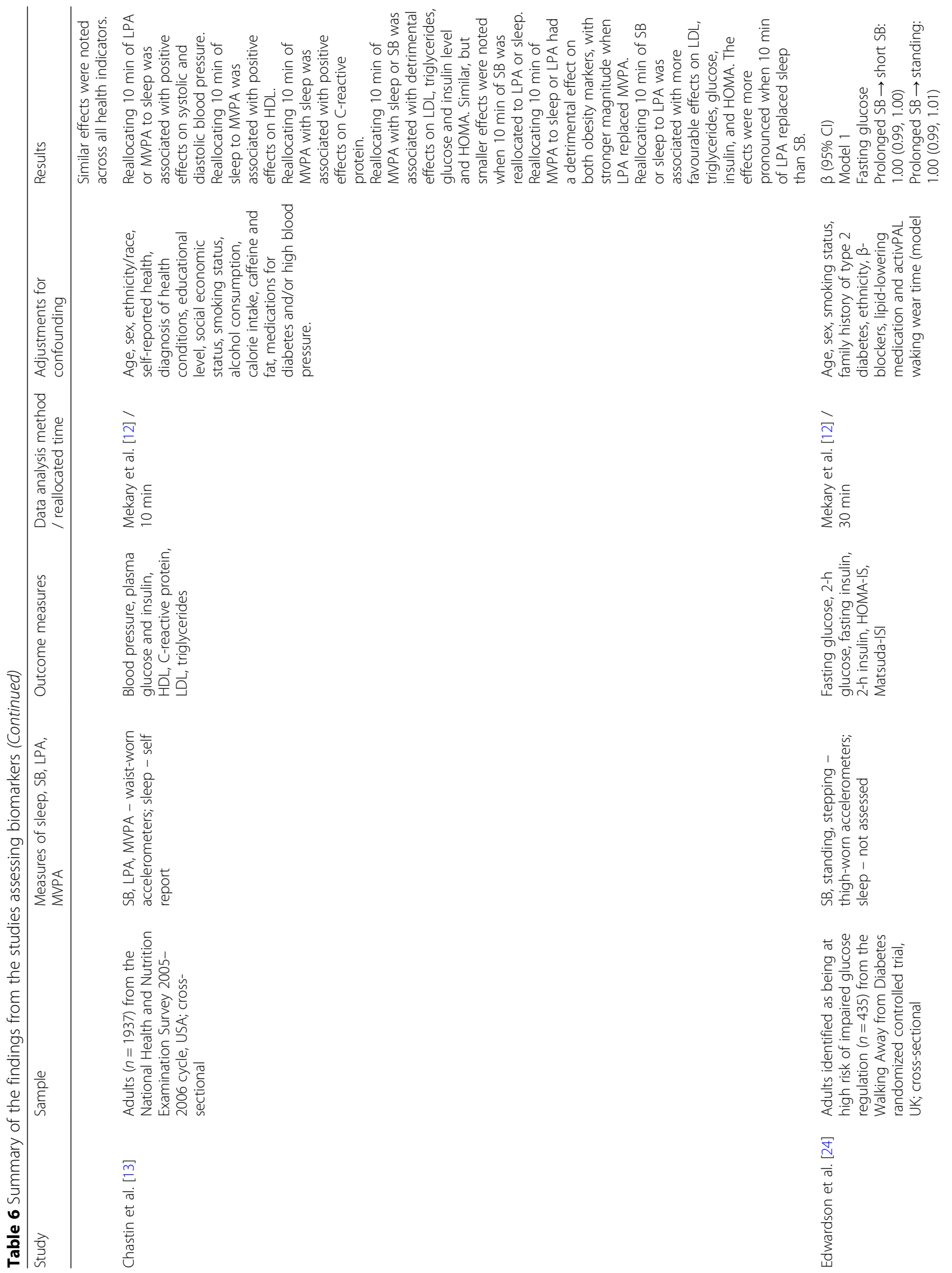




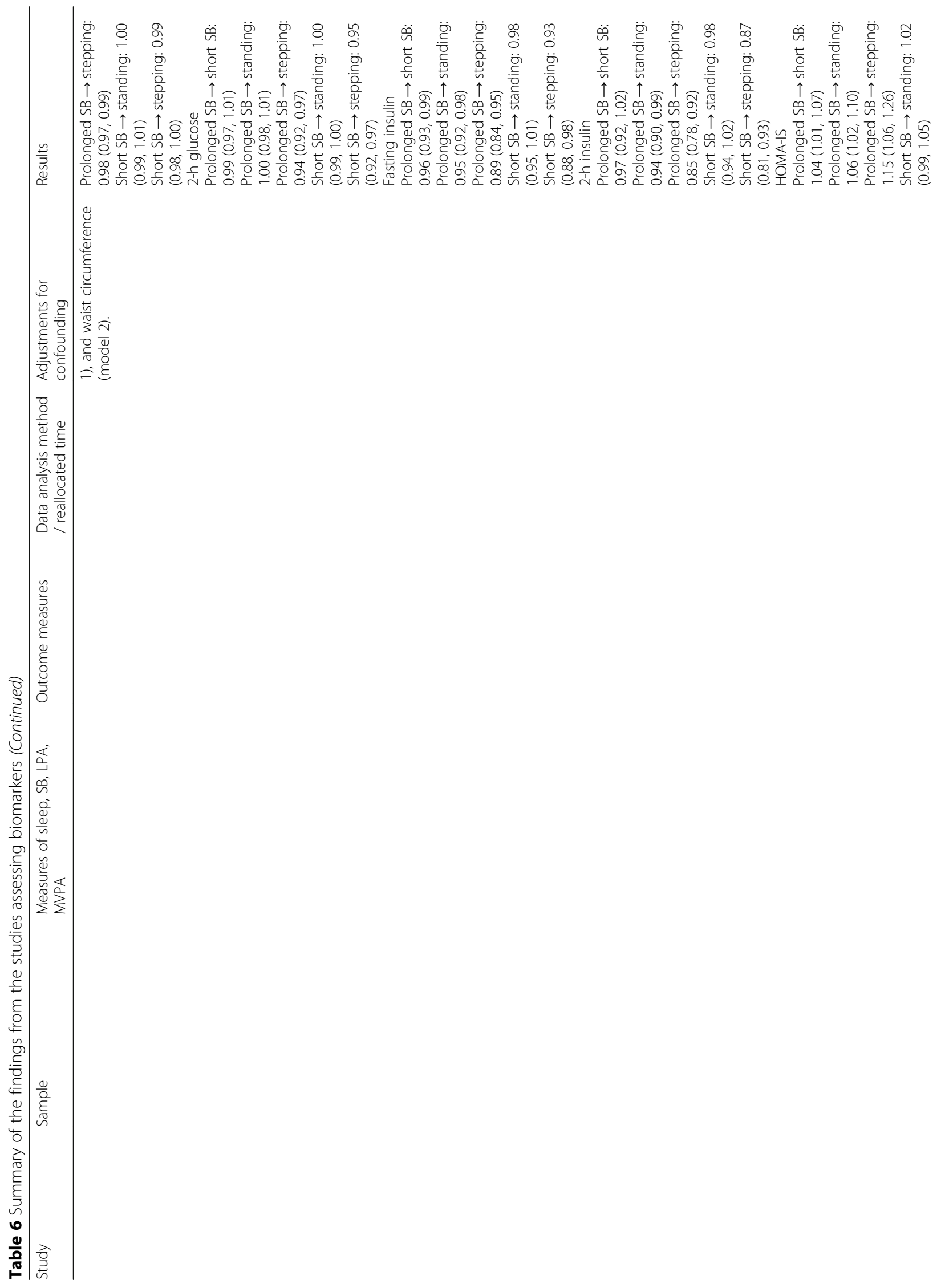




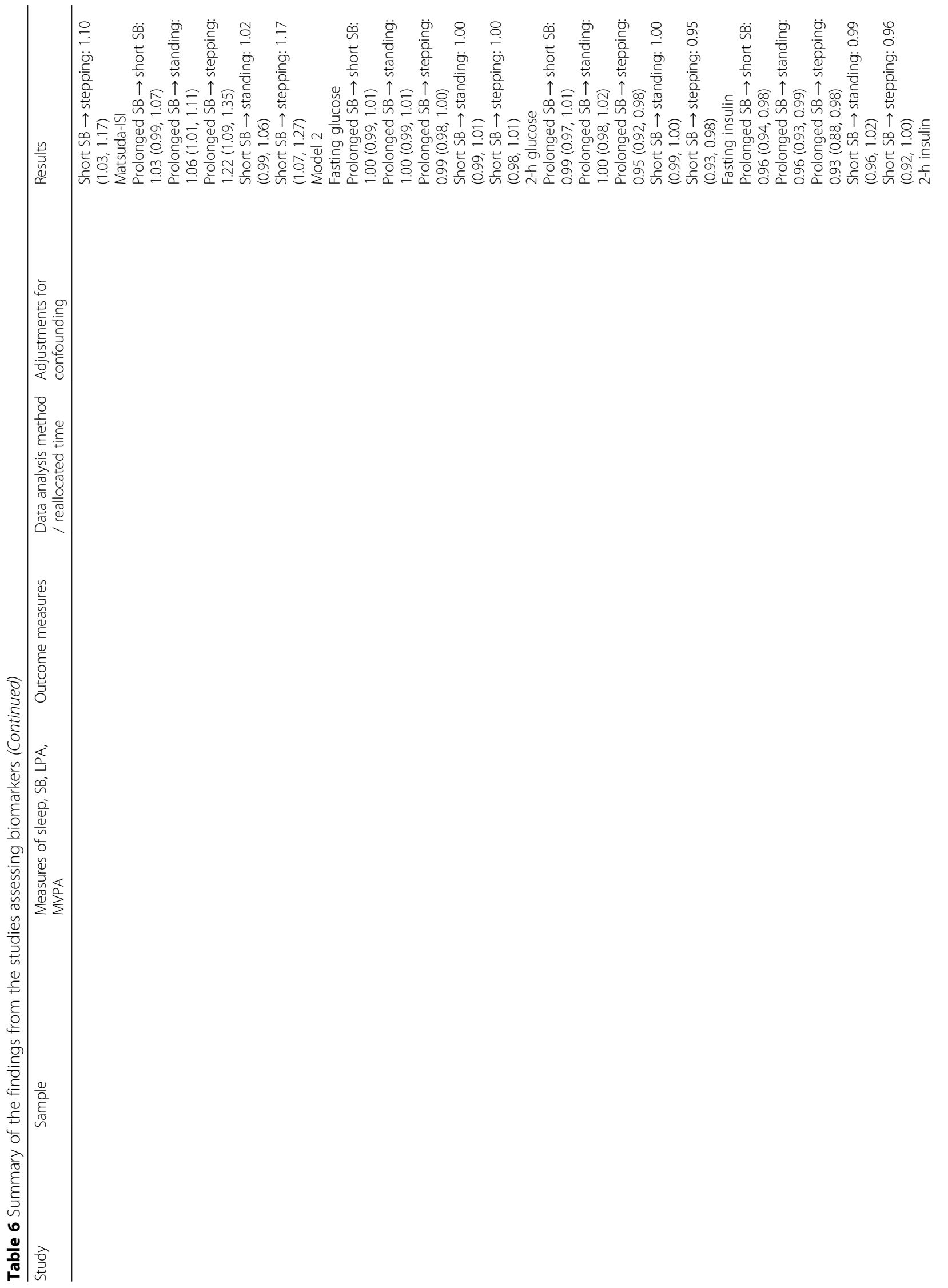




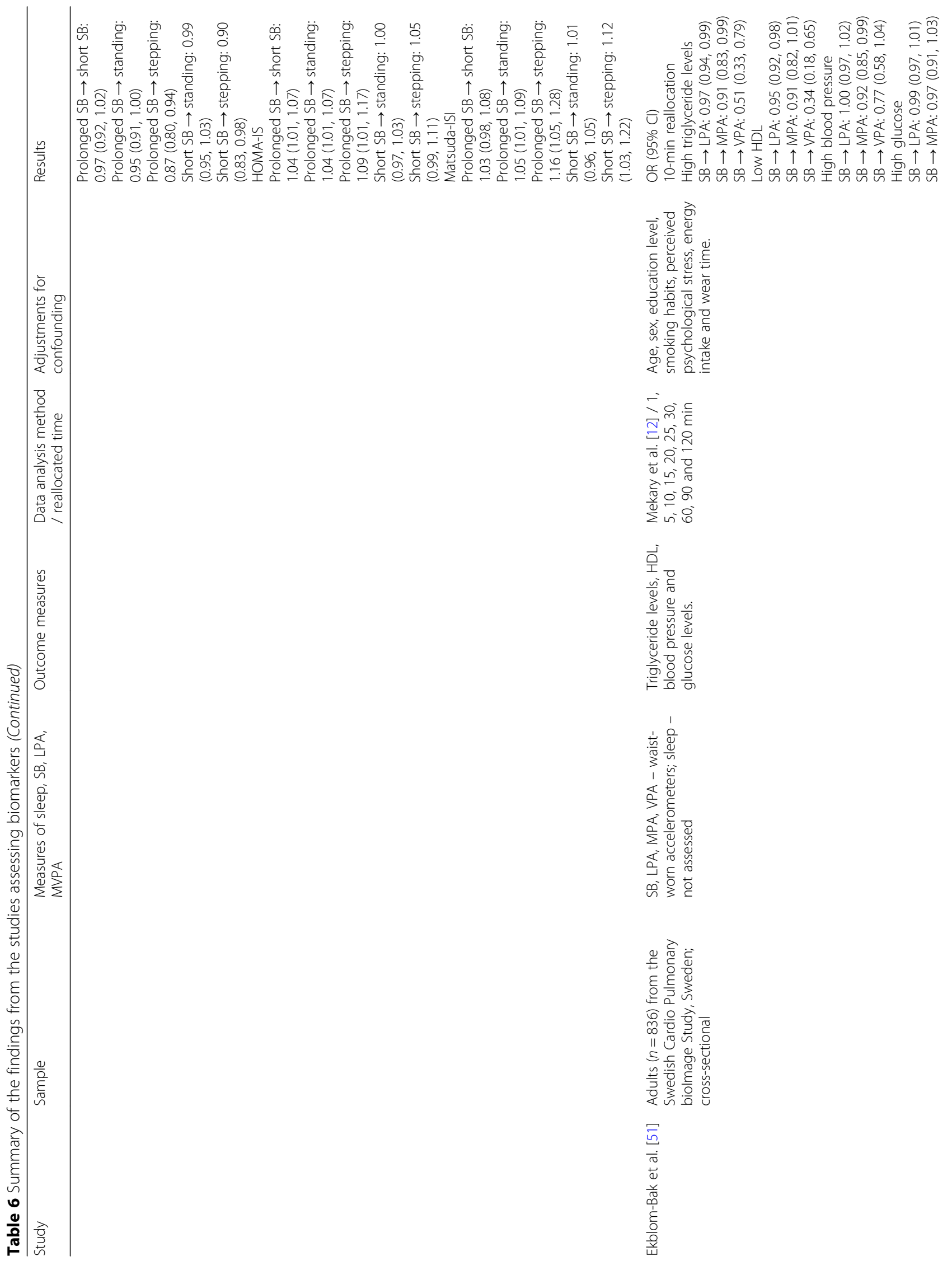




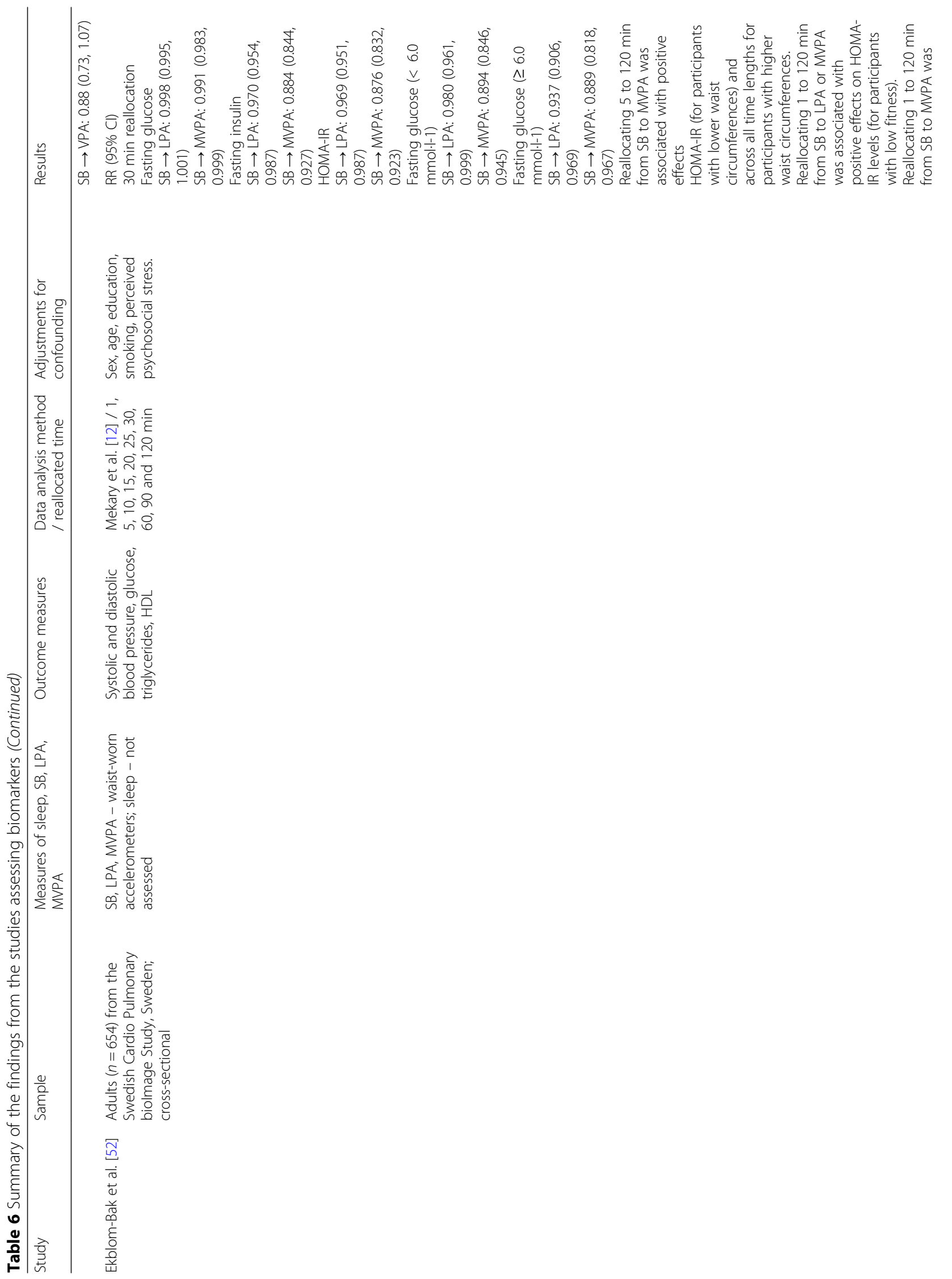




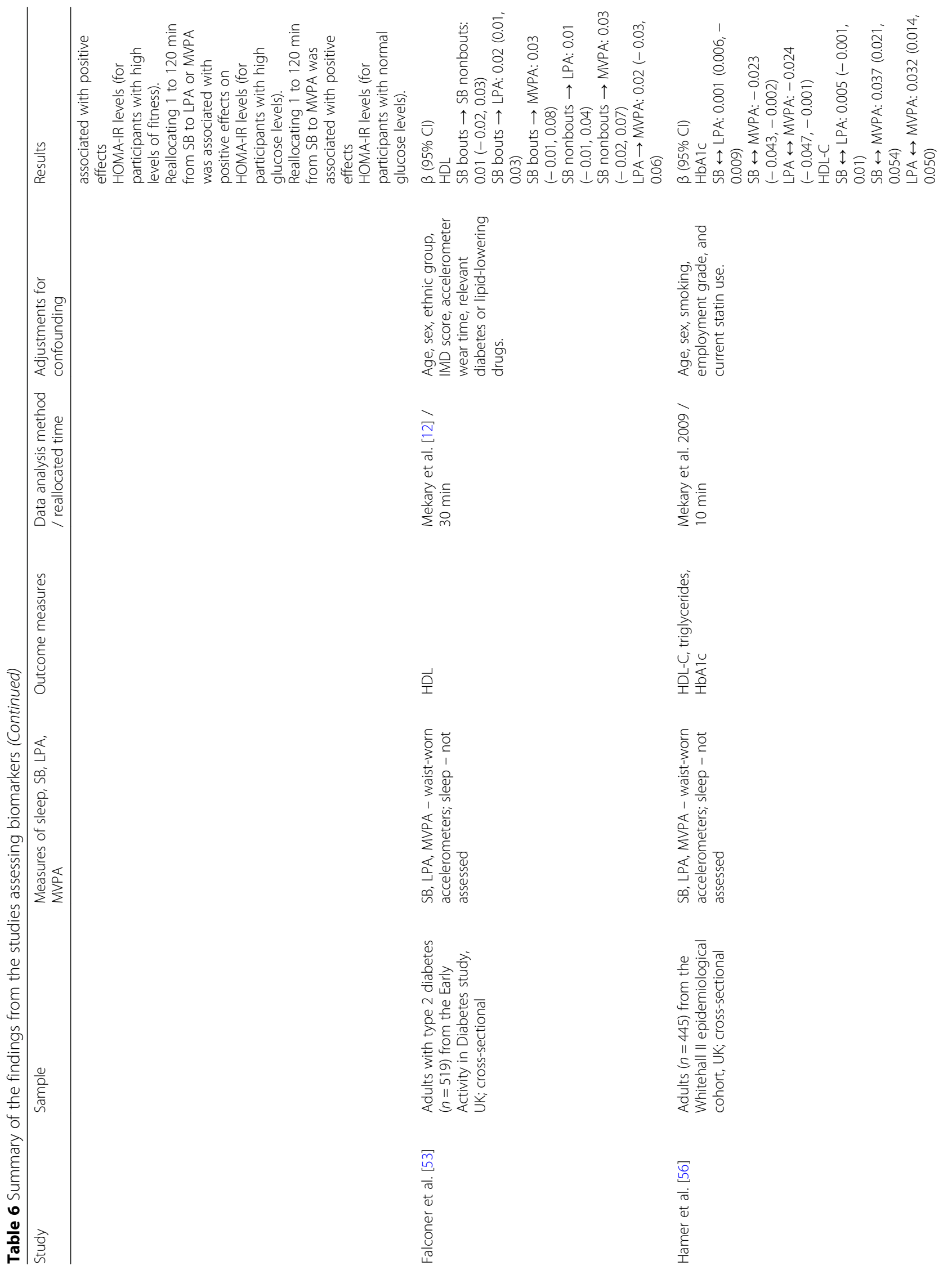




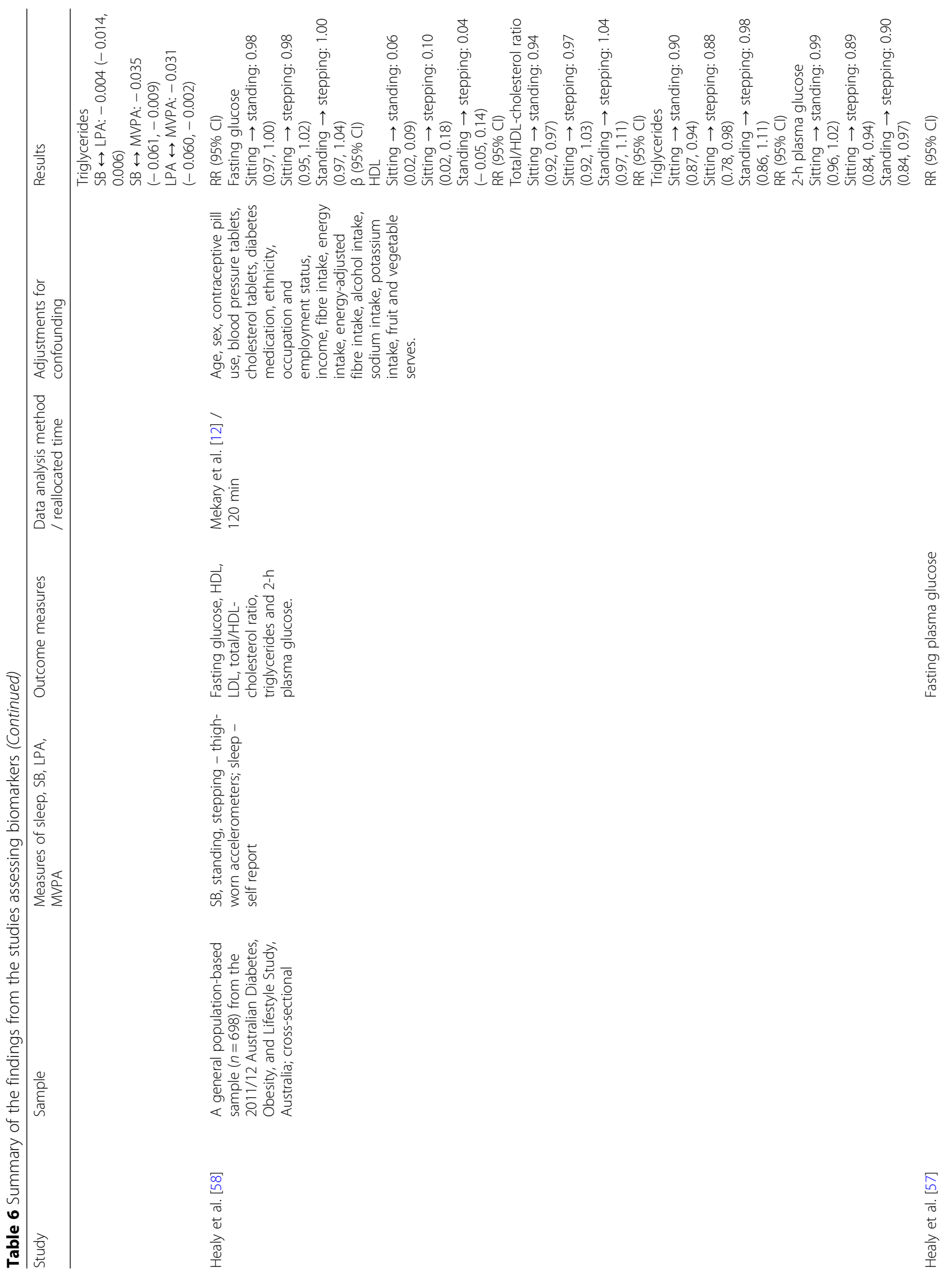




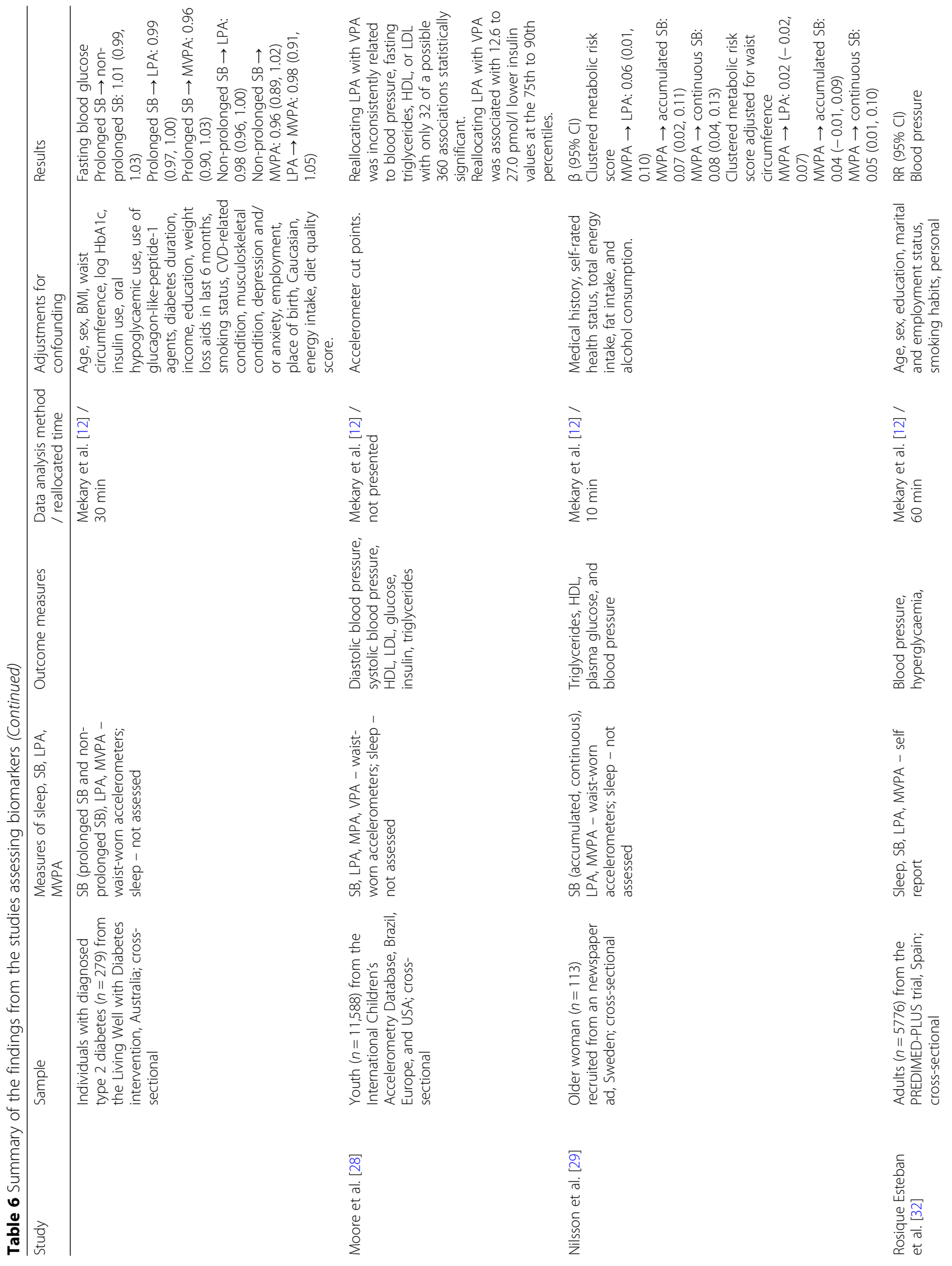




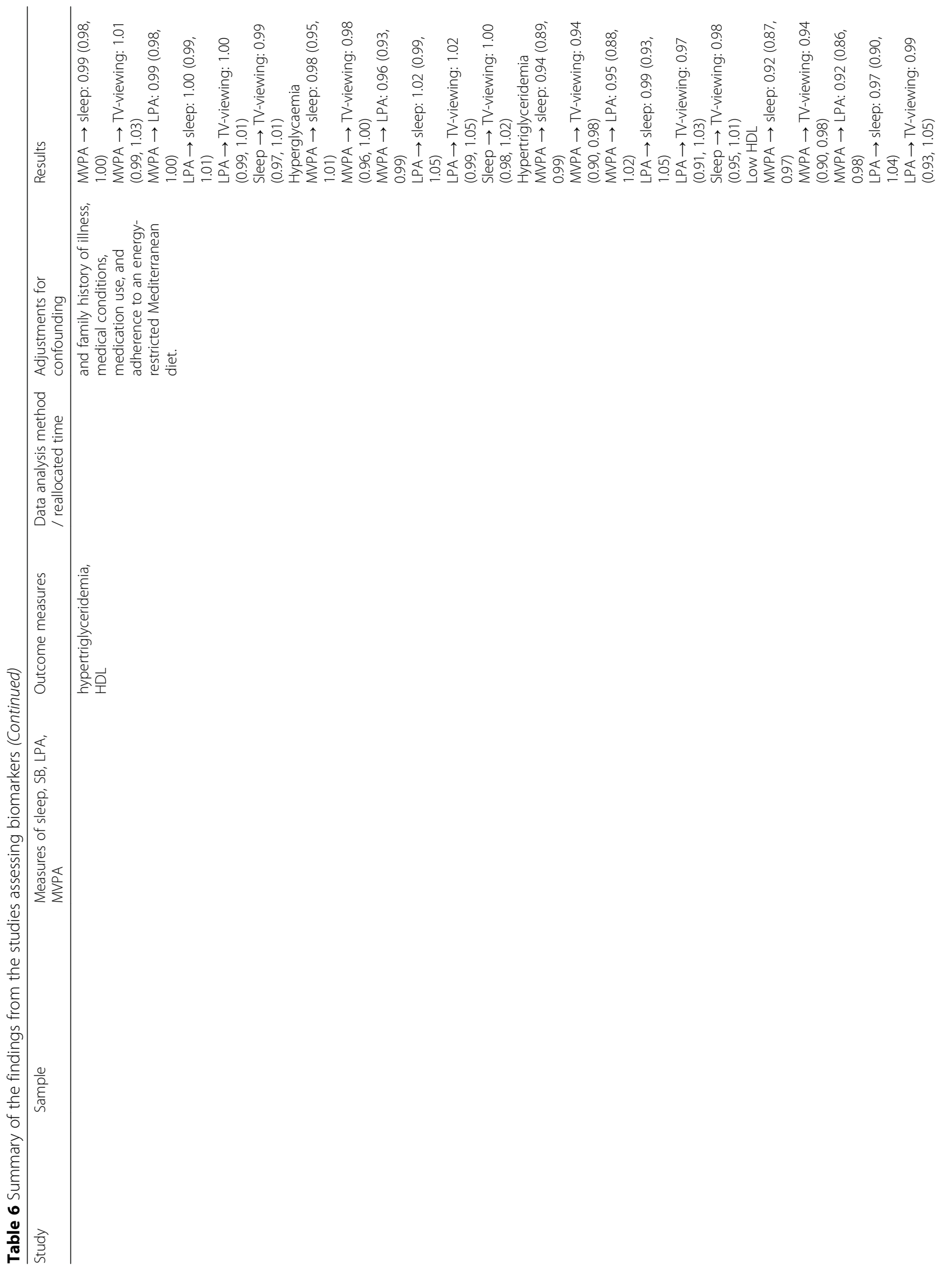




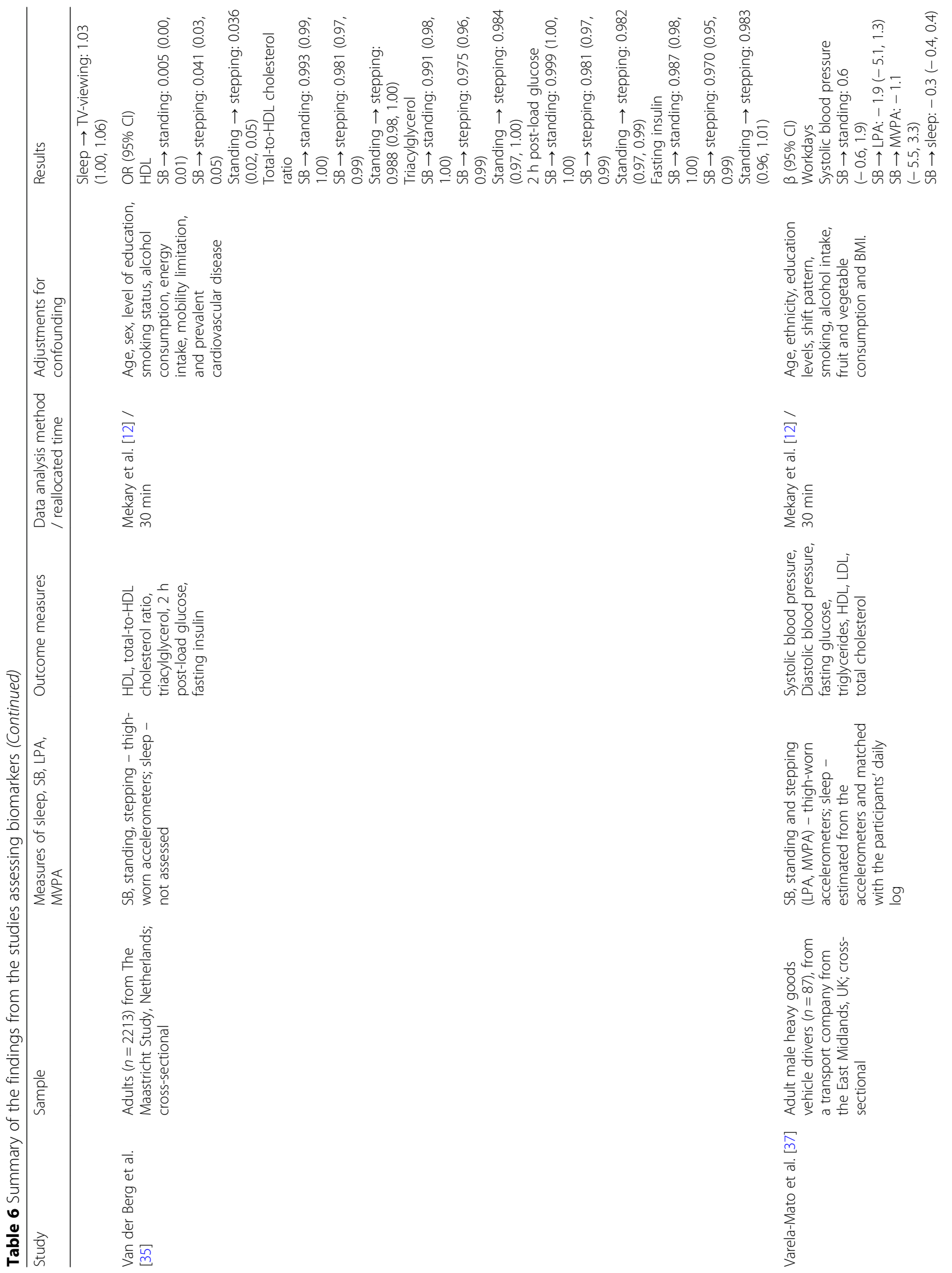




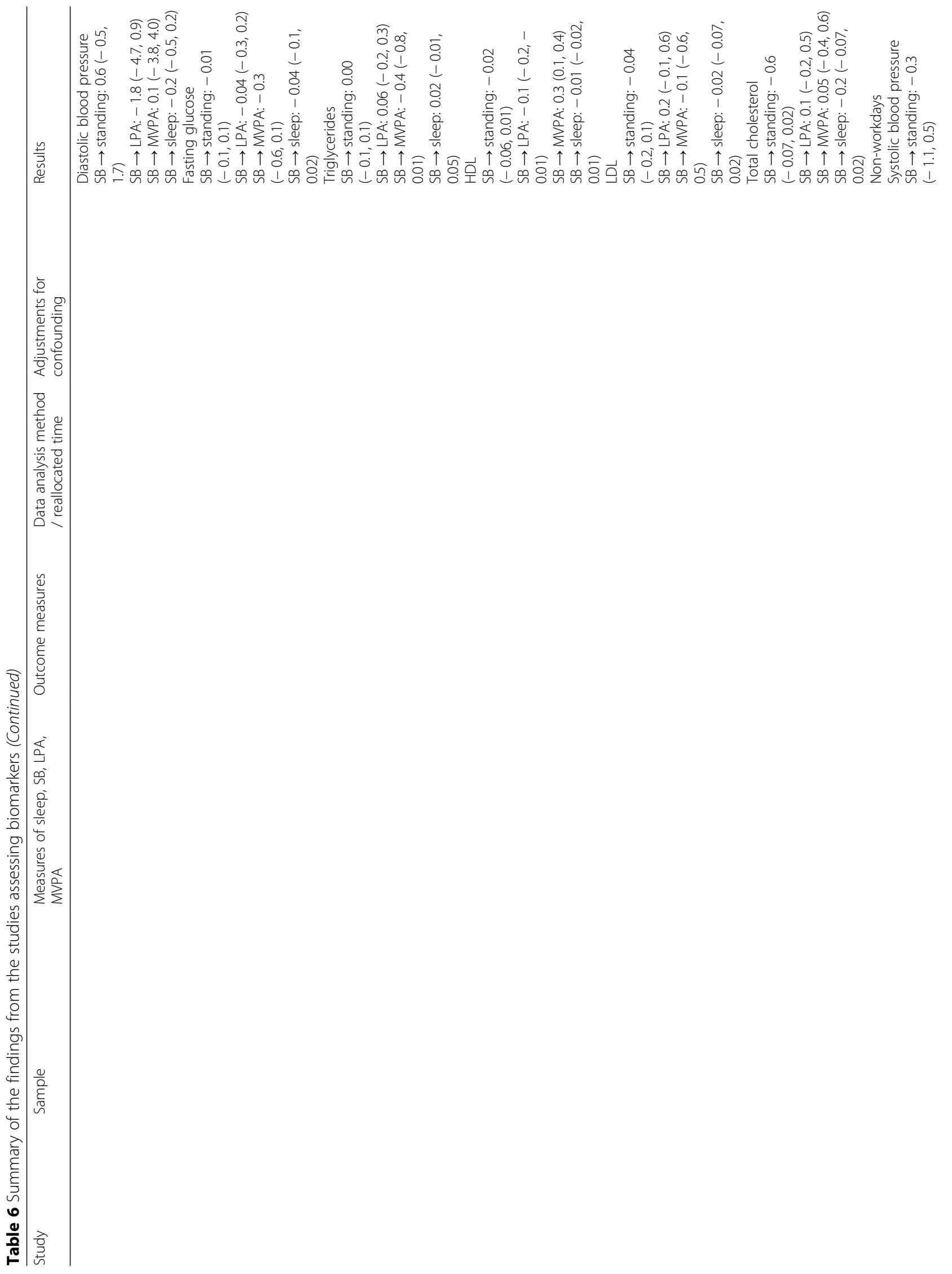




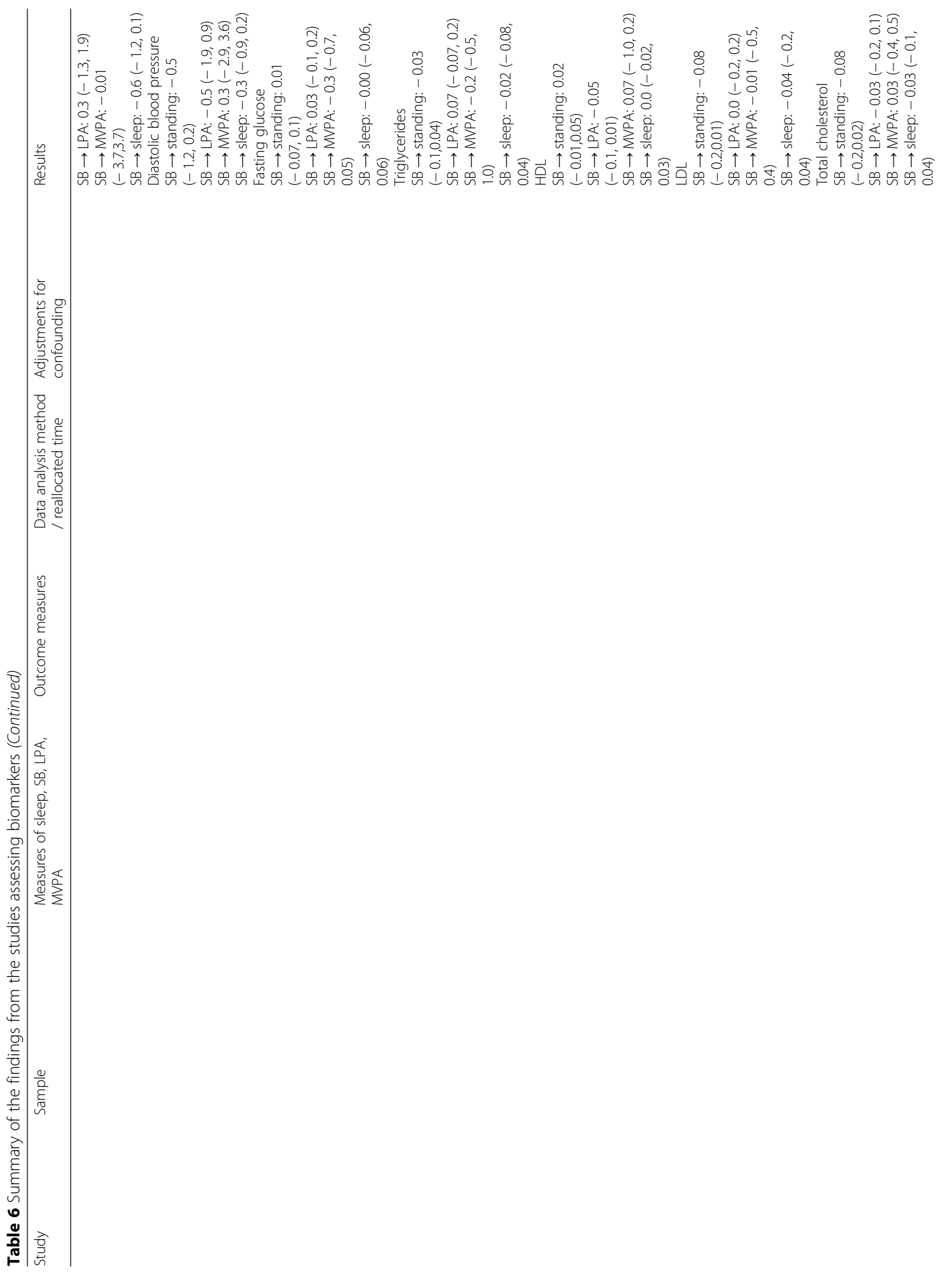




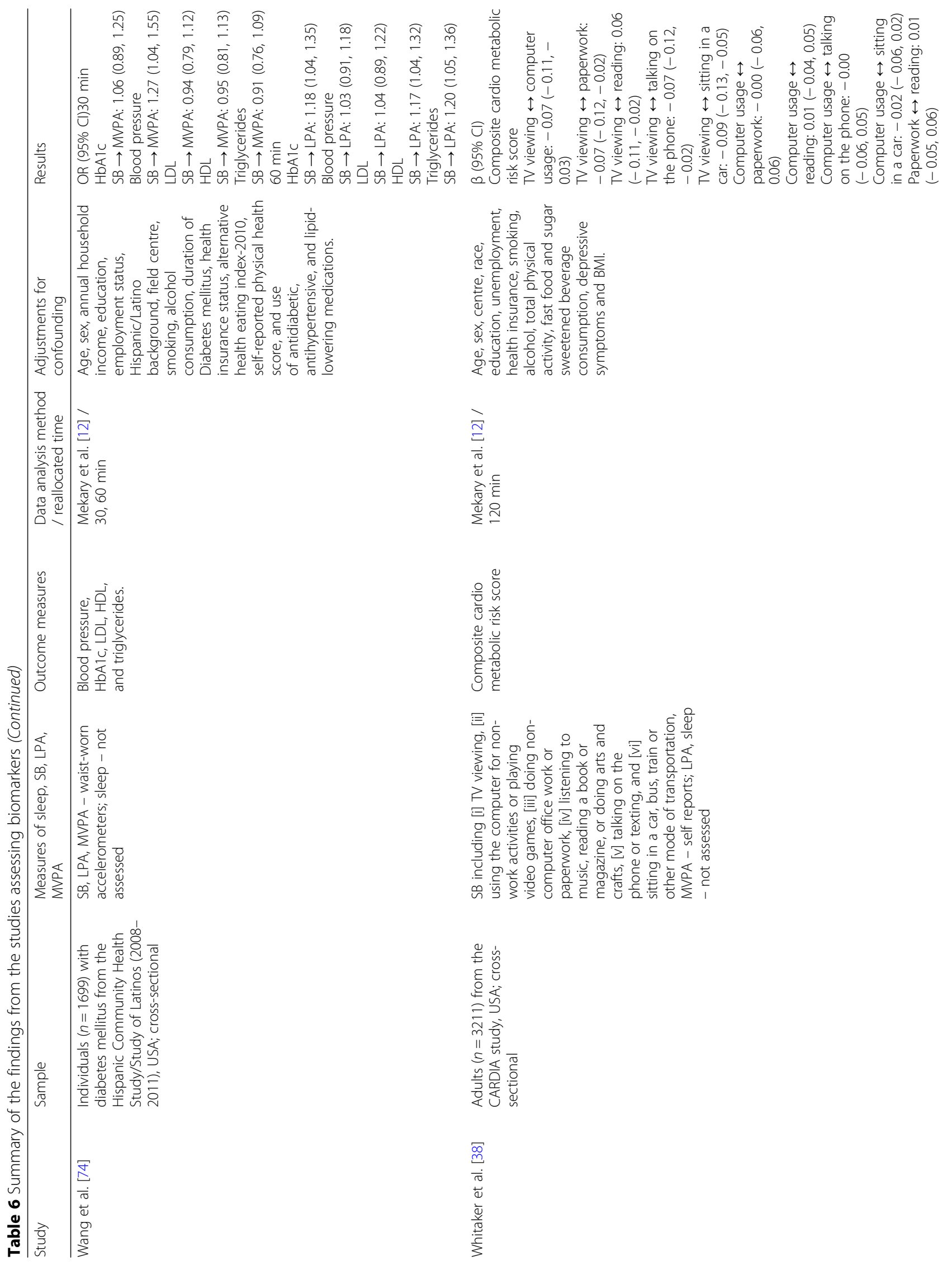




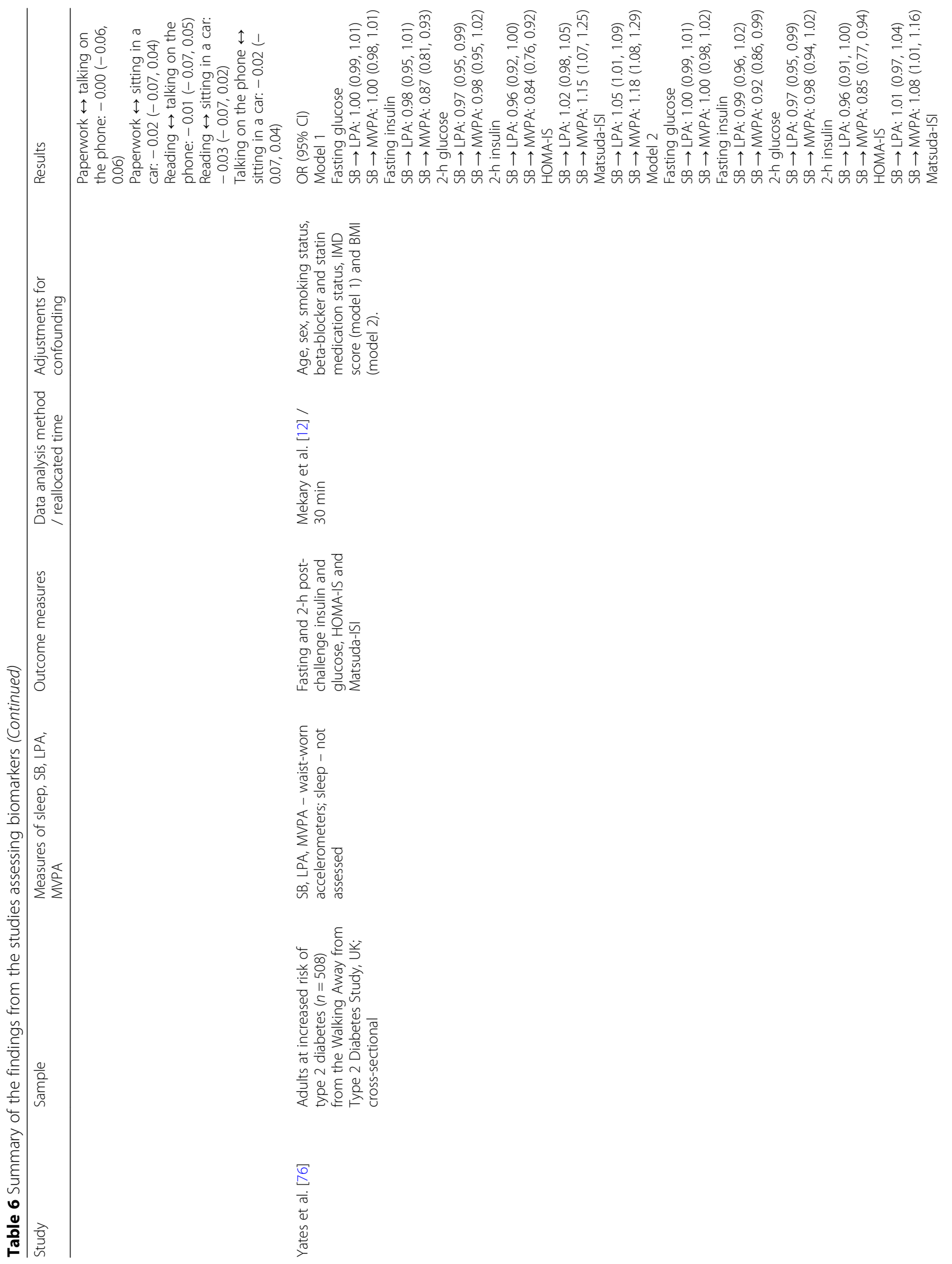




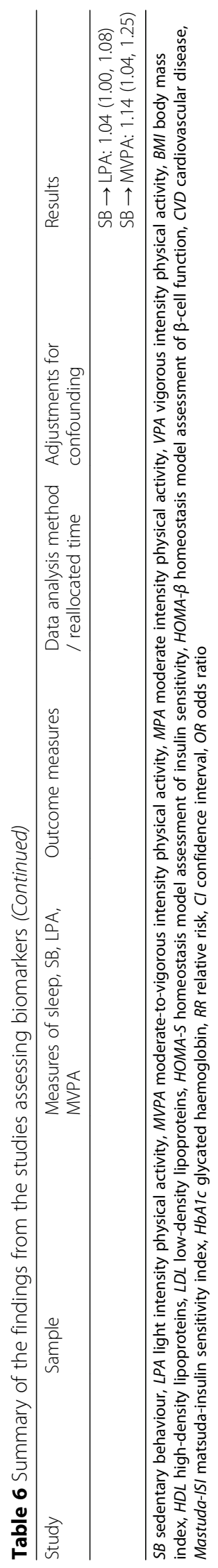




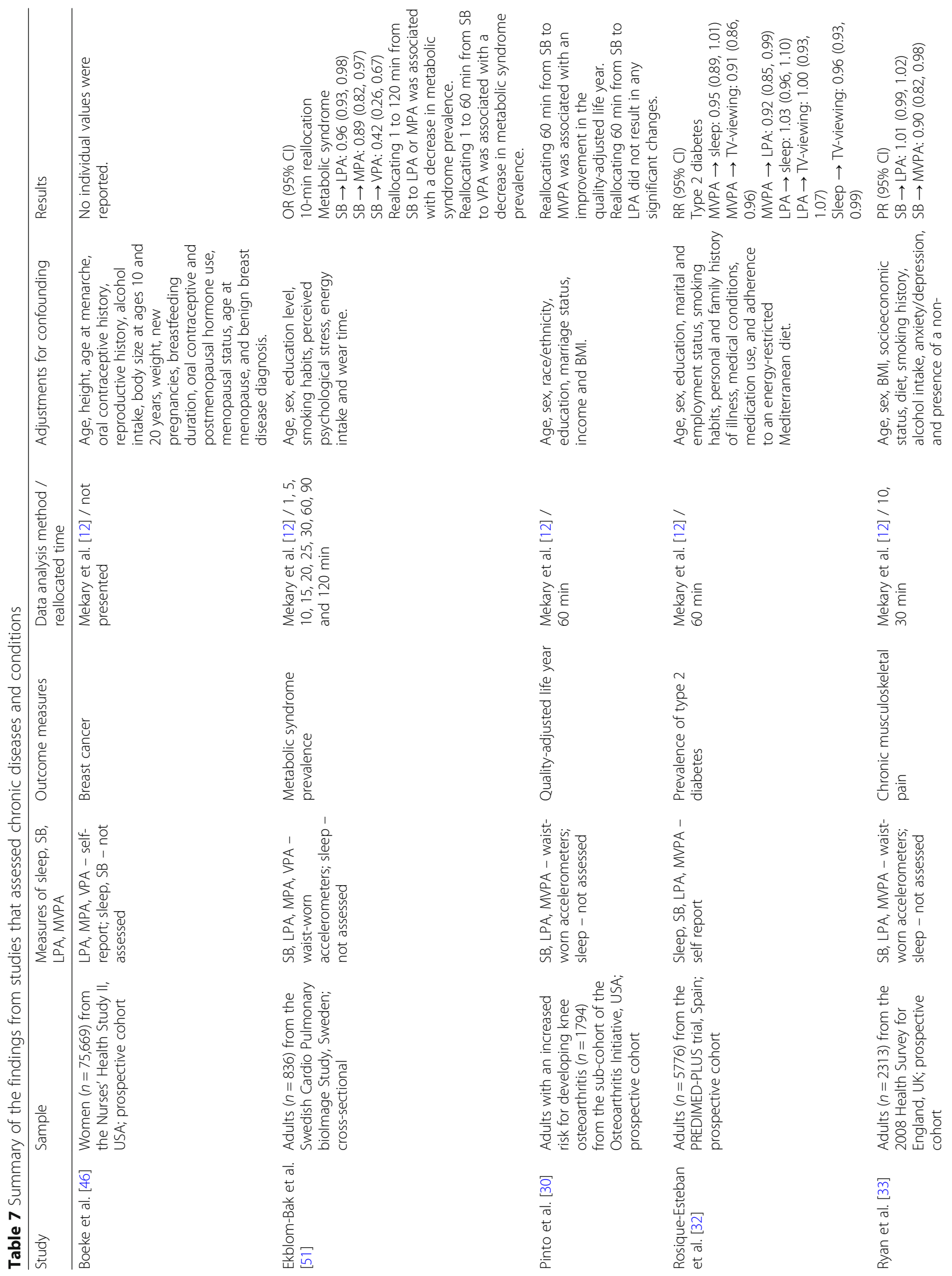


Grgic et al. International Journal of Behavioral Nutrition and Physical Activity (2018) 15:69

Page 59 of 68

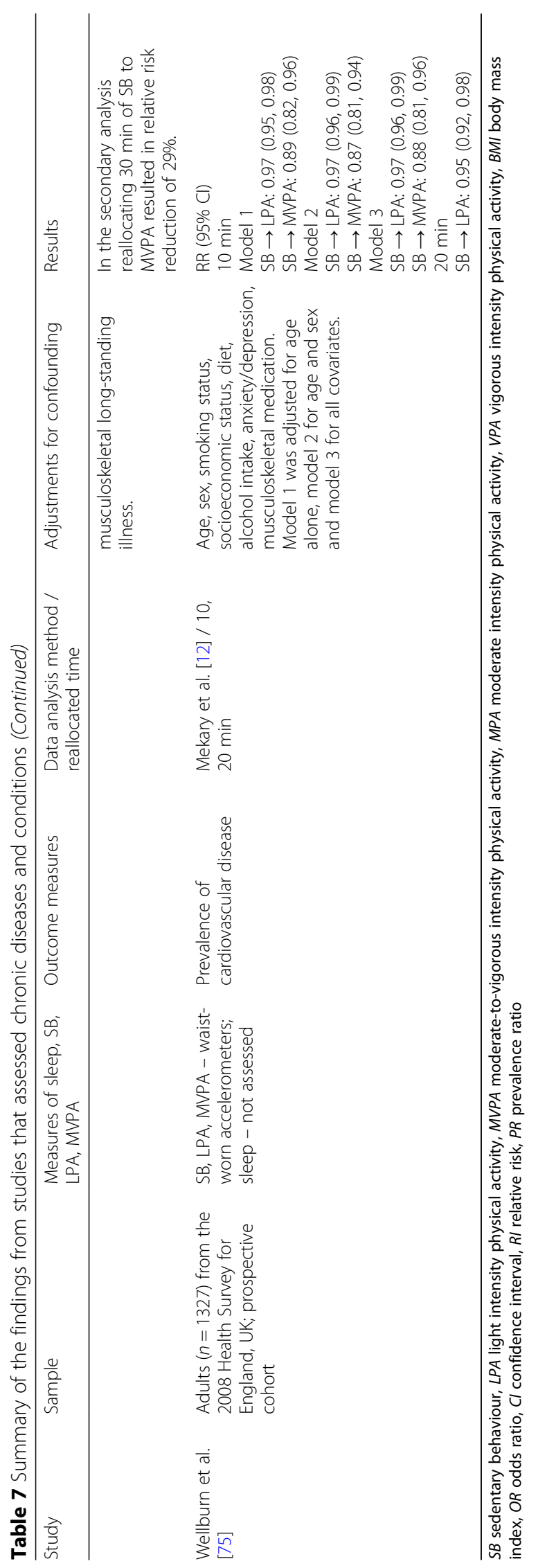




\section{Methodological quality}

The average score on the Newcastle-Ottawa scale for cross-sectional studies was 6, while the individual scores ranged from 5 to 8 points. Nine of the cross-sectional studies were classified as being of high quality, while 29 were appraised as being of moderate quality. The average score for prospective cohort studies was also 6, with the individual scores ranging from 4 to 8 points. Ten of the studies were classified as being of high quality, and the remaining ten were classified as being of moderate methodological quality. The methodological quality appraisal result for cross-sectional and prospective cohort studies can be found in Additional files 2 and 3, respectively.

\section{Discussion}

This is the first review of health outcomes associated with reallocations of time between movement-related behaviours, compiling available evidence for all previously studied health outcomes across all age groups. The number of publications using ISM for health outcomes is increasing each year. Most commonly studied health outcomes in relation to isotemporal substitutions were mortality, general health, mental health, adiposity, fitness, and cardiometabolic biomarkers. The Mekary et al. [12] model has been by far the most often used method for investigating health outcomes of isotemporal substitution, but it is has also been available for the longest period of time. Findings from studies using ISM are of great value as they contribute evidence for the construction of meaningful recommendations for increasing physical activity, reducing sedentary behaviour, and optimizing sleep duration, by taking into account all the behaviours across the energy expenditure spectrum, and not just focusing on one behaviour in isolation from the others.

\section{Mortality}

The current body of literature suggests that high sedentary time and low MVPA are predictive of premature mortality $[8,77]$. When analysing data from the 2003-2006 US National Health and Nutrition Examination Survey (NHANES), Fishman et al. [54] concluded that reallocating $30 \mathrm{~min} /$ day of sedentary time with LPA reduced mortality risk by $20 \%$ over a five-year follow-up period. One study reported a $13 \%$ reduction in mortality risk when substituting $30 \mathrm{~min} /$ day of sedentary time with LPA [65]. The study found that replacement of the same amount of sedentary time with MVPA would reduce the mortality risk by as much as $81 \%$. In addition to total volume, it seems therefore that physical activity intensity may play an important role in reducing the risk of premature mortality.

In a large-scale epidemiological study, Stamatakis et al. [72] reported beneficial associations on reducing the mortality risk when total sitting time was replaced with standing, walking, or MVPA. The study also considered sleep duration and indicated that reallocating $60 \mathrm{~min} /$ day of sedentary time to sleep may reduce the risk of mortality by $6 \%$. However, this was found to be relevant only among individuals that reported sleeping fewer than seven hours per day.

When reallocating sedentary time to physical activity, Matthews et al. [66] reported a greater reduction in mortality risk for less active $(<2 \mathrm{~h}$ of total activity per day), than for more active ( $\geq 2 \mathrm{~h}$ of total activity per day) individuals. Follow-up work from the same group found that replacing one hour of sedentary time with LPA reduced mortality risk by $18 \%$ [67]. The reduction in mortality risk was more than doubled (42\%) when sedentary time was reallocated to MVPA. In their analysis of the UK Biobank data, Wijndaele et al. [39] found that the substitution of $30 \mathrm{~min} /$ day of screen time with strenuous sports was associated with $15 \%$ reduction in the mortality risk. While in this study strenuous sports provided the most substantial associations, it is important to note that replacing screen time with $30 \mathrm{~min} /$ day of walking, also resulted in a considerable decrease in mortality risk (5\%). Schmid et al. [71] reported that replacing $30 \mathrm{~min} /$ day of sedentary time with an equal amount of LPA or MVPA is associated with a 14 and $50 \%$ reduction in mortality risk, respectively. The same authors also found that replacing $30 \mathrm{~min} /$ day of sedentary time with LPA resulted in an $8 \%$ reduction in the risk of cancer mortality. The plausibility of these large estimated reductions in mortality risk needs to be confirmed in future studies.

Most of the evidence is currently focused on reallocations of time from sedentary behaviour to some intensity band of physical activity (e.g., LPA or MVPA). However, there is a lack of evidence on reallocating time spent in sedentary behaviour to standing. This might be because most devices for tracking physical activity, such as waist-worn accelerometers, are not able to differentiate between sedentary behaviour and standing. Furthermore, most questionnaires do not include questions regarding posture during certain types of typically sedentary activities, such as watching TV and inactive transport [1]. It is, therefore, unclear whether participants sat or stood while engaging in such activities. Nonetheless, one study suggested that replacing sedentary behaviour with standing might reduce the risk of premature mortality [72]. More such research seems to be needed to inform evidence-based decisions on the use of sit-stand desks and other methods for displacement of sitting with standing in the office setting. Given the increasing popularity of sit-stand desks, findings from these studies may have significant practical implications.

To summarise, it seems that reallocations of sedentary behaviour to LPA or MVPA are associated with significant reduction in mortality risk. Current evidence seems to consistently suggest that reductions in mortality risk 
are greater when time spent sedentary is replaced with higher intensities of physical activity. However, the generalizability of these findings remains limited, because the studies were conducted only in Australia [72], UK [39], and US [50, 54, 62, 65-67, 71]. There is no evidence for low and middle-income countries. Furthermore, most studies did not include sleep duration in their analysis. Due to the significant impact of sleep duration on health and its co-dependence on other components of time use, future studies should aim to include sleep duration in their ISMs along with all the remaining movement behaviours.

\section{Perceived/general health status}

Studies that assessed perceived/general health status were conducted among adults, older adults, and clinical populations. No studies were conducted among youth.

\section{Adults/older adults}

Health-related quality of life (HRQoL) is an indicator of general health emanating from the individual perception of the impact that diseases have on different areas of life [45]. Loprinzi and Loenneke [65] investigated the impact of time reallocation between movement behaviours on HRQoL among adults using data from 2003 to 2006 NHANES. The study reported that substituting sedentary behaviour with LPA or MVPA was associated with improved HRQoL, suggesting the need for strategies to promote increasing physical activity at the expense of sedentary behaviour. Further support for such findings comes from Buman et al. [47] who found that replacing sedentary time with equal amounts of LPA or MVPA was associated with better self-reported physical health.

\section{Clinical populations}

Among clinical populations, Van Roekel et al. [73] reported improvements in some aspects of HRQoL to be associated with the replacement of sedentary time with standing, LPA or MVPA in a group of colorectal cancer survivors. Vallance et al. [34] investigated these relationships in a group of non-Hodgkins lymphoma survivors and found that reallocating sedentary time, sleep, or LPA to MVPA was associated with lower levels of fatigue, but not with improved quality of life. Studies like the one performed by Vallance et al. [34] are needed as non-Hodgkin lymphoma survivors and many other clinical populations exhibit higher levels of fatigue and poorer general health compared to non-clinical populations [78], and participating in physical activity appears to improve these health aspects [79].

While there are several studies exploring aspects of perceived general health using ISM, more evidence is needed on this topic. This lack of empirical evidence opens up an avenue for future studies, specifically studies including older adults and clinical populations. Only two of the included studies that assessed perceived general health included sleep in their ISMs, which is a key limitation of the current body of evidence.

\section{Mental health}

Studies that assessed mental health were conducted among youth, adults, and older adults. No studies were conducted among clinical populations.

\section{Youth}

Janssen [60] investigated the associations of reallocating time between playing sedentary video games, playing active video games, and engaging in outdoor activities with mental health indicators among youth (mean age: 14.1 years; range 13.9-14.4 years). The results indicated that replacing time spent playing sedentary video games with playing active video games may be associated with more positive psychological outcomes, including indicators such as emotional problems, life satisfaction, and prosocial behaviours [60]. It should be noted that replacing active outdoor play with active video games was associated with the probability of high emotional problems, a reduced probability of high prosocial behaviour and high life satisfaction. The study supports active video games over sedentary video games; however, for the most positive mental health results, time spent on video games should be replaced with active outdoor play [60].

\section{Adults/older adults}

Depressive disorders are one of the most common mental health issues and affect around 10\% of the adult population in the USA [80]. Previous studies have suggested that physical inactivity may be a risk factor for depressive symptoms [81]. Mekary et al. [69] reported that reallocating time spent watching TV to walking at a fast pace may be protective against depression. However, this was not found for reallocating time to walking at a slower pace, reinforcing the potential importance of higher intensities of physical activity. Rethorst et al.'s [31] study supports the importance of physical activity intensity as they noted that replacing sedentary time with VPA was associated with a significant decrease in depressive symptoms. However, the same was not observed for replacing sedentary time with LPA or MPA. Due to the scarcity of studies using ISMs while assessing mental health outcomes, further evidence on the topic is warranted.

\section{Adiposity}

Studies assessing adiposity were conducted among youth, adults, older adults, and clinical individuals. 


\section{Youth}

Adiposity was the most common outcome assessed in the studies included in this review. Aggio et al. [44] found that reallocating sedentary time with MVPA was associated with a significant reduction in body fat percentage in children and adolescents (age range: 515 years). Further evidence among children was presented by Collings et al. [21] who found that substituting sedentary time with LPA or MVPA was inversely associated with fat mass index and trunk fat mass index. Moreover, this study reported that the association was stronger when sedentary time was substituted with vigorous physical activity (VPA) than with MVPA. Similar findings were obtained among children in Norway [23], Sweden [27, 63], Portugal [70], and the UK [25]. Coupled with the conclusions presented in a recent meta-analysis [18], this evidence highlights the potential importance of substituting sedentary time with physical activity, in particular physical activity at vigorous intensities, to offset unhealthy fat gain in children.

\section{Adults/older adults}

The associations of ISM with adiposity were also explored in healthy adult populations. Buman et al. [48] reported a $2.4 \%$ lower waist circumference expected when $30 \mathrm{~min} /$ day of sedentary time were replaced with MVPA. Similar observations were made by Gupta et al. [55], who reported significant reductions in multiple obesity indicators, including waist circumference, body fat percentage and body mass index (BMI), associated with reallocating time from sedentary behaviour to standing time or MVPA, with the associations being greater for substitutions with MVPA. The stronger associations observed for substitution of sedentary behaviour with MVPA than with standing are likely because there is not a large difference in energy expenditure between sedentary behaviour and standing, unlike between sedentary behaviour and MVPA [82]. Beneficial associations between BMI and the reallocation of sedentary time to MVPA were also observed by Chastin et al. [13], who used a compositional model of isotemporal substitution based on the change-prediction matrix. Reallocating time from TV watching to MVPA was associated with a lower prevalence of obesity in Rosique-Esteban et al. [32].

\section{Clinical populations}

ISM has also been used to investigate how reallocations of time are associated with measures of adiposity among clinical populations. Boyle et al. [19] observed that reallocating time from either sleep, sedentary behaviour, or LPA to MVPA was associated with lower waist circumference and BMI in a group of breast cancer survivors. It is well established that MVPA is beneficial in the prevention and management of T2D [83]. Studies using accelerometry-derived behaviours found that the majority of individuals with T2D spent a significant portion of the day (63\% of the day) in sedentary pursuits, with only $2 \%$ of the day spent in MVPA [84]. As reported by Healy et al. [57], reducing prolonged sedentary time and replacing it with MVPA was associated with lower waist circumference and BMI in individuals with T2D. Falconer et al. [53] found that even replacing prolonged bouts of sedentary time with shorter bouts of sedentary time was associated with lower BMI and waist circumference in adults with a recent diagnosis of T2D. While these findings would suggest that replacing sitting time with more 'active' behaviours might have significant health benefits in clinical populations, due to the cross-sectional nature of the studies, the causality of this relationship remains unclear.

In summary, it seems that reallocating sedentary time to physical activity may be associated with reduced BMI, body fat percentage and waist circumference in all populations, with the magnitude of associations being greater for higher intensity activities. However, most studies have not accounted for sleep time, which remains a major limitation in the current body of evidence. It is estimated that $\sim 40 \%$ of the population reports sleeping less than the recommended minimum of seven hours per night [85] which may negatively affect health [86]. Studies have indicated that short sleep duration is associated with increased risk of obesity among children and adults [6]. Given its co-dependence with sedentary behaviour, LPA, and MVPA, sleep should, when possible, be included in isotemporal substitution models. Further research should track sleep duration in addition to sedentary time and physical activity, to increase the robustness of the findings.

\section{Fitness}

Studies assessing fitness were conducted among youth, adults, and older adults. No such studies were conducted among clinical populations. Higher levels of muscular strength, as well as general and cardiorespiratory fitness, are considered important health markers in children and adolescents [87, 88]. Higher cardiorespiratory fitness is associated with a lower risk of being overweight or obese in puberty [88]. In adolescents, higher muscular strength is associated with a lower risk of premature mortality [89], and participation in resistance training is associated with more favourable body composition in overweight and obese children and adolescents [90].

\section{Youth}

When exploring fitness levels among children, Leppänen et al. [63] found that the reallocation of sedentary 
behaviour to LPA or MVPA was associated with greater cardiorespiratory fitness, as assessed by the 20 -m shuttle run test. The magnitude of the associations was larger when sedentary behaviour was replaced with MVPA, rather than LPA. In a cohort of 10-year-old children, replacing MVPA with any other movement behaviour (i.e., sleep, sedentary time, and LPA) was associated with lower levels of cardiorespiratory fitness [25]. Therefore, it seems that reallocating sedentary time to LPA or MVPA should be promoted among children.

\section{Adults/older adults}

At the other end of the age spectrum, in a cohort of aged Japanese woman (age range: 76-89 years), Kim [61] concluded that reallocating sedentary time to MVPA may improve performance in several measures of fitness, including usual and maximum gait speed, 5-chair sit-to-stand tests, and timed up-and-go test. In their analysis of data from the Maastricht Study, van der Velde et al. [36] found that replacing sedentary time with LPA was associated with higher cardio-respiratory fitness. The findings seem encouraging and of potentially great importance for individuals who may have difficulties engaging in MVPA. While reallocating sedentary time to LPA was reported to be beneficial for cardio-respiratory fitness, reallocating the same durations of time to MVPA was associated with somewhat greater associations [32]. Overall, studies suggest likely improvements in fitness when time is reallocated from sedentary behaviour to physical activity. However, an additional evidence is needed to form firm conclusions, particularly among adult and clinical populations.

\section{Cardiometabolic biomarkers}

Studies assessing cardiometabolic biomarkers were conducted among youth, adults, and older adults. There was no available evidence for clinical populations.

\section{Youth}

Only two studies thus far have used the ISM with cardiometabolic biomarkers as outcome variables [28, 49]. These studies used two different ISMs, and therefore, the comparability of their findings may be limited. A recent study compared the ISMs by Mekary et al. [12] and by Dumuid et al. [14] using the same dataset and reported differences in estimates between the models [91]. Using the model by Mekary et al. [12], Moore and colleagues [28] reported a beneficial associations of reallocating time from LPA to VPA with insulin levels. The association seemed stronger in individuals with higher baseline insulin levels. Carson et al. [49] employed the compositional ISM described by Chastin et al. [13] using data from the Canadian Health Measures Survey, with sleep, sedentary behaviour, LPA, and MPA as explanatory variables and systolic and diastolic blood pressure, C-reactive protein, HDL-cholesterol, triglycerides, and insulin level. The established associations were either unclear or practically insignificant. The cross-sectional design of both studies prevented drawing conclusions about causality of the established relationships. Future research is needed to strengthen the evidence base on the association between isotemporal substitutions and cardiometabolic markers in children and adolescents.

\section{Adults/older adults}

In their study using the 2005-2006 NHANES data, Buman et al. [48] investigated how reallocating time between sedentary behaviour, sleep, LPA, and MVPA was associated with waist circumference, systolic and diastolic blood pressure, high-density lipoprotein, C-reactive protein, low-density lipoprotein, plasma glucose, insulin, triglycerides, homeostasis model assessment of insulin sensitivity (HOMA-S), and homeostasis model assessment of $\beta$-cell function (HOMA- $\beta$ ). They found that reallocation of sedentary behaviour to MVPA was associated with increased levels of high-density lipoprotein cholesterol, and with a decrease in waist circumference, triglycerides, glucose, insulin, and HOMA-S [48]. Reallocating time from sedentary behaviour to LPA was beneficial for triglycerides, insulin sensitivity, and HOMA- $\beta$ [48]. The study also considered sleep duration and reported that reallocating time from sedentary behaviour to sleep was beneficially associated with insulin, HOMA-S, HOMA- $\beta$. The same association was found for LDL, albeit only in long sleepers ( $\geq 8 \mathrm{~h}$ of sleep per night). Consistent with studies on other health outcomes, Buman et al. [48] inferred that the greatest benefits might be expected from increasing MVPA at the expense of other movement behaviours.

Edwardson et al. [24] reported that reallocation of prolonged sitting to standing or stepping improved 2-h glucose levels, fasting and 2-h insulin levels, and insulin sensitivity in individuals at high risk of impaired glucose regulation or T2D. While modest in terms of magnitudes of associations, the results seem promising for this population. Increasing habitual MVPA levels may be difficult for some individuals and population sub-groups. Evidence from other studies further supports the findings that reallocating sedentary time to LPA (standing and stepping) is associated with more favourable Matsuda-Insulin sensitivity index, levels of high-density lipoprotein [48], and glycosylated hemoglobin [53]. Overall, studies indicated that reallocating sedentary time to LPA or MVPA was associated with favourable cardiometabolic outcomes. While there is a relatively large body of evidence regarding associations between time reallocation and cardiometabolic biomarkers among adults, few 
studies have been conducted among children, adolescents, and older adults. In addition, the studies among older adults were conducted on small sample sizes [29]. Future studies should employ longitudinal study designs to further investigate associations of isotemporal substitution with fitness-related outcomes.

\section{Chronic diseases and conditions}

Studies assessing chronic diseases and conditions were conducted among adults and older adults. There was no available evidence for clinical populations.

\section{Adults/older adults}

In total, six eligible studies were identified. The assessed outcomes included: cardiovascular disease, T2D, metabolic syndrome, breast cancer, chronic musculoskeletal pain, and quality-adjusted life years. Significant associations were found between reallocating time spent in sedentary behaviour to LPA or MVPA and a reduced risk of cardiovascular disease [75]. Furthermore, reallocation of time from TV-viewing to MVPA was associated with a significantly lower risk of T2D [32]. Ekblom-Bak et al. [51] noted that reallocating time from SB to LPA or MPA was associated with a decrease in the risk of metabolic syndrome. For breast cancer, Boeke et al. [46] found no evidence that substituting MVPA for walking was associated with breast cancer risk. Ryan et al. [33], reported a $29 \%$ relative risk reduction in chronic musculoskeletal pain when reallocating 10 min of sedentary behaviour to MVPA. Evidence on various other chronic disease and conditions is scarce. A study by Pinto and colleagues [30] assessing quality-adjusted life years indicated that reallocating $60 \mathrm{~min}$ from SB to MVPA was associated with a significant improvement in this outcome. The study did not find any evidence that reallocating SB to LPA was associated with quality-adjusted life years. More research is needed about the effects of isotemporal substitutions on chronic diseases and conditions.

\section{Statistical considerations and methodological quality}

The ISM introduced by Mekary et al. [12] represents the first attempt within physical activity and sedentary behaviour research to deal with the constrained nature of time-use variables (i.e., the day only ever has $24 \mathrm{~h}$ for every participant), and to account for the fact that one time-use domain cannot be altered without compensatory changes in other time-use domains.

Subsequently, some researchers have suggested that time-use data are compositional data that occupy a constrained sample space and convey relative information $[1,2,13,14]$. Accordingly, statistical methods designed for vectors in real space (including the isotemporal substitution model proposed by Mekary et al. [12], which may, therefore, not be appropriate for time-use data which do not occupy real space $[1,2,13,14]$. The compositional isotemporal substitution (based on the change-prediction matrix) presented in Chastin et al. [13] and later used in Carson et al. [47] was the first attempt to apply the logic of the Mekary et al. [12] ISM method in a compositional data analysis framework. The compositional isotemporal approach was subsequently simplified by Dumuid et al. [14]. There is an ongoing discussion among researchers in the field of epidemiology about which of these methods should preferably be used [2, 14]. Interested readers can find detailed statistical reasoning about the potential implications of using each of the three methods elsewhere $[14,15]$.

It is important to highlight that from a methodological standpoint, all of the included studies were classified as being of high or moderate quality. The findings seem to be generally consistent across the studies, indicating that they were not significantly influenced by differences in study designs. A strength of most included studies is the use of device-based measures for assessing time spent in movement behaviours. Self-reports were used in some large-scale studies, which seems reasonable given accelerometry may significantly add to the administrative burden for researchers [92]. However, no systematic differences could be observed in the findings from studies relying on self-reports and device-based measures. The majority of the ISM studies used the linear regression model $[21,24,27,29,35,36,39,44-46,48,54,56,57$, 63, 70, 72, 76]. Most of them [21, 24, 27, 29, 35, 36, 39, $44-46,48,54,56,57,63,70,72,76]$ assessed the linearity of the relationships prior to running the ISM analysis and indicated that they were linear. Using compositional data analysis, Dumuid et al. [14] have shown that associations of isotemporal substitutions with health outcomes may be non-linear and may depend on the reference composition. Future studies should consider these possibilities.

Furthermore, statistical techniques underpinning Mekary et al. [12] ISM, Chastin et al. [13] ISM, and Dumuid et al. [14] ISM are different; hence the findings of studies using different ISM models may not necessarily be directly comparable. Moreover, a recent study [91] indicated there may be substantial differences in estimates obtained from ISMs proposed by Mekary et al. [12] and Dumuid et al. [14]. It is, therefore, important for future studies to clearly specify which ISM model was used. It is important to note, however, that none of the three ISMs can mitigate standard limitations of studies in this area, such as poor measurement of the exposure, potential reverse causality, and unmeasured or poorly measured potential confounding variables.

The main limitation of the current body of evidence pertains to the low number of studies that included all daily movement-related behaviours (e.g., sedentary behaviour, 
sleep, LPA, and MVPA) in the ISMs. While studies did adjust for many confounding variables, only those that included all of the behaviours received a point on the item regarding adjustments for confounding on the Newcastle-Ottawa scale, as otherwise the adjustments would be considered insufficient [2]. Future studies should endeavour to include sedentary behaviour, sleep, LPA, and MVPA in their models. Most of the studies were cross-sectional, which is a major limitation of the current body of evidence on isotemporal substitution effects. While there were 18 prospective cohort studies included in this review, they cover only a limited range of outcomes. More longitudinal studies are needed to covering a wide range of health outcomes that are potentially associated with isotemporal substitutions.

\section{Conclusions}

There is a notable increase in interest in the associations between time reallocation among movement-related behaviours and their relationship to health outcomes. While much media coverage has focused on the adverse effects of prolonged sedentary behaviour [93], evidence in this review suggests it would be more appropriate to shift the focus on the importance of reallocating time spent in sedentary behaviour to time spent in physical activity. The approach taken in this review broadens the physical activity behavioural arena, for both researchers and policymakers. While the current body of evidence indicates that time reallocation between sleep, sedentary behaviour, LPA, and MVPA may be associated with a number of health outcomes, there is a need for future studies employing longitudinal study designs, taking into account all movement behaviours, and examining a wider range of health, psychological, social, economic, and environmental outcomes. Future ISM studies on outcomes such as stroke, myocardial infarction, and cardiovascular disease death endpoints are warranted, given the current lack of evidence in this area.

\section{Additional files}

Additional file 1: Search syntax. (DOCX $11 \mathrm{~kb}$ )

Additional file 2: Methodological quality appraisal of cross-sectional studies. (DOCX $18 \mathrm{~kb}$ )

Additional file 3: Methodological quality appraisal of prospective cohort studies. (DOC $15 \mathrm{~kb}$ )

\section{Authors' contributions}

ZP conceived the idea for the review. JG and ZP conceptualised the review. ZP designed the systematic search strategies. JG and EGB conducted the study selection. JG and NS did the data extraction. JG and NGB did the quality assessment. JG drafted the initial manuscript. ZP, DD, EGB, NS, AB, and TO contributed to writing the manuscript. All authors read and approved the final manuscript.
Ethics approval and consent to participate

Not applicable.

\section{Consent for publication}

Not applicable.

\section{Competing interests}

All authors declare that they have no competing interests.

\section{Publisher's Note}

Springer Nature remains neutral with regard to jurisdictional claims in published maps and institutional affiliations.

\section{Author details}

${ }^{1}$ Institute for Health and Sport (IHES), Victoria University, Melbourne, Australia. ${ }^{2}$ Department of Physical Education and Sport Sciences, Faculty of Education and Health Sciences, University of Limerick, Limerick, Ireland. ${ }^{3}$ Alliance for Research in Exercise, Nutrition and Activity (ARENA), School of Health Sciences, University of South, Adelaide, Australia. ${ }^{4}$ Prevention Research Collaboration, School of Public Health, Sydney University, Sydney, NSW, Australia.

Received: 29 December 2017 Accepted: 13 June 2018

Published online: 13 July 2018

\section{References}

1. Pedišić Ž. Measurement issues and poor adjustments for physical activity and sleep undermine sedentary behaviour research - the focus should shift to the balance between sleep, sedentary behaviour, standing and activity. Kinesiology. 2014:46(1):135-46.

2. Pedišić $\check{Z}$, Dumuid D, Olds TS. Integrating sleep, sedentary behaviour, and physical activity research in the emerging field of time-use epidemiology: definitions, concepts, statistical methods, theoretical framework, and future directions. Kinesiology. 2017;49(2):1-18.

3. Cappuccio FP, Cooper D, D'Elia L, Strazzullo P, Miller MA. Sleep duration predicts cardiovascular outcomes: a systematic review and meta-analysis of prospective studies. Eur Heart J. 2011;32(12):1484-92.

4. Cappuccio FP, D'Elia L, Strazzullo P, Miller MA. Quantity and quality of sleep and incidence of type 2 diabetes: a systematic review and meta-analysis. Diabetes Care. 2010;33(2):414-20.

5. Cappuccio FP, D'Elia L, Strazzullo P, Miller MA. Sleep duration and all-cause mortality: a systematic review and meta-analysis of prospective studies. Sleep. 2010;33(5):585-92.

6. Cappuccio FP, Taggart FM, Kandala N, Currie A, Peile E, Stranges S, Miller MA. Meta-analysis of short sleep duration and obesity in children and adults. Sleep. 2008;31(5):619-26.

7. de Rezende LF, Rodrigues Lopes M, Rey-Lopez JP, Matsudo VK, Luiz Odo C. Sedentary behavior and health outcomes: an overview of systematic reviews. PLoS One. 2014;9(8):e105620.

8. Lee IM, Shiroma EJ, Lobelo F, Puska P, Blair SN, Katzmarzyk PT. Lancet physical activity series working group. Effect of physical inactivity on major non-communicable diseases worldwide: an analysis of burden of disease and life expectancy. Lancet. 2012;380(9838):219-29.

9. Xi B, He D, Zhang M, Xue J, Zhou D. Short sleep duration predicts risk of metabolic syndrome: a systematic review and meta-analysis. Sleep Med Rev. 2014;18(4):293-7.

10. Zhao H, Yin JY, Yang WS, Qin Q, Li TT, Shi Y, Deng Q, Wei S, Liu L, Wang X, et al. Sleep duration and cancer risk: a systematic review and meta-analysis of prospective studies. Asian Pac J Cancer Prev. 2013;14(12):7509-15.

11. Tremblay MS, Carson V, Chaput JP, Connor Gorber S, Dinh T, Duggan M, Faulkner G, Gray CE, Gruber R, Janson K, et al. Canadian 24-hour movement guidelines for children and youth: an integration of physical activity, sedentary behaviour, and sleep. Appl Physiol Nutr Metab. 2016;41(6 Suppl 3):S311-27.

12. Mekary RA, Willett WC, Hu FB, Ding EL. Isotemporal substitution paradigm for physical activity epidemiology and weight change. Am J Epidemiol. 2009;170(4):519-27.

13. Chastin SF, Palarea-Albaladejo J, Dontje ML, Skelton DA. Combined effects of time spent in physical activity, sedentary behaviors and sleep on obesity and cardio-metabolic health markers: a novel compositional data analysis approach. PLoS One. 2015;10(10):e0139984. 
14. Dumuid D, Pedišić Ž, Stanford TE, Martín-Fernández JA, Hron K, Maher CA, Lewis LK, Olds T. The compositional isotemporal substitution model: a method for estimating changes in a health outcome for reallocation of time between sleep, sedentary behaviour, and physical activity. Stat Methods Med Res. https://doi.org/10.1177/0962280217737805.

15. Dumuid D, Stanford TE, Martin-Fernández JA, Pedišić Ž, Maher CA, Lewis LK, Hron K, Katzmarzyk PT, Chaput JP, Fogelholm M, et al. Compositional data analysis for physical activity, sedentary time and sleep research. Stat Methods Med Res. https://doi.org/10.1177/0962280217710835.

16. Kahlmeier S, Wijnhoven TM, Alpiger P, Schweizer C, Breda J, Martin BW. National physical activity recommendations: systematic overview and analysis of the situation in European countries. BMC Public Health. 2015:15:133.

17. Oja P, Titze S. Physical activity recommendations for public health: development and policy context. EPMA J. 2011;2(3):253-9.

18. García-Hermoso A, Saavedra JM, Ramírez-Vélez R, Ekelund U, Del PozoCruz B. Reallocating sedentary time to moderate-to-vigorous physical activity but not to light-intensity physical activity is effective to reduce adiposity among youths: a systematic review and meta-analysis. Obes Rev. 2017;18(9):1088-95.

19. Boyle T, Vallance JK, Buman MP, Lynch BM. Reallocating time to sleep, sedentary time, or physical activity: associations with waist circumference and body mass index in breast cancer survivors. Cancer Epidemiol Biomark Prev. 2017;26(2):254-60.

20. Collings PJ, Brage S, Bingham DD, Costa S, West J, McEachan RRC, Wright J, Barber SE. Physical activity, sedentary time, and fatness in a biethnic sample of young children. Med Sci Sports Exerc. 2017;49(5):930-8.

21. Collings PJ, Westgate K, Väistö J, Wijndaele K, Atkin AJ, Haapala EA, Lintu N, Laitinen T, Ekelund U, Brage $S$, et al. Cross-sectional associations of objectively-measured physical activity and sedentary time with body composition and cardiorespiratory fitness in mid-childhood: the PANIC study. Sports Med. 2017;47(4):769-80.

22. Dahl-Petersen IK, Brage S, Bjerregaard P, Tolstrup JS, Jørgensen ME. Physical activity and abdominal fat distribution in Greenland. Med Sci Sports Exerc. 2017;49(10):2064-70

23. Dalene KE, Anderssen SA, Andersen LB, Steene-Johannessen J, Ekelund U, Hansen BH, Kolle E. Cross-sectional and prospective associations between physical activity, body mass index and waist circumference in children and adolescents. Obes Sci Pract. 2017; https://doi.org/10.1002/osp4.114.

24. Edwardson CL, Henson J, Bodicoat DH, Bakrania K, Khunti K, Davies MJ, Yates T. Associations of reallocating sitting time into standing or stepping with glucose, insulin and insulin sensitivity: a cross-sectional analysis of adults at risk of type 2 diabetes. BMJ Open. 2017;7(1):e014267.

25. Fairclough SJ, Dumuid D, Taylor S, Curry W, McGrane B, Stratton G, Maher C, Olds T. Fitness, fatness and the reallocation of time between children's daily movement behaviours: an analysis of compositional data. Int J Behav Nutr Phys Act. 2017;14:64

26. Fanning J, Porter G, Awick EA, Ehlers DK, Roberts SA, Cooke G, Burzynska AZ, Voss MW, Kramer AF, McAuley E. Replacing sedentary time with sleep, light, or moderate-to-vigorous physical activity: effects on self-regulation and executive functioning. J Behav Med. 2017:40(2):332-42.

27. Leppänen $M H$, Henriksson P, Delisle Nyström C, Henriksson H, Ortega FB, Pomeroy J, Ruiz JR, Cadenas-Sanchez C, Löf M. Longitudinal physical activity, body composition, and physical fitness in preschoolers. Med Sci Sports Exerc. 2017:49(10):2078-85

28. Moore JB, Beets MW, Brazendale K, Blair SN, Pate RR, Andersen LB, Anderssen SA, Grøntved A, Hallal PC, Kordas K, et al. Associations of vigorous-intensity physical activity with biomarkers in youth. Med Sci Sports Exerc. 2017:49(7):1366-74.

29. Nilsson A, Wåhlin-Larsson B, Kadi F. Physical activity and not sedentary time per se influences on clustered metabolic risk in elderly community-dwelling women. PLoS One. 2017;12(4):e0175496

30. Pinto D, Song J, Lee J, Chang RW, Semanik PA, Ehrlich-Jones LS, Pellegrini CA, Dunlop DD. The association between sedentary time and quality of life from the osteoarthritis initiative: who might benefit most from treatment? Arch Phys Med Rehabil. 2017;98(12):2485-90.

31. Rethorst CD, Moncrieft AE, Gellman MD, Arredondo EM, Buelna C, Castañeda SF, Daviglus ML, Khan UI, Perreira KM, et al. Isotemporal analysis of the association of objectively measured physical activity with depressive symptoms: results from Hispanic community health study/study of Latinos (HCHS/SOL). J Phys Act Health. 2017;14(9):733-9.
32. Rosique-Esteban N, Díaz-López A, Martínez-González MA, Corella D, Goday A, Martínez JA, Romaguera D, Vioque J, Arós F, Garcia-Rios A, et al. Leisuretime physical activity, sedentary behaviors, sleep, and cardiometabolic risk factors at baseline in the PREDIMED-PLUS intervention trial: a cross-sectional analysis. PLoS One. 2017;12(3):e0172253.

33. Ryan CG, Wellburn S, McDonough S, Martin DJ, Batterham AM. The association between displacement of sedentary time and chronic musculoskeletal pain: an isotemporal substitution analysis. Physiotherapy. 2017:103(4):471-7.

34. Vallance JK, Buman MP, Lynch BM, Boyle T. Reallocating time to sleep, sedentary, and active behaviours in non-Hodgkin lymphoma survivors: associations with patient-reported outcomes. Ann Hematol. 2017;96(5):749-55.

35. VAN DER Berg JD, VAN DER Velde JHPM, DE Waard EAC, Bosma $H$, Savelberg HHCM, Schaper NC, VAN DEN Bergh JPW, Geusens PPMM, Schram MT, Sep SJS, et al. Replacement effects of sedentary time on metabolic outcomes: the Maastricht study. Med Sci Sports Exerc. 2017;49(7): 1351-8.

36. VAN DER Velde JHPM, Koster A, VAN DER Berg JD, Sep SJS, VAN DER Kallen CJH, Dagnelie PC, Schram MT, Henry RMA, Eussen SJPM, VAN Dongen MCJM, et al. Sedentary behavior, physical activity, and fitness-the Maastricht study. Med Sci Sports Exerc. 2017:49(8):1583-91.

37. Varela-Mato V, O'Shea O, King JA, Yates T, Stensel DJ, Biddle SJ, Nimmo MA, Clemes SA. Cross-sectional surveillance study to phenotype lorry drivers' sedentary behaviours, physical activity and cardio-metabolic health. BMJ Open. 2017;7(6):e013162

38. Whitaker KM, Buman MP, Odegaard AO, Carpenter KC, Jacobs DR, Sidney S, Pereira MA. Sedentary behaviors and cardiometabolic risk, an isotemporal substitution analysis. Am J Epidemiol. 2017; https://doi.org/10.1093/aje/ kwx209.

39. Wijndaele K, Sharp SJ, Wareham NJ, Brage S. Mortality risk reductions from substituting screen time by discretionary activities. Med Sci Sports Exerc. 2017:49(6):1111-9.

40. Moher D, Liberati A, Tetzlaff J, Altman DG, PRISMA Group. Preferred reporting items for systematic reviews and meta-analyses: the PRISMA statement. PLoS Med. 2009;6(7):e1000097.

41. World Health Organization. 2010. Global recommendations on physical activity for health. Geneva: WHO Press.

42. Wells G, Shea B, O'connell D. Peterson, V Welch, M Losos, P Tugwell. The Newcastle-Ottawa Scale (NOS) for assessing the quality of nonrandomized studies in meta-analyses. 2000; Available from: http://www.ohri.ca/ programs/clinical_epidemiology/oxford.htm

43. Gao Y, Huang YB, Liu XO, Chen C, Dai HJ, Song FJ, Wang J, Chen KX, Wang YG. Tea consumption, alcohol drinking and physical activity associations with breast cancer risk among Chinese females: a systematic review and meta-analysis. Asian Pac J Cancer Prev. 2013;14(12):7543-50.

44. Aggio D, Smith L, Hamer M. Effects of reallocating time in different activity intensities on health and fitness: a cross sectional study. Int J Behav Nutr Phys Act. 2015;12:83.

45. Balboa-Castillo T, León-Muñoz LM, Graciani A, Rodríguez-Artalejo F, GuallarCastillón P. Longitudinal association of physical activity and sedentary behavior during leisure time with health-related quality of life in community-dwelling older adults. Health Qual Life Outcomes. 2011;9:47.

46. Boeke CE, Eliassen AH, Oh H, Spiegelman D, Willett WC, Tamimi RM. Adolescent physical activity in relation to breast cancer risk. Breast Cancer Res Treat. 2014;145(3):715-24.

47. Buman MP, Hekler EB, Haskell WL, Pruitt L, Conway TL, Cain KL, Sallis JF, Saelens $B E$, Frank LD, King AC. Objective light-intensity physical activity associations with rated health in older adults. Am J Epidemiol. 2010;172(10):1155-65.

48. Buman MP, Winkler EA, Kurka JM, Hekler EB, Baldwin CM, Owen N, Ainsworth BE, Healy GN, Gardiner PA. Reallocating time to sleep, sedentary behaviors, or active behaviors: associations with cardiovascular disease risk biomarkers, NHANES 2005-2006. Am J Epidemiol. 2014;179(3):323-34.

49. Carson V, Tremblay MS, Chaput JP, Chastin SF. Associations between sleep duration, sedentary time, physical activity, and health indicators among Canadian children and youth using compositional analyses. Appl Physiol Nutr Metab. 2016;41(6 Suppl 3):S294-302.

50. Chomistek AK, Cook NR, Flint AJ, Rimm EB. Vigorous-intensity leisure-time physical activity and risk of major chronic disease in men. Med Sci Sports Exerc. 2012;44(10):1898-905.

51. Ekblom-Bak E, Ekblom Ö, Bergström G, Börjesson M. Isotemporal substitution of sedentary time by physical activity of different intensities 
and bout lengths, and its associations with metabolic risk. Eur J Prev Cardiol. 2016;23(9):967-74.

52. Ekblom-Bak E, Ekblom Ö, Bolam KA, Ekblom B, Bergström G, Börjesson M. SCAPIS pilot study: sitness, fitness and fatness - is sedentary time substitution by physical activity equally important for everyone's markers of glucose regulation? J Phys Act Health. 2016;13(7):697-703.

53. Falconer CL, Page AS, Andrews RC, Cooper AR. The potential impact of displacing sedentary time in adults with type 2 diabetes. Med Sci Sports Exerc. 2015;47(10):2070-5.

54. Fishman El, Steeves JA, Zipunnikov V, Koster A, Berrigan D, Harris TA, Murphy R. Association between objectively measured physical activity and mortality in NHANES. Med Sci Sports Exerc. 2016;48(7):1303-11.

55. Gupta N, Heiden M, Aadahl M, Korshøj M, Jørgensen MB, Holtermann A. What is the effect on obesity indicators from replacing prolonged sedentary time with brief sedentary bouts, standing and different types of physical activity during working days? A cross-sectional accelerometer-based study among blue-collar workers. PLoS One. 2016;11(5):e0154935.

56. Hamer M, Stamatakis E, Steptoe A. Effects of substituting sedentary time with physical activity on metabolic risk. Med Sci Sports Exerc. 2014;46(10):1946-50.

57. Healy GN, Winkler EA, Brakenridge CL, Reeves MM, Eakin EG. Accelerometerderived sedentary and physical activity time in overweight/obese adults with type 2 diabetes: cross-sectional associations with cardiometabolic biomarkers. PLoS One. 2015;10(3):e0119140.

58. Healy GN, Winkler EAH, Owen N, Anuradha S, Dunstan DW. Replacing sitting time with standing or stepping: associations with cardio-metabolic risk biomarkers. Eur Heart J. 2015;36(39):2643-9.

59. Huang WY, Wong SH, He G, Salmon JO. Isotemporal substitution analysis for sedentary behavior and body mass index. Med Sci Sports Exerc. 2016;48(11): 2135-41.

60. Janssen I. Estimating whether replacing time in active outdoor play and sedentary video games with active video games influences youth's mental health. J Adolesc Health. 2016;59(5):517-22.

61. Kim MJ. Isotemporal substitution analysis of accelerometer-derived sedentary behavior, physical activity time, and physical function in older women: a preliminary study. Exerc Sci. 2015;24(4):373-81.

62. Lee PH. Examining non-linear associations between accelerometermeasured physical activity, sedentary behavior, and all-cause mortality using segmented cox regression. Front Physiol. 2016;7:272.

63. Leppänen MH, Nyström CD, Henriksson P, Pomeroy J, Ruiz JR, Ortega FB, Cadenas-Sánchez C, Löf M. Physical activity intensity, sedentary behavior, body composition and physical fitness in 4-year-old children: results from the ministop trial. Int J Obes. 2016;40(7):1126-33.

64. Loprinzi PD, Cardinal BJ, Lee H, Tudor-Locke C. Markers of adiposity among children and adolescents: implications of the isotemporal substitution paradigm with sedentary behavior and physical activity patterns. J Diabetes Metab Disord. 2015;14:46.

65. Loprinzi PD, Loenneke JP. Mortality risk and perceived quality of life as a function of waking time in discretionary movement-based behaviors: isotemporal substitution effects. Qual Life Res. 2017;26(2):343-8.

66. Matthews CE, Moore SC, Sampson J, Blair A, Xiao Q, Keadle SK, Hollenbeck A, Park Y. Mortality benefits for replacing sitting time with different physical activities. Med Sci Sports Exerc. 2015;47(9):1833-40.

67. Matthews CE, Keadle SK, Troiano RP, Kahle L, Koster A, Brychta R, Van Domelen D, Caserotti P, Chen KY, Harris TB, et al. Accelerometer-measured dose-response for physical activity, sedentary time, and mortality in US adults. Am J Clin Nutr. 2016;104(5):1424-32.

68. Mekary RA, Grøntved A, Despres JP, De Moura LP, Asgarzadeh M, Willett WC, Rimm EB, Giovannucci E, Hu FB. Weight training, aerobic physical activities, and long-term waist circumference change in men. Obesity (Silver Spring). 2015;23(2):461-7.

69. Mekary RA, Lucas M, Pan A, Okereke OI, Willett WC, Hu FB, Ding EL. Isotemporal substitution analysis for physical activity, television watching, and risk of depression. Am J Epidemiol. 2013;178(3):474-83.

70. Sardinha LB, Marques A, Minderico C, Ekelund U. Cross-sectional and prospective impact of reallocating sedentary time to physical activity on children's body composition. Pediatr Obes. 2017;12(5):373-9.

71. Schmid D, Ricci C, Baumeister SE, Leitzmann MF. Replacing sedentary time with physical activity in relation to mortality. Med Sci Sports Exerc. 2016; 48(7):1312-9.

72. Stamatakis E, Rogers $K$, Ding D, Berrigan D, Chau J, Hamer M, Bauman A. All-cause mortality effects of replacing sedentary time with physical activity and sleeping using an isotemporal substitution model: a prospective study of 201,129 mid-aged and older adults. Int J Behav Nutr Phys Act. 2015;12:121.

73. van Roekel EH, Bours MJ, Breedveld-Peters JJ, Willems PJ, Meijer K, Kant I, van den Brandt PA, Beets GL, Sanduleanu S, Weijenberg MP. Modeling how substitution of sedentary behavior with standing or physical activity is associated with health-related quality of life in colorectal cancer survivors. Cancer Causes Control. 2016;27(4):513-25.

74. Wang X, Strizich G, Hua S, Sotres-Alvarez D, Buelna C, Gallo LC, Gellman MD, Mossavar-Rahmani Y, O'Brien MJ, Stoutenberg M, et al. Objectively measured sedentary time and cardiovascular risk factor control in US Hispanics/Latinos with diabetes mellitus: results from the Hispanic community health study/study of Latinos (HCHS/SOL). J Am Heart Assoc. 2017;6(6)

75. Wellburn S, Ryan CG, Azevedo LB, Ells L, Martin DJ, Atkinson G, Batterham AM. Displacing sedentary time: association with cardiovascular disease prevalence. Med Sci Sports Exerc. 2016;48(4):641-7.

76. Yates T, Henson J, Edwardson C, Dunstan D, Bodicoat DH, Khunti K, Davies MJ. Objectively measured sedentary time and associations with insulin sensitivity: importance of reallocating sedentary time to physical activity. Prev Med. 2015;76:79-83.

77. Rezende LFM, Sá TH, Mielke GI, Viscondi JYK, Rey-López JP, Garcia LMT. Allcause mortality attributable to sitting time: analysis of 54 countries worldwide. Am J Prev Med. 2016;51(2):253-63.

78. Oerlemans S, Mols F, Nijziel MR, Lybeert M. Van de poll-Franse LV. The impact of treatment, socio-demographic and clinical characteristics on health-related quality of life among Hodgkin's and non-Hodgkin's lymphoma survivors: a systematic review. Ann Hematol. 2011;90(9):993-1004.

79. Vallance JK, Courneya KS, Jones LW, Reiman T. Differences in quality of life between non-Hodgkin's lymphoma survivors meeting and not meeting public health exercise guidelines. Psychooncology. 2005; 14(11):979-91.

80. Blazer DG, Kessler RC, McGonagle KA, Swartz MS. The prevalence and distribution of major depression in a national community sample: the National Comorbidity Survey. Am J Psychiatry. 1994;151(7):979-86.

81. Farmer ME, Locke BZ, Mościcki EK, Dannenberg AL, Larson DB, Radloff LS. Physical activity and depressive symptoms: the NHANES I epidemiologic follow-up study. Am J Epidemiol. 1988;128(6):1340-51.

82. Shrestha N, Kukkonen-Harjula KT, Verbeek JH, ljaz S, Hermans V, Bhaumik S. Workplace interventions for reducing sitting at work. Cochrane Database Syst Rev. 2016;3:CD010912.

83. American College of Sports Medicine and the American Diabetes Association. 2010. Exercise and type 2 diabetes: American College of Sports Medicine and the American Diabetes Association: joint position statement. Med Sci Sports Exerc. 2010;42:2282-2303.

84. Cichosz SL, Fleischer J, Hoeyem P, Laugesen E, Poulsen PL, Christiansen JS, Ejskjær N, Hansen TK. Objective measurements of activity patterns in people with newly diagnosed type 2 diabetes demonstrate a sedentary lifestyle. Diabet Med. 30(9):1063-6.

85. National Sleep Foundation. International bedroom poll 2013. Available from: https://sleepfoundation.org/sites/default/files/RPT495a.pdf

86. Saner NJ, Bishop DJ, Bartlett JD. Is exercise a viable therapeutic intervention to mitigate mitochondrial dysfunction and insulin resistance induced by sleep loss? Sleep Med Rev. 2018;37:60-8.

87. Ortega FB, Ruiz JR, Castillo MJ, Sjöström M. Physical fitness in childhood and adolescence: a powerful marker of health. Int J Obes. 2008;32(1):1-11.

88. Ortega FB, Labayen I, Ruiz JR, Kurvinen E, Loit HM, Harro J, Veidebaum T, Sjöström M. Improvements in fitness reduce the risk of becoming overweight across puberty. Med Sci Sports Exerc. 2011;43(10):1891-7.

89. Ortega FB, Silventoinen K, Tynelius P, Rasmussen F. Muscular strength in male adolescents and premature death: cohort study of one million participants. BMJ. 2012;345:e7279.

90. Schranz N, Tomkinson G, Olds T. What is the effect of resistance training on the strength, body composition and psychosocial status of overweight and obese children and adolescents? A systematic review and meta-analysis. Sports Med. 2013;43(9):893-907.

91. Dumuid D, Stanford TE, Pedišić Ž, Maher C, Lewis LK, Martín-Fernández JA, Katzmarzyk PT, Chaput JP, Fogelholm M, Standage M, et al. Adiposity and the isotemporal substitution of physical activity, sedentary time and sleep among school-aged children: a compositional data analysis approach. BMC Public Health. 2018;18:311. 
92. Pedišić Ž, Bauman A. Accelerometer-based measures in physical activity surveillance: current practices and issues. Br J Sports Med. 2015;49(4):219-23.

93. Chau JY, Bonfiglioli C, Zhong A, Pedisic Z, Daley M, McGill B, Bauman A. Sitting ducks face chronic disease: an analysis of newspaper coverage of sedentary behaviour as a health issue in Australia 2000-2012. Health Promot J Austr. 2017;28(2):139-43.

Ready to submit your research? Choose BMC and benefit from:

- fast, convenient online submission

- thorough peer review by experienced researchers in your field

- rapid publication on acceptance

- support for research data, including large and complex data types

- gold Open Access which fosters wider collaboration and increased citations

- maximum visibility for your research: over $100 \mathrm{M}$ website views per year 